W.

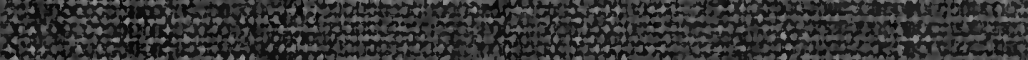

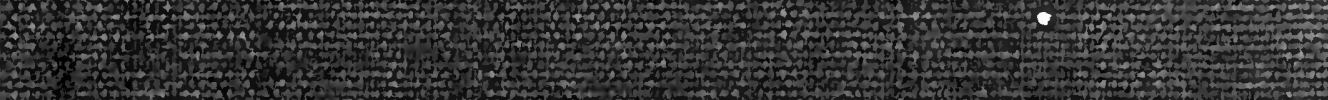

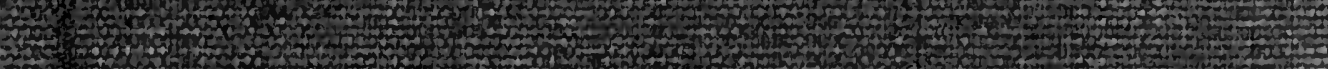

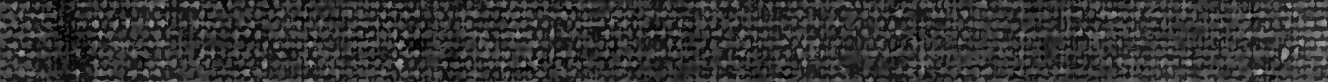
(1)

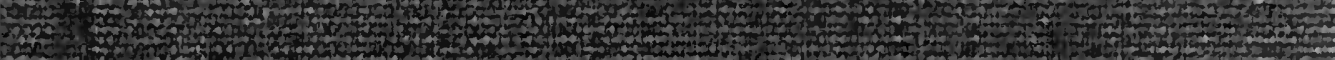

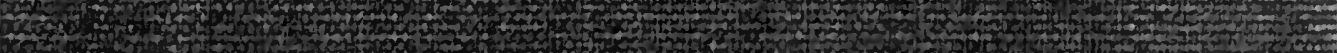

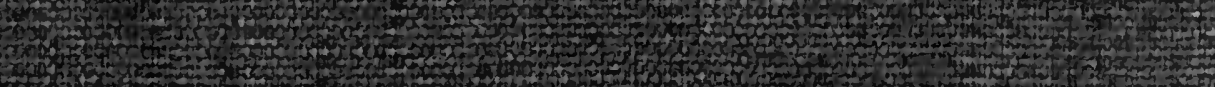

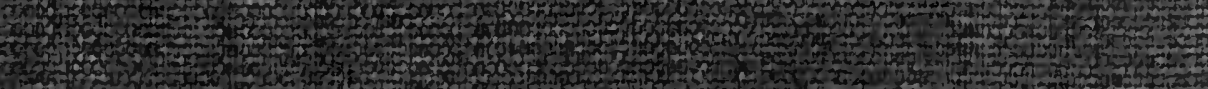

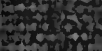

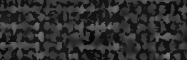

mo

S. Wh
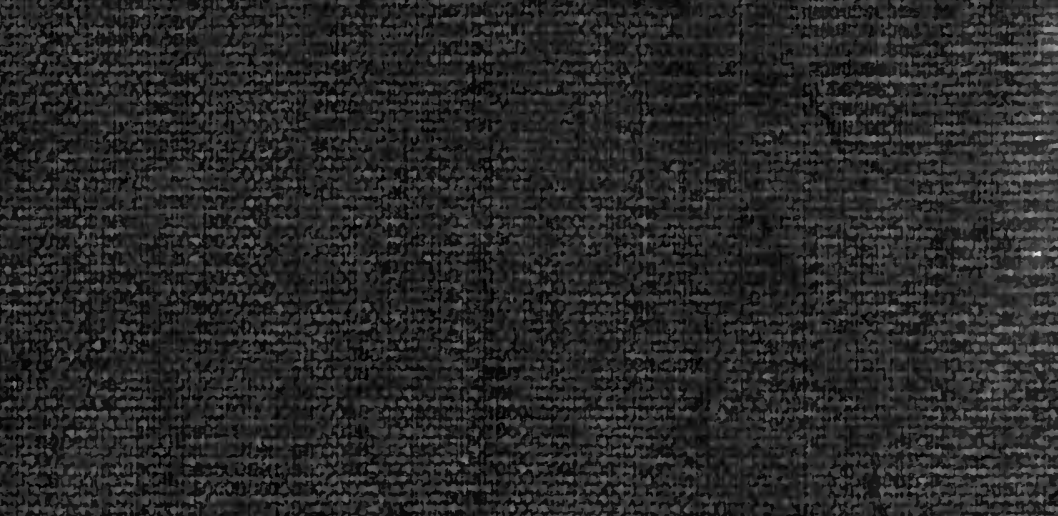

wention

ar

Hist 30 .

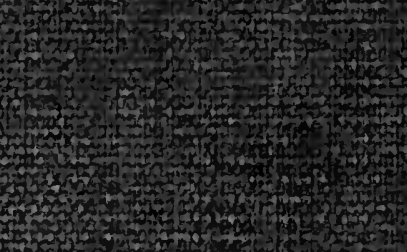

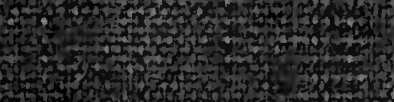

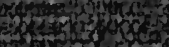

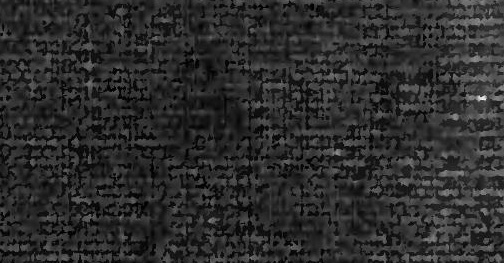

4,5

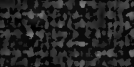

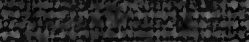

(5)

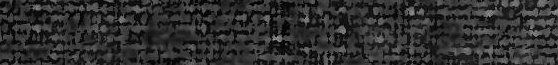
Sto

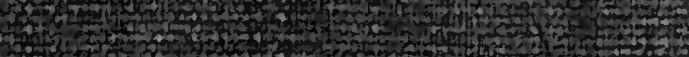

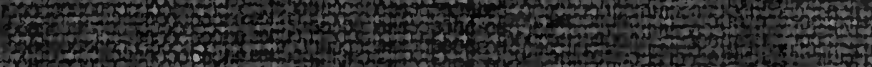

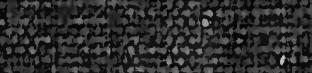

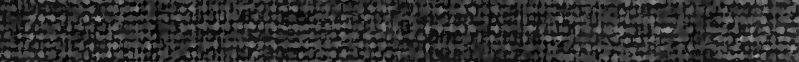

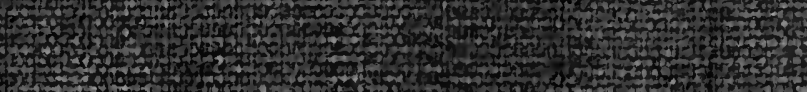
TH. T.

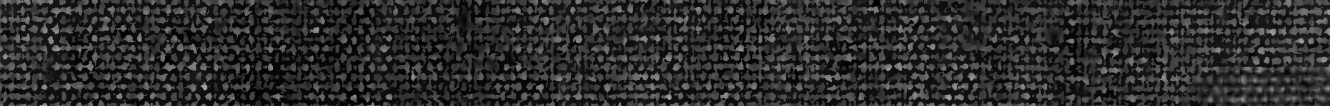

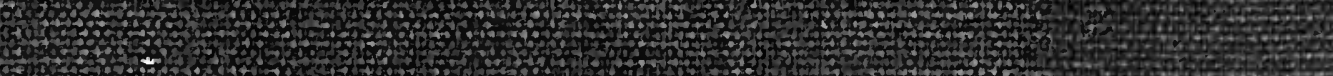

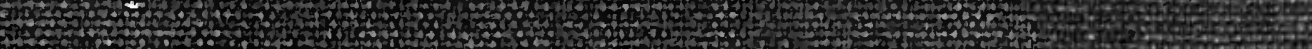




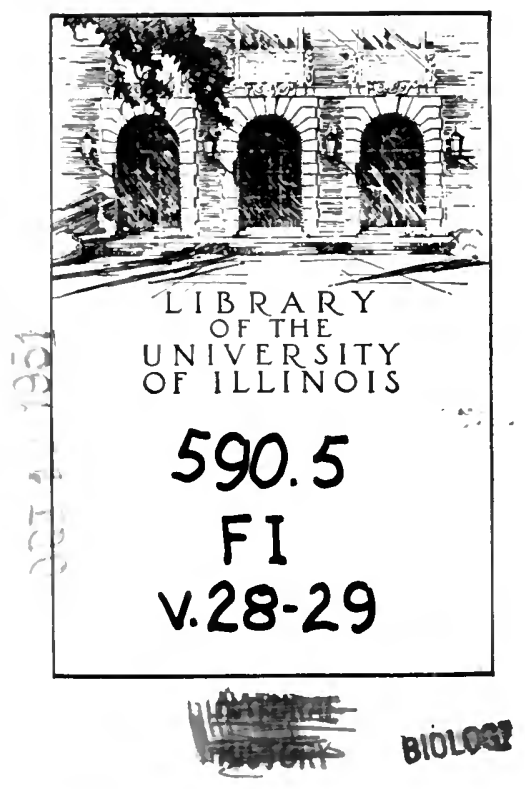


The person charging this material is responsible for its return to the library from which it was withdrawn on or before the Latest Date stamped below.

Theft, mutilation, and underlining of books are reasons for disciplinary action and may result in dismissal from the University.

UNIVERSITY OF ILLINOIS IIBRARY AT URBANA-CHAMPAIGN

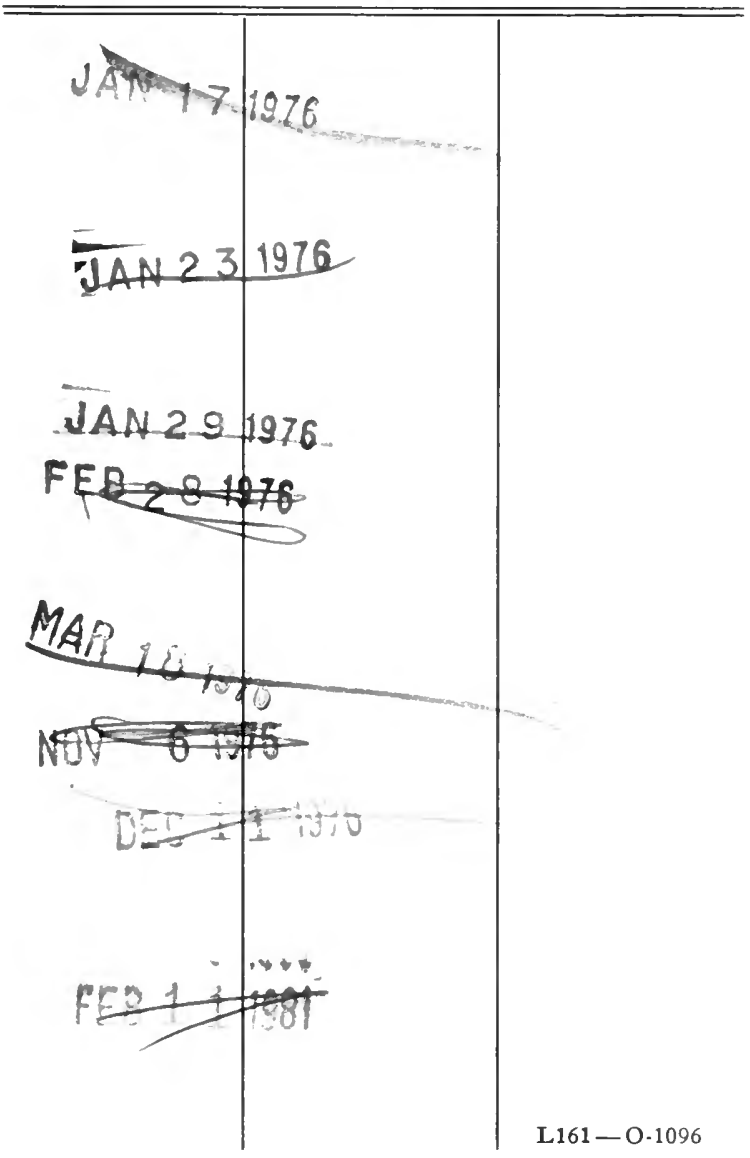







\title{
ON THE CLASSIFICATION OF THE HISTERID BEETLES
}

\author{
BY \\ RUPERT L. WENZEL \\ ASSISTANT CURATOR OF INSECTS
}

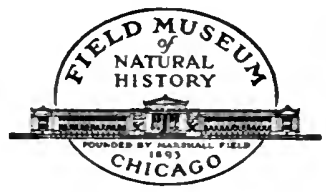

ZOOLOGICAL SERIES

FIELD MUSEUM OF NATURAL HISTORY

VOLUME 28, NUMBER 2

JANUARY 19, 1944

PUBLICATION 545 





\title{
ON THE CLASSIFICATION OF THE
}

\section{HISTERID BEETLES}

\author{
BY \\ RUPERT L. WENZEL \\ ASSISTANT CURATOR OF INSECTS
}

THE LIBRARY OF THE

\section{FEB 221944}

UNIVERSITY OF ILLINOIS

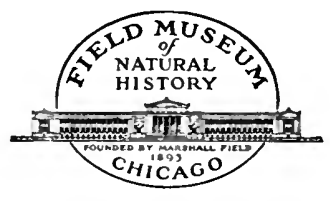

ZOOLOGICAL SERIES

FIELD MUSEUM OF NATURAL HISTORY

VOLUME 28, NUMBER 2

JANUARY 19, 1944

PUBLICATION 545 
PRINTED IN THE UNITED STATES OF AMERICA BY FIELD MUSEUM PRESS 


\section{ON THE CLASSIFICATION OF THE HISTERID BEETLES}

BY RUPERT L. WENZEL

In the summer of 1941, Field Museum acquired the Charles A. Ballou collection of histerid beetles. This collection, including numerous types, and with a world-wide representation of this interesting family, is a most important addition to the Museum's research material. Represented in it are many undescribed species; some of these are described herein, ${ }^{1}$ together with others from the collections of the United States National Museum, the Museum of Comparative Zoology, the American Museum of Natural History, Carnegie Museum, Dr. Edward S. Ross, Mr. William Spector, and the author. Perhaps the richest lots involved were a small collection of Costa Rican histerids sent to Mr. Ballou by the late Ferdinand Nevermann and a similar lot acquired by the United States National Museum with the Nevermann collection.

Acknowledgment is due the individuals and the officials of the institutions mentioned above for their kind co-operation in making material available for study.

As a result of some experience in dealing with the higher categories of the coleopterous family Histeridae, it has become evident to me that the classification of the family as proposed by Bickhardt $(1916,1917)$, largely following Marseul and Lacordaire, is replete with untenable generic assignments and subfamilial and tribal definitions. Some of these errors are excusable; others may be laid to a complete lack of appreciation of convergent evolution and a lack of perspective and balance in "weighting" the relative value of particular structural characters; some are the result of careless observation. A painstaking morphological study is necessary before one can attempt a revisional and more satisfactory classification and definition of some of the subfamilies. However, a few of the more obvious changes necessary can be noted at this time, and it is desirable that this be done in order to clarify certain generic assignments made in this paper.

${ }^{1}$ Certain portions of these more or less fragmentary studies were originally undertaken as more comprehensive revisions, the completion of which must be postponed. 
The Histeridae may be divided into two great and apparently natural groups on the basis of the presence or absence of a prosternal lobe. For convenience it might be well to distinguish them as follows:

A prosternal lobe not present............... Division I. Saprinomorphae. A prosternal lobe present.................. Division II. Histeromorphae.

Thesaprinomorph subfamilies are rather well-defined assemblages, but the histeromorphs need considerable study and probably redivision. The Chlamydopsini, a tribe of Hetaeriinae erected by Bickhardt (l.c.) lack a prosternal lobe, and in genital structure bear no apparent relationship with the Hetaeriomorphini or Hetaeriini; they are here included with the saprinomorphs as a distinct subfamily. They are the only saprinomorphs in which the prosternal alae ${ }^{1}$ close the antennal cavities from below, the cavities being situated in the anterior prothoracic angles.

\section{Key to the Subfamilies of the SaprinomorphaE}

1. Antennal cavities closed beneath by the prosternal alae, situated in the anterior prothoracic angles; antennal scape strongly angulate and usually greatly expanded, the club greatly elongated, at least three times as long as broad.

Chlamydopsinae

Antennal cavities, if present, open beneath; antennal scape normal, the club usually a little, but never three times, longer than broad . . . . . . . . . 2

2. Form round, oval, or oblong oval ..................... 3

Form cylindrical, sometimes stoutly so............... 4

3. Antennal cavities situated in front of the procoxae, next to and nearly always encroaching upon the prosternal keel; dorsal elytral striae rarely absent, if so, then at least a sutural stria is present; lateral, longitudinal pronotal

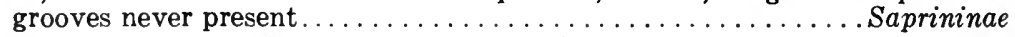

Antennal cavities situated in the anterior prothoracic angles, or in front of the procoxae (laterally or at middle); if they rarely do lie next to the keel, then they do not encroach upon it, and lateral, longitudinal grooves are present on the pronotum; dorsal elytral striae never present though rather vague impressions may be ................

4. Antennae inserted "on the front," the fossae cutting into the margin of the front medial to the eyes......................

Antennae inserted under the margin of the front, anterior to the eyes... . 5

5. Head produced anteriorly into two horns of variable length; mandibles deflexed, moving in a plane at right angles to the long axis of the head.

Niponiinae

Head not produced into two horns, though it may be produced as a long pointed rostrum in the female; mandibles moving in the same plane as the

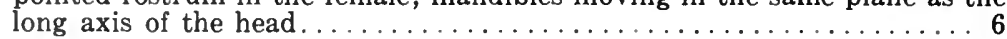

1 The writer here uses the term ala (plural alae) to refer to the arms or expansions that extend laterally from the anterior region of the prosternal keel to unite with the hypomera. The procoxal cavities are in large part bounded by them anteriorly. 
6. Head horizontal in repose; antennae consisting of eight segments and a club; anterior margin of prosternal alae at most with only a very slight notch, antennal cavities not defined.................... Trypanaeinae

Head vertical in repose; antennae consisting of seven segments and a club; anterior margins of prosternal alae with rather deep longitudinal incisions for the reception of the antennal funicle in repose.......... Trypeticinae

KEY TO THE SUBFAMILIES OF THE HiSTEROMORPHAE

1. Antennal scape normal, neither expanded nor strongly angulate . . . . . . 2 Antennal scape expanded and strongly angulate Hetaeriinae

2. Labrum with setigerous punctures.................... 3 Labrum without setigerous punctures.

Histerinae

3. Antennal cavities completely open, usually situated just anterior to the procoxae at middle of hypomera; prosternal alae deeply and longitudinally incised for the reception of the antennal funicle in repose; protibiae oligo-

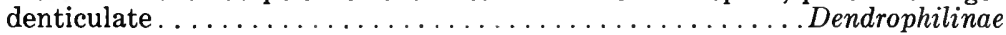

Antennal cavities situated in the anterior prothoracic angles, at least partly closed beneath by the prosternal alae; protibiae multidenticulate.

Tribalinae

As outlined here, the Histerinae include the Hololeptinae of other authors. The latter seem to be very closely related to the Platysomini and would seem best placed next to them as a separate tribe. The tribe Tribalini of Bickhardt has been given subfamily rank.

\section{Subfamily Abraeinae}

Unfortunately, many of the workers who have published studies on the minute members of this subfamily have been handicapped by a lack of adequate optical and lighting equipment. Many of the species have distinctive characters which can be observed only with rather high magnifications. In drawing up the following descriptions and keys, the writer has used magnifications of from 100 to 150 diameters; occasionally magnifications of about 200 diameters have been used to check certain characters. Accordingly, the terms applying to density and coarseness of punctures are to a considerable extent relative to the magnifications used. Specimens must be well cleaned and in the majority of cases can be identified only if the sternal disks are kept free for examination. Instead of gluing the beetles directly to cardboard triangles, it is convenient to glue them to a short length of bristle or human hair, one end of which has been attached to the end of a short triangle. A very small drop of dark shellac serves as an excellent adhesive and the tip of the bristle should be applied to the elytral flank or the elevated metasternal sides of the insect. 
As constituted in the Genera insectorum (Bickhardt, 1916) the Abraeinae are a heterogeneous assemblage. A study of genital structure correlated with external characters indicates that of the genera previously placed in the group only the following may be retained: Abraeus, Acritus, Halacritus, Aeletes, Spelaeacritus, Plegaderus, Eubrachium, and Phloeolister; Acritomorphus gen. nov. and the genera which have comprised the subfamily Teretriinae may be added, and the Abraeinae may then be characterized as follows:

Antennae inserted "on the front" medial to the eyes, the antennal fossae cutting into the margin of the front; composed of eight segments in addition to the club, the latter variable and consisting of from one to three segments. Labrum with setigerous punctures. Dorsal elytral striae not developed, though vague oblique basal impressions may be present. Antennal cavities open, consisting of fossae which are situated either laterally and immediately in front of the procoxae, or in the anterior angles of the prothorax; in the latter case they may extend posteriorly to the procoxae. Prosternum without a lobe; prosternal alae longitudinally incised for the reception of the antennal funicle in repose. Anterior margin of mesosternum generally produced at middle though the production is usually covered by the basal flange of the prosternal keel so that the mesosternum appears truncate or obtuse anteriorly. Tibial adornment highly variable, usually finely multispinulose or setose, sometimes with only a few spinules. Aedeagus without an articulating ring-shaped or tubular basal piece, though the ventral posterior edge of the tegmen is sometimes produced as an apodeme ${ }^{1}$ of varying length which may be strongly deflexed.

Of the genera to be removed from the Abraeinae, Bacanius, Anapleus, and Abraeomorphus may be placed in the Dendrophilinae. Why they were not thus assigned before is difficult to explain, since there is not a single character which would justify their being placed elsewhere. Presumably they were adjudged to be related to Acritus and Abraeus because of their minute size. Onthophilus, Epiechinus, ${ }^{2}$ Glymma, and Peploglyptus cannot be satisfactorily placed until revisional studies of the Histeromorphae have been made. All of these have a well-developed prosternal lobe, and the aedeagus in Onthophilus and Epiechinus possesses a tubular or ring-shaped articulating basal piece, respectively. The genitalia of

${ }_{1}$ The basal piece may actually be fused to the rest of the tegmen and the "apodeme," when present, is probably a part of the fused basal piece.

${ }^{2}$ There is reason to suspect that these genera may belong in the Tribalinae. 
Glymma and Peploglyptus have not been examined, since both of these are monotypic genera represented by unique types.

In order to indicate the relationships of the genera of the Abraeinae, it is convenient to divide the subfamily into tribes. Since this has not previously been done, the following may be regarded as new, though naturally they have no nomenclatorial status.

\section{Key to the Tribes of Abraeinae}

1. Hind tarsi with four segments. . . . . . . . . . . . . Acritini

Hind $\operatorname{tarsi}$ with five segments $\ldots \ldots \ldots \ldots \ldots \ldots \ldots \ldots \ldots \ldots \ldots \ldots \ldots \ldots \ldots$

2. Antennal cavities as in Acritus, large, situated in the anterior angles of the prothorax and extending posteriorly to the procoxae..3. Acritomorphini

Antennal cavities situated in front of the procoxae, well separated from the

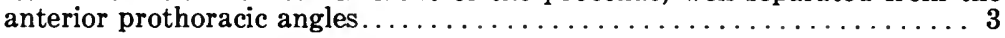

3. Pronotum with a longitudinal groove on each side, these often connected by a transverse, median or submedian groove........... Plegaderini

Pronotum without such grooves.

4. Form oval or round, usually rather strongly convex; basal margin of prosternal keel not incised to receive an angulate convex mesosternal projection.

1. Abraeini

Form cylindrical; basal margin of prosternal keel angulately incised to accommodate the mesosternal projection.............. Teretriini

\section{Tribe 1. Abraeini}

This tribe contains but one genus, Abraeus, and is sufficiently characterized in the key to obviate further definition.

\section{Tribe 2. Plegaderini}

\section{KEY TO THE GENERA}

1. Prosternum divided into four lobes, the anterior and posterior lobes separated by two transverse, lancet-shaped lobes............ Phloeolister Bickhardt Prosternum simple or with a deep, median, saddle-shaped excavation.... . 2

2. Prosternum simple....................Eubrachium Wollaston

Prosternum with deep lateral sulci and a large, very deep, transverse, saddleshaped excavation, the margins of which are internally fringed with dense

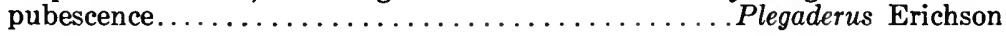

\section{Tribe 3. Acritomorphini}

This tribe contains the single isolated genus described below. 
Acritomorphus gen. nov.

Genotype Acritomorphus praecursor sp. nov.

Diagnosis.-Size small. Form elongate-oblong. Antennae inserted on the front; club with two pubescent annuli, one at apical third, the other approximate to the apical margin. Labrum with setigerous punctures. Marginal pronotal stria present, lateral striae absent. Scutellum visible, rather large, equilateral. Elytra with only a marginal epipleural stria. Prosternum truncate behind, long, with a rather narrow keel which is set off by striae, and a broad non-striate anterior region which is produced and somewhat resembles a prosternal lobe. Antennal cavities large, situated in the anterior prothoracic angles and extending posteriorly to the procoxae. Anterior margin of mesosternum not produced, feebly emarginate. Protibiae expanded apically, slender basally, oligodenticulate. Meso- and metatibiae with a few marginal spinules in a single row. Tarsal segments 5-5-5; tarsomeres $1-4$ of the protarsi each with a normal ventral seta and one which is flattened, expanded, and transparent. Aedeagus without a ring-shaped articulating basal piece; the tegmen with a deflexed, ventral, basal projection which is apparently an apodeme for muscle insertions.

Remarks.-This genus possesses characters which seem to indicate a position between the Teretriini and less specialized members of the Abraeinae, though it could hardly be regarded as being a type directly ancestral to either. The antennal cavities resemble those of Acritus and allied genera, while the prosternum is similar to that of Teretrius but much longer.

\section{Acritomorphus praecursor sp. nov.}

Type from Binaluan, northern Palawan Island, Philippine Islands. A male in the collection of Field Museum of Natural History.

Description.-Form elongate-oblong, subparallel, rather feebly convex. Color black, shining. Head finely, sparsely punctate. Pronotum strongly, moderately punctate, the punctures mostly somewhat elongate and usually separated by their diameters or a little more, a little finer along the sides and anterior margin; a few very fine punctures on the middle of the disk. Marginal pronotal stria complete, well impressed.

Elytral discal punctures similar to the larger pronotal punctures, a few of them finer along the suture; flanks more finely and a little 
more closely punctate. Propygidial and pygidial punctures round and deep, a little larger than the pronotal punctures and mostly separated by less than their diameters. Marginal epipleural stria complete, very close to the margin. Epipleural fossette not distinct, alutaceous.

Prosternum rather long, very finely, sparsely punctate; that portion of the keel enclosed by striae is rather narrow, extending about three-fourths the prosternal length; carinal striae fine, subcariniform, feebly divergent apically, not united apically or basally; prosternum finely, strongly and more closely punctate anteriorly than on the enclosed keel; apical margin with a stria (very close to the edge) which does not quite reach the lateral stria on each side. Anterior mesosternal margin feebly, broadly emarginate; marginal mesosternal stria entire, well impressed and continuous on each side with the lateral metasternal stria, which is straight, oblique, and extends nearly to the hind coxa. Meso- and metasternal disks finely, sparsely punctate, the punctures becoming moderately coarse in the region of the metacoxae.

Protibiae slender basally, abruptly expanded on a little more than apical half, the external margin of the expanded portion bearing four or five minute denticles. Mesotibiae with about four slender spinules on outer edge, the most anterior of which is located at basal two-fifths. Metatibiae with two apical spinules on outer edge.

Length 1.73; width $1.07 \mathrm{~mm}$.

Remarks. - The modified setae of the protarsi may be a male secondary sexual character.

\section{Tribe 4. Acritini}

\section{KEY TO THE GENERA}

1. Eyes absent; sides of head with a forwardly projecting lobe where the eyes are ordinarily present; scutellum not visible...........Spelaeacritus Jeannel

Eyes present; sides of head normal . . . . . . . . . . . . . . 2

2. Scutellum not visible; epistoma with a marginal stria along each side and of ten along anterior margin (pl. 1, fig. 4); pygidium usually with a continuous stria along lateral and apical margins; mesosternal disk usually with a row of parallel, longitudinal, sulciform punctures or sulci which extend anteriorly from the meso-metasternal suture (pl. 1, figs. 2, 3) ......... Aeletes Horn

Scutellum visible, though sometimes minute; epistoma and pygidium not margined; mesosternum without sulciform, parallel, longitudinal punctures, though in Acritus the meso-metasternal stria rarely may be very strongly and crenately punctate and superficially resemble the sculpture found in

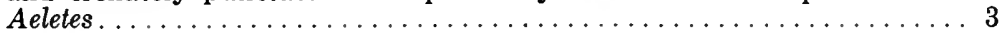


3. Prosternal striae parallel at base, rather strongly divergent anteriorly; protibiae distinctly expanded apically, their outer margins adorned with spinules; mesosternum projecting forward, its marginal stria strongly angulate (pl. 1, fig. 5) .................... Halacritus Schmidt

Prosternal striae (a) parallel, or (b) divergent posteriorly, or (c) divergent anteriorly and posteriorly, or (d) feebly divergent anteriorly; protibiae slender and finely multisetose (rarely expanded and bearing spinules, but the prosternal striae are not divergent anteriorly in these species); anterior mesosternal margin not strongly projecting as in Halacritus, the marginal stria at most rather feebly angulate.............. Acritus Le Conte

\section{Genus Acritus Le Conte}

Acritus tuberculatus Wenzel and Dybas

Acritus tuberculatus Wenzel and Dybas, Field Mus. Nat. Hist., Zool. Ser., 22, p. 439, 1941-Colombia (Villavicencio).

Brazil: Nova Teutonia, Santa Catherina, forty specimens, October, 1941 (collected by Fritz Plaumann).

Dutch Guiana: Paramaribo, two specimens, June 4, 1927 (Cornell University Collection).

British Guiana: Tumatumari, one specimen, July 2, 1911 (A.M.N.H.).

\section{Acritus atomus Le Conte}

Acritus atomus Le Conte, Proc. Acad. Nat. Sci. Phila., 6, p. 291, 1853-Cuba. Acritus atomulus Marseul (in error), Ann. Soc. Ent. Fr., (4), 2, p. 694, pl. 8, fig. 3, 1862-Louisiana (New Orleans).

Cuba: Havana, eight specimens, January and December, 1929; Marianao, one specimen, July 16, 1929; Caisuita, two specimens (all collected by Alexander Bierig).

The name atomulus Marseul, placed as a synonym of atomus, must be considered as applying to a distinct North American species, possibly one known to American workers under some other name. Marseul's figure shows an antescutellar pronotal stria, a character not found in the Cuban atomus, a species allied to exiguus Erichson and tuberculatus.

\section{Acritus ignobilis Lewis}

Acritus ignobilis Lewis, Biol. Centr.-Amer., Coleop., 2, pt. 1, p. 238, pl. 7, fig. 2, 1888-Panama (Volcan de Chiriqui).

Puerto Rico: Boqueron, one specimen, from cow dung, November 18, 1936 (U.S.N.M.); Mayaguez, one specimen, from cow dung, April, 1936 (U.S.N.M.). 
Cuba: Havana, one specimen, June 9, 1929; Marianao, one specimen, May 19, 1929 (collected by Alexander Bierig).

This species has been recorded from Puerto Berrio and Puerto Salgar, Colombia, by Wenzel and Dybas (l.c.).

\section{Acritus exiguus Erichson (=Bacanius subdepressus Blatchley)}

Acritus exiguus Erichson, Jahrb. Ins., 1, p. 208, 1834.

Bacanius subdepressus Blatchley, Can. Ent., 54, p. 13, 1922.

The writer has examined the type and several paratypes of Blatchley's subdepressus and found it to be identical with $A$. exiguus.

\section{Genus Halacritus Schmidt}

The species of the genus Halacritus are maritime and without a known exception are found in and under decaying seaweed. Specific information regarding their food habits is lacking, but it is possible that they might be scavengers rather than predators. The group has previously been regarded as constituting a subgenus of Acritus, but it is a well-defined assemblage, morphologically ${ }^{1}$ and ecologically.

To date only four species of Halacritus have been recognized; in the following section six species are added (four of them new), a generic name is placed in synonymy, and a provisional key to the known species of the world is outlined.

\section{Halacritus Schmidt (= Paracritus Brethes)}

Halacritus Schmidt, Bull. Soc. Ent. Fr., 1893, p. ciii, 1893.

Paracritus Brethes, Rev. Chil. Hist. Nat., 27, p. 40, 1923.

Brethes' species australis, the type of Paracritus, is probably a synonym of riparius Bickhardt. The type of australis is from the state of Santiago; riparius is known from Concepcion, Valparaiso, Guayacan, and Iquique.

\section{Halacritus parallelus Casey ${ }^{2}$}

Acritus (Halacritus) parallelus Casey, Mem. Coleop., 16, p. 251, 1916-West Virginia (Fort Monroe).

1 It might be well to note that the aedeagus in Halacritus does not closely resemble that found in any of the species of Acritus examined by the writer.

${ }^{2}$ At the time this paper was written, the author had not yet seen Casey's types of parallelus or the additional specimens recorded above. Since then the writer has been able to study the types, but no examples of maritimus, a closely related species, were available for comparison, consequently no attempt has been made to separate them in the key, though the two are distinct. The inner wings of parallelus can be seen through the elytra and seem to be well developed. 
Maryland: Piney Point, two specimens (U.S.N.M.; collected by Hubbard and Schwarz).

\section{Halacritus salinus Le Conte}

Acritus salinus Le Conte, Proc. Amer. Phil. Soc., 13, p. 402, 1878-Florida (Cedar Keys).

Florida: Dunedin, two specimens (collected by W. S. Blatchley).

\section{Halacritus lividus Lea}

Acritus lividus Lea, Trans. Ent. Soc. Lond., 1924, p. 258, 1925-Lord Howe Island.

Though there are no examples of this species at hand, it is obvious from Lea's description that lividus belongs in Halacritus.

\section{Halacritus glabrus sp. nov.}

Type from Albany, West Australia. A specimen of undetermined sex in the collection of Rupert L. Wenzel.

Paratypes.-Five specimens, same data as the type; three in the collection of Field Museum, two in the collection of Rupert L. Wenzel.

Description.-Form oblong-oval. Color dark reddish-brown, strongly shining. Surface glabrous throughout, with the exception of the feebly alutaceous mesepimera. Head very finely, strongly, somewhat sparsely punctate.

Pronotal punctures fine, strong and rather sparse, noticeably sparser at sides and anterior angles. Ely.tral punctures sparse, as large medially as the coarsest pronotal punctures but shallower and becoming sparser and finer laterally, the flanks being virtually impunctate. Disk with an oblique impression basally near the sides. Marginal elytral stria alone present, complete, well impressed, its outer edge finely cariniform.

Prosternum nearly smooth, with a very few fine punctures and with an extremely feeble indication of alutaceous ground sculpture. Meso- and metasternum finely, sparsely punctate; meso-metasternal stria strongly rounded at median angulation (not acute or subacute), outer edge subcariniform, continuous on each side with the lateral metasternal stria, which is very short, nearly absent. Meso-metasternal suture marked by a row of rather widely separated, coarse punctures.

Pygidia finely, very sparsely punctate; apical margin of pygidium somewhat elevated. 
Protibiae eight- to ten-spinulose, spinules stoutest and longest apically. Mesotibiae six- to seven-spinulose, the spinules becoming rather long and slender apically. Metatibiae four-to five-spinulose, spinules not as strong as those of the mesotibiae.

Length $0.97-1.16$; width $0.71-0.86 \mathrm{~mm}$.

Remarks.-This is apparently the only known species which has completely non-alutaceous pygidia and an obsolete lateral metasternal stria.

\section{Halacritus lewisi sp. nov.}

Type from Colombo, Ceylon. A specimen of undetermined sex in the collection of Field Museum of Natural History. Collected by George Lewis.

Paratypes.-Three specimens, same data as the type, in the collection of Field Museum.

Description.-Color yellowish-brown, strongly shining. Form oblong-oval. Surface not alutaceous with the exception of the pygidia, the metasternum immediately lateral and posterior to the middle coxae, the mesepimeron, the sides of the abdominal sterna, and the prosternum, which is feebly alutaceous apically and strongly so on the sides. Head strongly, sparsely punctulate, the punctures stronger on vertex. Pronotum very finely, strongly, sparsely punctate.

Elytral punctures much coarser than those of the pronotum and for the most part aciculate or subaciculate, the aciculations not anastomosed; flanks impunctate or nearly so. Inner wings reduced to small pads which are about one-third the length of the elytra. Marginal stria as in glabrus. Propygidium and pygidium not evidently punctate; apical margin of pygidium feebly reflexed.

Mesosternum with a few rather fine punctures; marginal stria complete, its median angulation obtuse and arcuate, continuous on each side with the oblique lateral metasternal stria which extends posteriorly about one-half the length of the metasternum. Metasternal disk finely punctate on about anterior half, the punctures on posterior half moderately coarse, all the punctures a little denser along the median line; elevated metasternal sides moderately coarsely or coarsely, sparsely punctate.

Protibiae seven- to eight-spinulose. Mesotibiae four- to fivespinulose. Metatibiae apparently two- to three-spinulose.

Length $0.90-1.01$; width $0.60-0.72 \mathrm{~mm}$. 
Remarks.-The types of this species are from a series collected by Lewis, representatives of which were sent to Schmidt by Lewis under the name Acritus algarum sp. nov. In describing algarum, Schmidt retained Lewis's name but designated his own specimens from the Seychelles as the types; his description obviously does not apply to the Ceylon examples, though he did mention the specimens as supplementary to the type series.

\section{Halacritus alutiger sp. nov.}

Type from Bentotta, Ceylon. A specimen of undetermined sex in the collection of Field Museum of Natural History. Collected in 1899 by Walther Horn.

Paratypes.-One specimen, same data as the type, and three specimens from Puttalam, Ceylon, in the collection of Field Museum. Collected in 1899 by Walther Horn.

Description.-Form oval. Color light yellowish-brown, sometimes clouded with darker brown, rather feebly shining. Surface distinctly alutaceous throughout, with the exception of the elytral scutellar region and the feebly alutaceous or smooth median area of the metasternum. Head deeply, rather sparsely punctulate. Pronotum finely, strongly, rather evenly and sparsely punctate, a few punctures somewhat larger basally.

Elytral punctures for the most part the same size and density as the pronotal punctures, but more elongate (subaciculate) and a trifle finer apically; scutellar region punctulate; epipleura impunctate. Marginal elytral stria very coarse, its outer margin finely cariniform. Pygidia with a few very feebly impressed, fine punctures; apical margin of pygidium a little reflexed.

Prosternal striae nearly parallel on basal two-thirds, thence arcuately diverging apically. Punctures very feeble if at all discernible. Mesosternum impunctate; marginal stria complete, its outer edge subcariniform and its median angle rather obtusely rounded, continuous on each side with the lateral metasternal stria; the latter oblique (at about an 80-degree angle to the transverse axis of the beetle), extending a little more than a third the length of the metasternum.

Protibiae ten- to eleven-spinulose. Mesotibiae six-spinulose. Metatibiae four- or five-spinulose.

Length 1.2-1.4; width $0.90-1.05 \mathrm{~mm}$.

Remarks.-Colombo, the type locality of lewisi, is situated between Puttalam and Bentotta on the west coast of Ceylon. Thus 
lewisi and alutiger have the same range at least in part. The types of alutiger had been identified by Lewis as algarum, though the two species are very different. Inasmuch as both Schmidt and Lewis obviously confused several species of Halacritus, it is probably best to regard with suspicion any distribution records, with the exception of the Seychelles, which have been published for algarum.

\section{Halacritus blackwelderi sp. nov.}

Type from High Point on Parham Sound, five miles northeast of St. Johns, Antigua, British West Indies. A specimen of undetermined sex in the collection of the United States National Museum. Collected under seaweed, August 15, 1936, by R. E. Blackwelder.

Paratypes.-Five specimens, sex undetermined, same data as the type; three in the collection of the United States National Museum, one each in the collections of Field Museum and R. L. Wenzel.

Description.-Form oblong-oval, rather feebly convex. Color yellowish-brown, shining. Pygidium feebly alutaceous; prosternal keel, mesepimeron, elevated sides of metasternum, and sides of first abdominal sternum strongly alutaceous. Head deeply, rather sparsely punctulate.

Pronotum strongly, finely, sparsely punctate. Elytral punctures along the suture distinctly coarser than the pronotal punctures, but finer laterally; flanks punctulate. Pygidium sparsely punctulate.

Carinal striae of prosternum strongly divergent anteriorly. Meso- and metasternal disks sparsely punctulate (density variable in the series, one specimen being rather densely punctulate); anterior half of elevated metasternal sides with moderately coarse punctures.

Length 1.02-1.05; width $0.74-0.76 \mathrm{~mm}$.

Remarks.-This species is related to salinus Le Conte. A specimen collected by Dr. Blackwelder at St. Kitts, British West Indies, October 9, 1936, may be blackwelderi, but it differs in several respects from the types and thus is not included in the series.

\section{Provisional Key to the Species of Halacritus ${ }^{1}$ of the World}

1. Elytra strongly, strigosely punctate on apical half; metasternum coarsely punctate. riparius Bickhardt (1914, p. 310$)$

Elytral punctures simple, or if at all strigose the metasternum is punctulate

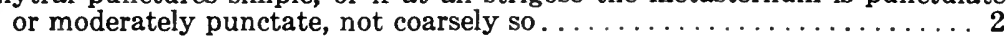

${ }^{1}$ Although the genotype, algarum Schmidt (1893, p. 103), is distinct from the other described species, it is not included in the key because the original description does not mention some of the characters used by the writer as alternatives in separating the species. 
2. Entire surface alutaceous, though the disks of the elytra may be rather feebly so . . . . . . . . . . . . . . . . . . . . 3

Elytra never alutaceous; pronotum alutaceous at sides and along anterior margin, if at all; under surface completely alutaceous in one species (see

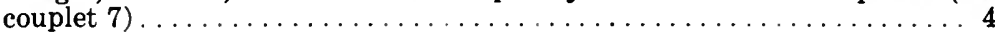

3. Under surface black; elytra with a smooth sutural space........ lividus Lea

Under surface pale yellowish-brown, with a few dark areas; elytra equally as punctate along the suture as on disks..............alutiger sp. nov.

4. Lateral metasternal stria extending obliquely posteriorly for about half the length of the metasternum, thence strongly recurved and extending anteriorly to the metasternal-mesepimeral suture (pl. 1, fig. 5).

$$
\text { maritimus Le Conte }
$$
parallelus Casey

Lateral metasternal stria obsolete or extending obliquely posteriorly for about half the length of the metasternum (pl. 1, fig. 5) and then terminating without recurving anteriorly, or broadly interrupted apically so that an oblique isolated portion may be present near the metasternal-mesepimeral suture. . 5

5. Lateral metasternal stria obsolete, scarcely entering upon the metasternal disk, if at all distinguishable (pl. 1, fig. 5) . ........... glabrus sp. nov.

Lateral metasternal stria extending obliquely posteriorly for about half the

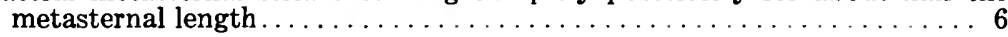

6. Metasternum punctulate, sometimes nearly smooth $\ldots \ldots \ldots \ldots \ldots \ldots 7$

Metasternum moderately, strongly punctate throughout or posteriorly at

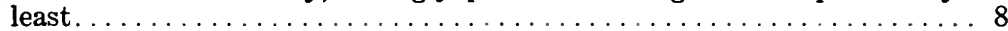

7. Lateral and anterior margins of pronotum, pygidia, and entire under surface alutaceous, though disks of meso- and metasternum may be feebly so. salinus Le Conte

Pygidia, prosternal keel, elevated metasternal sides, and sides of first abdominal segment alutaceous. . . . . . . . . . . . . . . . blackwelderi $\mathrm{sp}$. nov.

8. Metasternal punctures even from base to apex, very fine in a median longitudinal area, of moderate size on each side...punctum Aubé (1842, p. 232)

Metasternal punctures minute anteriorly, becoming moderate and strong

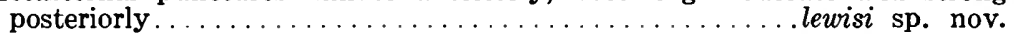

Species

algarum Schmidt alutiger sp. nov. blackwelderi sp. nov. glabrus sp. nov. lewisi sp. nov. lividus Lea

maritimus Le Conte

parallelus Casey

punctum Aubé riparius Bickhardt

(?)australis Brethes salinus Le Conte
Wing condition

Subapterous

Fully developed

Fully developed

Fully developed

Subapterous

Not examined

Partially reduced, about as long as the elytra; sometimes complete?

Not examined

Fully developed

Not examined

Partially reduced, about as long as the elytra
Known distribution

Seychelles

Ceylon: Bentotta; Puttalam

British West Indies: Antigua

West Australia: Albany

Ceylon: Colombo

Lord Howe Island. New South Wales: Sydney; Wallongong. S. Australia: Adelaide Dist.

California: Santa Barbara to San Diego

Virginia: Fort Monroe Maryland: Piney Point

Mediterranean region Chile

Florida: Cedar Keys; Dunedin 
The reduction of the inner wings in species of this genus is interesting; the distribution of each species and the condition of the wings, as far as they are known, are noted in the table on page 64 .

Darlington (1936) has shown that ground beetles living along stream and river banks or their flood plains are characteristically fully winged, while in those species which live in woodlands and fields (excepting those living on plants) the wings may undergo various stages of reduction and atrophy. The reason advanced by Darlington for this difference is that wings have a high survival value in species which live in such an insecure habitat as the frequently flooded banks or near vicinity of streams and rivers, and that selection pressure consequently operates against mutations for wing atrophy that may appear. On the other hand, in a habitat where wings have no especial value, reduction and atrophy may take place in the absence of such selection pressure.

Interestingly enough, Darlington notes further that coast-dwelling beetles frequently have reduced wings, and he states that they probably have less need for flying wings than their inland relatives. Though this may be true in part, it hardly seems explanation enough, for, while it must be granted that the two habitats (seashore and river bank) each have unique characteristics, yet one finds in both the same general sort of highly variable physical factors which presumably make for the retention of wings in the riparian species. Perhaps the distinction lies in this: although ability to fly might be expected to have survival value in such a niche, nevertheless, because of strong coastal winds which would carry many flying individuals away from the narrow zone to which they are adapted (either to sea or inland), the reduction of wings and consequent loss of flight would have greater survival value than the alternative, and mutations for this character would be selected for. For example, specimens of H. maritimus from Redondo, California, which have been examined by the writer, have inner wings which are so much reduced that it is difficult to see how they could be capable of even very inefficient flight. However, Fall (1901) has recorded inland specimens from Pasadena and Pomona as "flying in the early evening." It would seem reasonable to assume, therefore, that within the population of maritimus, specimens with fully or nearly fully developed wings do occur. Since our knowledge of the biology of this species indicates that it is maritime, one might infer that such records as Fall's represent individuals which have been carried away from, or have flown away from (or both), the narrow breeding and feeding zone to which 
they are adapted. Further, since such errant-winged individuals would not further perpetuate the species, or possibly to a limited extent only, mutations for reduction of the inner wings might be expected to be selected for within the population, other factors being equal. Although not all the species of Halacritus have reduced flying wings, the percentage which do is significant.

\section{Genus Aeletes Horn}

In 1941 Wenzel and Dybas placed Acritus simpliculus Marseul and $A$. rugulosus Marseul in Aeletes; until that time only one other neotropical histerid (ctenomyphilus Bickhardt) was thus assigned. In the following section the writer adds to the genus seventeen neotropical species-fourteen of them new-places one name in synonymy, and gives a key to the known neotropical species.

Aeletes simpliculus Marseul (=A. rugulosus Marseul)

Acritus simpliculus Marseul, Ann. Soc. Ent. Fr., (3), 4, p. 616, pl. 14, fig. 15, 1856-Venezuela (Caracas).

Aeletes simpliculus Wenzel and Dybas, Field Mus. Nat. Hist., Zool. Ser., 22, p. 442, 1941.

Acritus simpliciculus Gemminger and Harold, Cat. Coleop., 3, p. 798, 1868.

Acritus rugulosus Marseul, 1.c., p. 617, pl. 14, fig. 16, 1856-Venezuela (Caracas).

Aeletes rugulosus Wenzel and Dybas, 1.c.

After examining a large series of specimens from Mexico and additional examples previously reported upon from Colombia, the writer is convinced that rugulosus is the female of simpliculus. Without exception, all the specimens studied bear this out. Similar sexual dimorphism, in which the elytral punctures of the male are simple and those of the female are strongly aciculate, is known for the European Acritus nigricornis Hoffmann, the female of which was described under the name seminulum by Küster.

\section{Aeletes termitophilus sp. nov.}

Type from Hamburg Farm, Reventazon, upper Limon, Costa Rica. A specimen of undetermined sex in the collection of the United States National Museum. Collected in a colony of Coptotermes niger Snyder, February 10, 1938, by Ferdinand Nevermann.

Description.-Form oval, rather strongly convex. Color deep reddish-brown, strongly shining. Marginal epistomal stria complete; epistoma feebly, sparsely punctulate. Entire surface otherwise 
impunctate. Pronotum with an arcuate, strongly crenate antescutellar stria; antescutellar interval glabrous, without punctures or plicae.

Prosternal keel broader than it is long along the median line; striae distinctly arcuate; basal margin broadly, angulately emarginate for the reception of the projecting mesosternum. Anterior margin of mesosternum obtusely produced at middle. The usual meso-metasternal row of plicae replaced by a very strongly arcuate and strongly crenato-punctate stria whose middle portion arches a little more than halfway up the mesosternal disk. Lateral metasternal stria extending obliquely posteriorly and terminating without recurving anteriorly. Middle femora, when extended posteriorly, reaching more than half the distance from the meso-metasternal suture to the hind coxae.

Length 0.85 ; width $0.57 \mathrm{~mm}$.

Remarks.-The emarginate basal margin of the prosternal keel, the projecting anterior mesosternal margin, and the character of the mesosternal stria separate termitophilus from all other described neotropical species of Aeletes.

Aeletes schwarzi sp. nov.

Type from Cayamas, Cuba. A specimen of undetermined sex in the collection of the United States National Museum. Collected February 25 by E. A. Schwarz.

Paratype.-One specimen from the same locality as the type, in the collection of Field Museum of Natural History. Collected March 6 by E. A. Schwarz.

Description.-Form oblong-oval. Color stramineous. Head glabrous, sparsely punctulate; marginal epistomal stria present along the sides only. Pronotum without an antescutellar stria; surface aciculately punctate, the punctures strong and sparse, being moderately coarse and densest in front of the scutellum, becoming minute along the anterior and lateral margins. Elytral punctures aciculate, being strong and moderate along the suture (a trifle coarser basally) and becoming a little finer laterally, disappearing on the flanks; aciculations outwardly oblique. Pygidium strongly, finely, sparsely punctate; marginal stria fine, complete.

Prosternal keel finely, strongly, sparsely punctate, at least onehalf longer than broad, the striae feebly arcuate, basal width about equal to the apical. Mesosternum coarsely, closely punctate, the punctures somewhat elongate, sometimes subconfluent; transverse row of elongate sulciform punctures or sulci absent. Metaster- 
num similarly punctate anteriorly, the punctures apparently ${ }^{1}$ becoming moderate and sparse posteriorly, at least on the elevated metasternal sides.

Middle femora, when extended posteriorly, reaching about half the distance from the meso-metasternal suture to the first abdominal sternum.

Length $0.80-0.86$; width $0.60-0.62 \mathrm{~mm}$.

Remarks.-This is the only neotropical species of Aeletes known to the writer which has aciculate pronotal punctures.

Aeletes rugiceps sp. nov.

Type from Cayamas, Cuba. A specimen of undetermined sex in the collection of the United States National Museum. Collected March 6 by E. A. Schwarz.

Description.-Form elongate-oval, rather strongly convex. Color deep yellowish-brown, shining. Epistoma finely, transversely rugulose, and finely, very sparsely punctate; marginal epistomal stria present on the sides only; vertex feebly rugulose and punctulate. Pronotum minutely, sparsely punctulate; disk at middle with feeble, longitudinal rugulae, these becoming even less evident laterally. Antescutellar pronotal stria absent. Elytra with long, parallel, very feeble aciculations along the suture, these visible only in certain lights; disks microscopically punctulate. Pygidium obtusely pointed and a little produced at apex; surface glabrous, very sparsely, minutely punctate; marginal stria fine, complete, punctate.

Prosternal keel sparsely punctulate, about as long as wide at apex; carinal striae subparallel on basal half, arcuate and divergent apically (not strongly so). Meso-metasternal disk minutely, rather feebly, sparsely punctulate; mesosternal disk without a row of sulciform punctures or sulci.

Middle femora, when extended posteriorly, reaching slightly more than half the distance from the meso-metasternal suture to the first abdominal sternum.

Length 0.75 ; width $0.53 \mathrm{~mm}$.

Remarks. - This species may be separated from its allies by the characters given in the key.

${ }^{1}$ Both the type and paratype are mounted in such a way that it is impossible to see the median and posterior areas of the metasternal disk. 
Aeletes troglodytes sp. nov. (pl. 1, fig. 2)

Type from Aripo Valley, Trinidad, British West Indies. A specimen of undetermined sex in the collection of the Museum of Comparative Zoology. Collected deep in a cave at 2,600 feet elevation, April 19, 1935, by Neal A. Weber.

Description.-Form oval, moderately convex. Color reddishbrown, shining. Epistoma with a few fine punctures; marginal stria present on each side but not along anterior edge. Marginal pronotal stria complete. Antescutellar stria absent. Basal margin crenated by a few fine punctures. Elytra impunctate; marginal elytral stria complete. Propygidium smooth. Pygidium finely, transversely rugose, the rugae long.

Prosternum between a third and a fourth longer than greatest width, basal width about equal to the apical; carinal striae distinctly, but not strongly, inwardly, arcuate. Marginal mesosternal stria absent behind the prosternum, continuous on each side with the lateral metasternal stria which recurves anteriorly and extends to the metasternal-mesepimeral suture. Meso-metasternal suture marked by a row of deep punctures, of which the median ones are elongate and longitudinal, the lateral ones round; two discal, widely separated mesosternal punctures behind the anterior margin.

Protibiae with dense short setae on about apical half of outer margin. Mesotibiae with sparse, very fine, short setae and an apical spinule on outer edge. Metatibiae apparently without adornment on outer margin.

Length 0.90 ; width $0.66 \mathrm{~mm}$.

Remarks.-A. troglodytes is related to the North American politus Le Conte and differs from it chiefly in the characters of the pygidium and of the pro- and metasternum (figured for both species on pl. 1, figs. 2 and 3).

Aeletes lissosternus sp. nov.

Type from Montserrat, British West Indies. A specimen of undetermined sex in the collection of the United States National Museum. Collected March 22, by H. G. Hubbard.

Description.-Form oblong-oval, moderately convex. Color stramineous, shining. Epistoma with a few very fine punctures, marginal stria present laterally only. Pronotal sides strongly arcuate and convergent. Pronotum and elytra apparently impunctate. Antescutellar pronotal stria absent. Pygidium impunctate, basal 
margin strongly arcuate at middle, disk strongly convex near apex, marginal stria not evident.

Prosternal keel elongate, about twice as long as median width, the striae subparallel on basal half, divergent apically, but not strongly so. Mesosternum impunctate, without a transverse row of sulci. Metasternum impunctate. Region of meso-metasternal suture transversely impressed. Posterior margin of first abdominal sternum deeply emarginate at middle for the reception of the following segments when retracted.

Legs slender, middle and hind tarsi filiform. Middle femora, when extended posteriorly, reaching the hind coxae and almost reaching the first abdominal sternum (medial to the hind coxae).

Length 0.80 ; width $0.62 \mathrm{~mm}$.

Remarks. - This species belongs to the group containing aciculatus sp. nov. and floridae Marseul by virtue of its long legs and filiform tarsi as well as the deeply emarginate first abdominal sternum; the latter is probably a secondary male character, as in floridae.

\section{Aeletes laevis sp. nov.}

Type from Santarem, Brazil. A specimen of undetermined sex in the collection of Carnegie Museum. Collected in April.

Description.-Form oval, moderately convex, color reddishbrown, shining. Marginal epistomal stria present along sides and anterior margin; epistomal punctures sparse. Pronotum, elytra, and under side impunctate. Pygidium finely, transversely, rugulose; marginal stria well impressed. Prosternal keel slightly broader than long, carinal striae distinctly, inwardly arcuate, but not strongly so. Mesosternal disk rather broadly impressed at middle; sulciform punctures somewhat as in troglodytes, though more numerous and not as long at middle. Marginal mesosternal stria continuous posteriorly on each side with the lateral metasternal stria, which extends obliquely posteriorly for about a third the length of the metasternum and then recurves anteriorly to the metasternalmesepimeral suture. Posterior margin of metasternum (between the hind coxae) broadly, feebly, outwardly arcuate. Middle femora, when extended posteriorly, almost reaching the posterior coxae.

Length 0.77 ; width $0.63 \mathrm{~mm}$.

Remarks.-This species is closely related to troglodytes and may be separated from it by the characters given in the key. 
Aeletes dybasi sp. nov. (pl. 1, fig. 1)

Type from Cordoba, Vera Cruz, Mexico. A male in the collection of Field Museum. Collected July 11, 1941, by Henry S. Dybas.

Paratypes.-Twelve specimens, same data as the type; one specimen from Penuela, Vera Cruz, July 17, 1941; one specimen from EI Fortin, Vera Cruz, July 12, 1941; in the collection of Field Museum of Natural History. Collected by Henry S. Dybas.

Description.-Form oval, strongly convex. Color reddish-brown, strongly shining. Upper surface very sparsely, remotely punctulate, excepting the pygidia, which are strongly punctulate. Marginal epistomal stria present along sides only.

Pronotum with an evenly (not strongly) arcuate and strongly crenate antescutellar stria, which is a little wider than a third of the basal pronotal width; antescutellar interval smooth. Marginal stria complete. Elytra with two or three poorly defined longitudinal impressions laterally and basally. Marginal elytral stria complete, well impressed.

Prosternal keel strongly, sparsely punctulate, a little longer than greatest width; carinal striae strongly arcuate, divergent anteriorly and posteriorly; basal width a little less than the anterior. Marginal mesosternal stria subcariniform, absent behind the prosternum, continuous on each side with the lateral metasternal stria which extends obliquely posteriorly for about two-thirds the metasternal length and terminates near the metasternal-metepisternal suture. Disk with two oblique crenate striae as illustrated. Mesometasternal suture represented by a dark line. Pygidium without marginal stria.

Protibiae with fine, short, dense setae along outer margin on a little more than apical half. Mesotibiae with a row of seven or eight fine short setae on outer margin. Metatibiae with four or five inconspicuous setae on outer edge.

Length $0.71-0.82$; width $0.56-0.67 \mathrm{~mm}$.

Remarks.-This is one of the described New World species of Aeletes which lacks both a marginal pygidial stria and a row of longitudinal plicae or elongate punctures on the mesosternal disk. The oblique mesosternal striae are distinctive.

Aeletes rectistrius sp. nov.

Type from Ortoire River, five miles southeast of Rio Claro, Trinidad, British West Indies. A specimen of undetermined sex 
in the collection of the Museum of Comparative Zoology. Collected January 3, 1935, by Neal A. Weber.

Paratypes.-Four specimens, same data as the type; two in the collection of the Museum of Comparative Zoology, two in the collection of Field Museum.

Description.-Form oval, moderately convex. Color reddishbrown, shining. Epistoma very finely, sparsely punctate; marginal stria present along sides only. Marginal pronotal stria complete. Pronotal disk impunctate. Antescutellar stria straight, very finely and closely crenate, present on about middle third of basal pronotal width and abruptly terminating on each side without running parallel to basal margin, the latter crenated by a row of distant fine punctures; antescutellar interval not plicate. Elytra impunctate; marginal elytral stria fine, complete. Pygidia impunctate; pygidium with a fine, well-impressed marginal stria along apical and lateral margins.

Prosternum rectangular, about a fourth longer than greatest width, striae feebly arcuate, basal width equal to the apical. Marginal mesosternal stria absent behind the prosternum, continuous on each side with the lateral metasternal stria which recurves anteriorly and reaches the metasternal-mesepimeral suture. Mesometasternal suture marked by a row of longitudinal punctures which are shortest laterally.

Outer margins of protibiae fringed with dense, short setae on a little more than apical half. Mesotibiae with two or three fine spinules on outer edge near apex. Metatibiae without spinules or setae on outer margins.

Length $0.73-0.77$; width $0.48-0.52 \mathrm{~mm}$.

Remarks.-This species is allied to laeviusculus Marseul and may be separated from it by the characters given in the key.

\section{Aeletes subniger sp. nov.}

Type from Villavicencio, Meta Intendencia, Colombia. A male in the collection of Rupert L. Wenzel. Collected from under bark, July 25, 1938, by Henry S. Dybas.

Paratypes.-Two examples, same data as the type; one in the collection of Field Museum, the other in the collection of Edward S. Ross.

Description.-Form oval, rather strongly convex. Color brownish-black, shining. Head strongly, sparsely, very finely punctate. 
Lateral and anterior margins of epistoma with a continuous marginal stria.

Pronotum sparsely, deeply, moderately punctate, the punctures finer along the sides. Antescutellar stria arcuate, strongly crenate, present on about middle half of basal pronotal width; antescutellar interval plicate, the median plicae neither well impressed nor reaching posteriorly to the basal margin. Marginal pronotal stria complete.

Elytra sparsely punctulate on outer half and apically on inner half, the punctures a little stronger basally on inner half; a few apical punctures along suture may be finely aciculate; surface glabrous in the scutellar region, elsewhere somewhat dulled by an extremely fine and feeble alutaceous sculpture which is detectable only under high magnification (about $\times 144$ ). Marginal elytral stria fine and complete, finely and crenately punctate on apical half.

Pygidia sparsely, strongly, rather finely punctate, pygidium with a well-impressed stria along apical and lateral margins.

Prosternal keel about a fourth longer than broad, striae feebly arcuate, subparallel, basal and apical widths equal, surface sparsely, deeply, rather finely punctate. Marginal mesosternal stria absent behind the prosternum (though represented there in one specimen by a row of disconnected punctures), continuous on each side with the lateral metasternal stria, which recurves anteriorly and reaches the metasternal-mesepimeral suture; mesosternal disk with a few punctures, tumid in a narrow area behind the prosternum; mesometasternal suture marked on middle three-fourths by a row of longitudinal plicae which extend a little more than halfway up the mesosternal disk. Metasternal disk for the most part sparsely punctulate, the punctures larger anteriorly; elevated sides with sparse, strong, moderate punctures.

Length 1.05-1.16; width $0.75-0.79 \mathrm{~mm}$.

Remarks.-At hand are two specimens from Caracas, Venezuela, which have the elytral punctures aciculate on inner half from about basal fifth nearly to apex. These may be females of subniger.

Aeletes rugipygus sp. nov.

Type from Tilaran, Guanacaste, Costa Rica. A specimen of undetermined sex in the collection of the United States National Museum. Collected March 3, 1934, by Ferdinand Nevermann. 
Description.-Form rather elongate-oval, moderately convex. Color deep brownish-black. Head very sparsely punctulate. Marginal epistomal stria present along the sides only.

Pronotum very finely, sparsely punctate, the punctures a little stronger medially. Antescutellar stria strongly crenate, feebly arcuate and feebly re-entrant at middle, well separated from the basal pronotal margin for about the middle third of its width, very close to the basal margin laterally. Antescutellar interval plicate, the plicae indistinct at middle. Surface apparently very feebly alutaceous, this sculpture discernible only under favorable lighting.

Elytra sparsely punctulate, the punctures coarser (though still fine) along the suture on about basal two-thirds, those near the middle very feebly aciculate. Pygidium transversely rugulose. Marginal stria fine, complete.

Prosternal keel about a third longer than broad, the striae parallel basally, very feebly divergent apically; keel sparsely punctulate, distinctly convex anteriorly. Mesosternum with a row of sulciform punctures of rather even size which extend anteriorly from the meso-metasternal suture about one-third (or a trifle more) the length of the mesosternal disk. Metasternum very sparsely, minutely punctate.

Middle femora, when extended posteriorly, reaching a little more than one-half the distance from the meso-metasternal suture to the first abdominal sternum.

Length 0.90 ; width $0.63 \mathrm{~mm}$.

Remarks.-This species is rather close to subniger, but the latter differs in the following respects: (1) pygidium glabrous and strongly, finely punctate; (2) marginal epistomal stria complete; (3) elevated metasternal sides strongly, sparsely, rather finely punctate; (4) mesosternal sulci less even, some reaching to middle of mesosternal disk or a little beyond.

Aeletes assimilis sp. nov.

Type from Cayamas, Cuba. A specimen of undetermined sex in the collection of the United States National Museum. Collected January 15 by E. A. Schwarz.

Description.-Form rather elongate-oval, moderately convex. Color yellowish-brown, shining. Head sparsely punctulate, glabrous; marginal epistomal stria present along the sides only.

Pronotum strongly, moderately, sparsely punctate at middle, the punctures becoming finer laterally; surface alutaceous at middle, 
the sculpture becoming feeble laterally. Antescutellar stria strongly crenate, present on about middle third of basal width; antescutellar interval plicate, except at middle.

Elytra microscopically, sparsely punctulate. Pygidium very finely, sparsely punctulate, its surface feebly, transversely rugulose, the rugulae short.

Prosternal keel sparsely punctulate, a little longer than wide at apex; carinal striae rather feebly arcuate and subparallel basally, a little more strongly divergent apically. Mesosternum with a row of about twelve closely placed, parallel, sulciform punctures which are longest at middle and extend anteriorly from the meso-metasternal suture more than halfway up the mesosternal disk. Metasternal disk very feebly alutaceous; punctures very fine and sparse, not becoming coarser on the elevated sides.

Middle femora, when extended posteriorly, reaching about onehalf the distance from the meso-metasternal suture to the anterior margin of the first abdominal sternum (medial to the hind coxae).

Length 0.76 ; width $0.55 \mathrm{~mm}$.

Remarks. - The type does not appear to have a marginal pygidial stria, but owing to the manner in which it is mounted, it is impossible to check upon this character with certainty. Assimilis is related to nevermanni and simpliculus, but may be separated from them by the characters given in the key.

\section{Aeletes nevermanni sp. nov.}

Type from Hamburg Farm, Reventazon, upper Limon, Costa Rica. A specimen of undetermined sex in the collection of Field Museum of Natural History. Collected January 4, 1932, on freshly cut sections of trees, by Ferdinand Nevermann.

Paratypes.-Seven specimens, same data as the type; one each in the collections of the United States National Museum, the Museum of Comparative Zoology, and Edward S. Ross.

Description.-Form oblong-oval, rather feebly convex. Color reddish-brown, shining. Head minutely, sparsely punctate, epistomal punctures setigerous; marginal stria of epistoma complete. Pronotum strongly, sparsely punctate medially, the punctures becoming extremely fine and almost indistinguishable laterally. Antescutellar stria arcuate or feebly angulate at middle, strongly crenate, present on about middle third of width of basal margin; antescutellar interval not distinctly plicate, though it has a few 
vague, punctiform impressions. Basal pronotal margin strongly crenated by punctures. Marginal pronotal stria complete.

Elytra microscopically, sparsely punctulate on lateral halves (flanks smooth); along the suture, from basal third to apex, the punctures are stronger and near the middle may be feebly aciculate. Pygidia glabrous, very finely, sparsely punctate.

Prosternal keel about one-half longer than apical width; carinal striae very feebly divergent basally, a little more distinctly so apically. Mesosternum with parallel, longitudinal sulci which are absent on each lateral fourth and which traverse the length of the disk. Marginal stria continuous with the lateral metasternal stria, which recurves anteriorly and reaches the mesepimeral-metasternal suture. Metasternal disk very sparsely punctulate, the elevated sides with a few moderate punctures.

Length $0.68-0.73$; width $0.53-0.57 \mathrm{~mm}$.

Remarks.-This species is allied to subniger and simpliculus, and may be separated from them by the characters given in the key.

Aeletes sulcipennis sp. nov.

Type from Hamburg Farm, Reventazon, Limon, Costa Rica. A specimen of undetermined sex in the collection of Field Museum of Natural History. Collected on freshly cut sections of trees, January 4, 1932, by Ferdinand Nevermann.

Paratypes.-Four specimens, same data as the type; three in the collection of Field Museum, one in that of the Museum of Comparative Zoology. Two specimens, same locality as the type, in the collection of the United States National Museum; collected on fallen Virola warburgii, February 23, 1934, by Ferdinand Nevermann.

Description.-Form oblong-oval, rather feebly convex. Color deep reddish-brown, shining. Head finely, very sparsely punctate. Marginal epistomal stria complete.

Pronotum strongly, moderately, sparsely punctate at middle, the punctures sparser and much finer laterally. Antescutellar stria strongly crenate, rather feebly arcuate, present on about middle third of basal width; antescutellar interval feebly and incompletely plicate.

Elytra sparsely, moderately punctate basally and moderately coarsely punctate apically; flanks and scutellar region smooth or nearly so; apices of elytra (apical fourth or a little more) with deep, 
longitudinal, parallel, closely placed, punctate sulci. Marginal elytral stria strong, complete.

Propygidium finely punctate basally, moderately coarsely, deeply, rather closely punctate apically. Pygidium coarsely, rather closely punctate, the punctures sparser and finer apically. Marginal stria well impressed.

Prosternal keel with a few fine punctures, nearly twice as long as median width, the striae rather feebly arcuate and subparallel basally, noticeably more divergent apically. Mesosternal disk strongly plicate, the plicae long and reaching to the anterior margin. Marginal stria absent behind the prosternum, continuous on each side with the lateral metasternal stria, which is coarsely punctate and recurves anteriorly to the metasternal-mesepimeral suture. Metasternal disk microscopically, sparsely punctate or smooth at middle, the punctures moderate in front of the hind coxae; punctures coarse and sparse on the elevated metasternal sides.

Length 0.83-0.89; width $0.60-0.67 \mathrm{~mm}$.

Remarks.-All the type specimens of sulcipennis were originally mounted on cards with a rather thick adhesive and in addition were very dirty and difficult to clean; consequently, certain details could not be observed easily, and the tibiae could not be studied at all. The elytral sulci are unique among the described species of Aeletes. At hand is a specimen which is very similar to the types but which lacks the elytral sulci and which has finer pronotal punctures, sparsely punctate pygidia and only a very few punctures on the elevated metasternal sides. There is a rather remote possibility that this could be the male of sulcipennis, but this cannot be confirmed from the material before me.

Aeletes aciculatus sp. nov.

Type from Hamburg Farm, Reventazon, Limon, Costa Rica. A male in the collection of Field Museum of Natural History. Collected on a freshly cut tree section, January 4, 1932, by Ferdinand Nevermann.

Paratypes.-Two specimens, same locality as the type, in the collection of the United States National Museum. Collected on fallen Virola warburgii, February 23, 1934, by Ferdinand Nevermann.

Description.-Form broadly oval, rather feebly convex. Color deep reddish-brown. Eyes with distinct setae. Epistoma with 
moderate, deep, setigerous punctures, the setae rather long; marginal epistomal stria complete; vertex with finer setigerous punctures, the setae shorter and finer than those of the epistoma.

Pronotum with moderate, deep punctures in a rather broad median area, the punctures separated by one to one and one-half times their diameters and becoming sparser and very fine laterally. Antescutellar stria strongly crenate, rather feebly arcuate, occupying a little more than middle third of width of basal margin; antescutellar interval not plicate. Basal margin strongly crenated by punctures.

Elytra deeply, moderately punctate, excepting elytral flanks above and a narrow area along the suture near the scutellum, these areas being sparsely punctulate; on basal half of elytra the punctures mostly separated by one and one-half to two times their diameters, but on apical half a trifle closer with their intervals finely aciculate.

Pygidium glabrous; surface deeply, rather densely, moderately coarsely punctate on a little less than basal half; apically the punctures become a little finer and along the middle become sparser as well. Marginal stria strong, complete.

Prosternal keel very sparsely, minutely punctate, about one and one-half times longer than greatest width; base a little wider than apex; carinal striae feebly arcuate, divergent basally and apically. Mesosternum with two oblique striae as in dybasi (but not crenate), the interval between them with longitudinal, parallel sulci which traverse the length of the disk and become shallower posteriorly. Region of meso-metasternal suture broadly, shallowly, transversely impressed. Marginal mesosternal stria continuous on each side with the lateral metasternal stria, which is coarsely impressed and extends obliquely posteriorly more than one-half the length of the metasternum and terminates abruptly without recurving anteriorly; an oblique stria, which apparently represents the portion of the lateral metasternal that ordinarily extends anteriorly, extends posteriorly from the mesepimeral-metasternal suture but is rather widely separated posteriorly from the lateral metasternal stria. Metasternal disk sparsely punctulate at middle, the punctures becoming coarser laterally, particularly in front of the hind coxae where they merge with the coarse punctures of the elevated sides. Apical margin of first abdominal sternum deeply, rather broadly, arcuately emarginate; disk with a longitudinal stria on each side medial to the coxae; this stria extends posteriorly to the hind margin without curving outwardly and anteriorly. 
Hind tarsi slender, as long as the tibiae, the ventral surface of the first tarsomere with short, dense, stiff hairs.

Length 0.92 ; width $0.72 \mathrm{~mm}$.

Remarks.-The apical emargination of the first abdominal sternum is probably a secondary male character as it is in floridae Marseul, a closely allied species from North America, which may be separated from aciculatus as follows:

1. Lateral metasternal stria extending obliquely posteriorly and terminating without recurving anteriorly; apical elytral punctures seldom connected with each other by the aciculations which are sometimes entirely independent of the punctures......................

Lateral metasternal stria recurving anteriorly and extending to the mesepimeral-metasternal suture; apical elytral punctures, when aciculate, connected by the aciculations....................floridae Marseul

\section{Key to the Neotropical Species of Aeletes ${ }^{1}$}

1. Basal margin of prosternal keel broadly, angulately emarginate for the reception of the obtusely produced anterior mesosternal margin; mesosternal disk with a strongly arcuate and strongly crenato-punctate line whose median portion approaches the anterior mesosternal margin.

termitophilus sp. nov.

Basal margin of prosternal keel truncate (pl. 1, figs. 1-3); anterior margin of mesosternum truncate at middle......................

2. Pronotum with an antescutellar stria................. 9

Pronotum without an antescutellar stria ............... 3

3. Mesosternum with a transverse row of parallel, closely placed sulci or sulciform punctures which extend anteriorly from the meso-metasternal suture

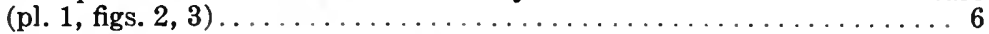

Mesosternum without a transverse row of parallel sulci or sulciform punc-

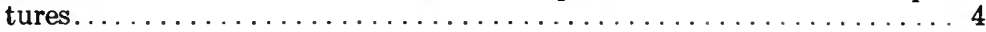

4. Pronotum and elytra aciculately punctate; mesosternum coarsely, closely punctate...........................

Pronotum and elytra impunctate or simply punctate; if punctate, feeble rugulae or aciculations which are independent of the punctures may be present; mesosternum minutely punctate or smooth.......... 5

5. Surface impunctate; epistoma not rugulose; prosternal keel elongate, about twice as long as wide at middle; middle femora long, reaching the hind coxae when extended posteriorly ............... lissosternus sp. nov.

Upper and under surfaces minutely, sparsely punctulate; epistoma finely, transversely rugulose, vertex feebly so; prosternal keel about as long as wide at apex; middle femora, when extended posteriorly, reaching only slightly more than one-half the distance from the meso-metasternal suture to the first abdominal sternum (medial to the hind coxae).

rugiceps sp. nov.

6. Elytra apically with an obliquely strigose microsculpture.

ctenomyphilus Bickhardt (1920, p. 236)

Elytra without such microsculpture................. 7

1 The characters of ctenomyphilus, gulliver, laeviusculus, and poeyi are taken from the original descriptions. 
7. Mesosternum with a row of parallel, closely placed sulci or sulciform punctures (pl. 1, figs. 2, 3); pygidium with a marginal stria laterally and apically ............................... 8

Mesosternum without a row of sulci or sulciform punctures, but with two fine, oblique, crenate striae (pl. 1, fig. 1); pygidium without a marginal

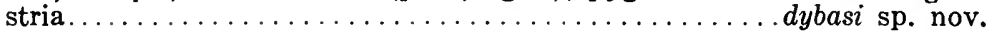

8. Prosternal keel between one-third and one-fourth longer than wide at apex (pl. 1, fig. 2); marginal epistomal stria present along sides only.

troglodytes sp. nov.

Prosternal keel hardly longer than broad; marginal epistomal stria present along lateral and anterior margins . .............. laevis sp. nov.

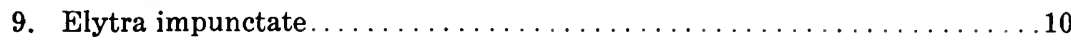

Elytra punctate, sometimes very finely so . . . . . . . . . . . . 12

10. Antescutellar interval (between basal margin and antescutellar pronotal stria) plicate; pronotum impunctate......gulliver Marseul (1856, p. 623)

Antescutellar interval not plicate . . . . . . . . . . . . . . . . 11

11. Pronotum sparsely punctulate; antescutellar stria arcuate; elytra microreticulate apically...............laeviusculus Marseul $(1856$, p. 622)

Pronotum impunctate; antescutellar stria straight; elytra not micro-reticulate apically ......................... rectistrius sp. nov.

12. Elytra with a row of longitudinal, parallel, closely placed sulci across apices. sulcipennis sp. nov.

Elytra sometimes aciculately or strigosely punctate, but never with a trans-

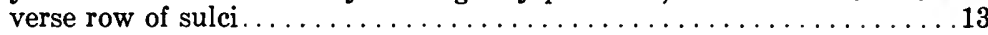

13. Antescutellar stria parallel with the basal margin, the interval narrow. poeyi Marseul (1862, p. 695)

Lateral portions of antescutellar stria sometimes parallel with the basal margin of the pronotum; medial portion of antescutellar stria straight or outwardly arcuate. . . . . . . . . . . . . . . . . . . .

14. Elytra moderately or finely and deeply punctate at least in a broad sutural area . . . . . . . . . . . . . . . . . . . . . . . . . .

Elytra punctulate, sometimes a little more coarsely and strongly punctate in a narrow sutural area, but never markedly so . . . . . . . . . . . 16

15. Strong punctures of elytra extending laterally to the flanks; lateral metasternal stria extending obliquely posteriorly and terminating without recurving anteriorly; middle femora, when extended posteriorly, nearly reaching the intercoxal disk of the first abdominal sternum.... aciculatus sp. nov.

Strong punctures of elytra present in a broad sutural area, not extending laterally to the flanks; lateral metasternal stria extending posteriorly for a short distance and then recurving anteriorly to the metasternal-mesepimeral suture; middle femora extending a little more than half the distance from the meso-metasternal suture to the first abdominal sternum.

simpliculus Marseul (1856, p. 616)

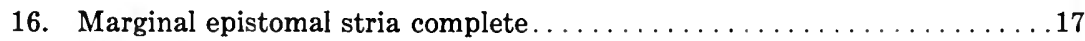

Marginal epistomal stria present along the sides only . . . . . . . . 18

17. Elytra sparsely punctulate, the punctures coarser, though still fine, along the suture on about basal two-thirds; pygidium distinctly, transversely rugulose, without evident punctation; prosternal keel about one-third longer than broad; mesosternum with a row of rather uniform sulciform punctures 
which extend anteriorly from the meso-metasternal suture for about onethird the length of the disk ................... rugipygus sp. nov.

Elytra minutely, uniformly, sparsely punctulate; pygidium sparsely punctulate and feebly, transversely rugulose, the rugulae short; prosternal keel a little longer than it is wide at apex; mesosternal row of sulciform punctures longest at middle, extending anteriorly for more than half the length of the disk ............................

18. Form oval, rather strongly convex; color deep brownish-black; elytra glabrous in the scutellar region, elsewhere dulled by an extremely fine, feeble, alutaceous ground sculpture, details of which can be detected only under high magnification (about $\times 150$ ); pygidium strongly, rather finely, sparsely punctate; prosternal keel about one-fourth longer than broad.

subniger sp. nov.

Form broader, oblong-oval, rather feebly convex; color reddish-brown; elytra glabrous throughout; pygidium very finely, sparsely punctate; prosternal keel about one-half longer than broad....nevermanni sp. nov.

\section{Subfamily Trypanaeinae}

Trypanaeus fucatus sp. nov. (fig. 10)

Type from Mount Duida, Venezuela. A male in the collection of the American Museum of Natural History. Collected November 4,1928 , by G. H. H. Tate.

Allotype.-Female, same data as the type, in the collection of the American Museum.

Paratypes, three males, same data as the type; one in the collection of the American Museum and two in the collection of Field Museum.

Description.-Ground color black, elytra pale yellow with the exception of apical third and a rather narrow lateral margin. Form narrowly cylindrical.

Male.-Front with a rather deep round impression whose lateral margins are distinct and which anteriorly is continuous with a shallowly impressed or flat rostral area. Vertex with a few moderate, sparse punctures. Rostral sides straight, not elevated, distinctly convergent anteriorly; anterior margin subtruncate, the tip with two very feeble elevations.

Pronotum coarsely, irregularly punctate; punctures noticeably finer and sparser on apical fifth, somewhat denser along the median line. Marginal stria absent behind the head, sometimes interrupted along the sides behind the lateral angulation.

Elytral punctures fine, densest along the suture, the apical margin, and the lateral margin (where they become elongate); elsewhere the punctures are very sparse, being nearly absent in the humeral region. 
Pygidium rather short, conical, the sides somewhat compressed; apex pointed from above (not spiniform), rounded in lateral profile; punctures setigerous, moderately coarse, separated by their diameters, becoming finer apically.

Prosternal keel impunctate, similar to that of transversalis Bickhardt (1916, text fig. 18, p. 46); sides margined and distinctly elevated, converging anteriorly, the striae

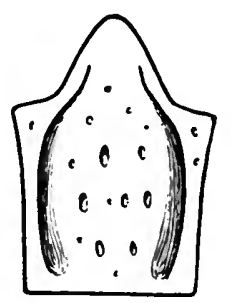

FIG. $10 . \quad$ Trypanaeus fucatus sp. nov. Male. Mesosternal disk. united in a rounded arch apically; basal margin angulately incised.

Mesosternum without a median groove, similar to that of $T$. breviculus Marseul (Bickhardt, op. cit., text fig. 14, p. 45) but more elongate, marginal stria rather coarse, not abbreviated though somewhat feeble posteriorly in two examples; disk with a few elongate, fine punctures. Metasternum sparsely, irregularly punctate, the punctures about half the size of the pronotal punctures, densest along the middle. Protibiae five-dentate. Metatibiae feebly expanded apically.

\section{Length 2.85-2.95; width $0.75-0.90 \mathrm{~mm}$.}

Female a little more elongate than the male. Front and rostrum with two longitudinal sulci, these margined laterally by elevated ridges and separated by a strongly elevated median carina which anteriorly unites with the strongly converging lateral ridges to form an acute apex; apical half of rostrum bent upward at a right angle to the front; posterior end of the median carina (at the level of the anterior margin of the eyes) elevated as a large, acute tubercle on each side of which the sulci are divided by transverse ridges into anterior and posterior portions, the latter being large deep foveae; neither sulci nor carinae extend further posteriorly than a point even with the middle of the eyes. Preocular tubercles minute.

Pronotum without indications of median tubercles and not flattened or excavated anteriorly; surface more shallowly, somewhat more sparsely punctate than in the male. Mesosternal sides converging behind the lateral angle, marginal stria obsolescent posteriorly. Metasternum a trifle more finely punctate posteriorly than in the male.

Pygidium shaped as in T. quadricollis Mars., the punctures dense, moderately coarse and setigerous. 
Remarks.-The male is apparently related to transversalis Bickhardt, the female of which is unknown, but that species has the head flat and has a very differently shaped mesosternum (Bickhardt, op. cit., text fig. 18, p. 46); fucatus runs to pictus in Bickhardt's key but that species is larger $(5 \mathrm{~mm}$.) and has the front only lightly impressed.

The female is related to bimaculatus Erichson and cornifrons Lewis. In the latter species the mesosternum is narrower, and its sides diverge posteriorly for the entire length, the striae deep and approximate; the sulci of the head are not divided into anterior and posterior portions, the rostral apex is longer (neither as abruptly nor as markedly bent upward), and the preocular tubercles are considerably larger. T. bimaculatus is larger $(4.5-5 \mathrm{~mm}$.), it has a longer, less narrowed and less markedly bent rostrum with blunt apex, large preocular tubercles, a less pronounced median carina, shallower sulci, and the median tubercle of the head is placed on a level with the posterior margin of the eyes; in addition, the anterior margin of the pronotum is somewhat excavated and has very shallow coarse punctures.

Lewis gives the length of cornifrons as $5.5 \mathrm{~mm}$. At hand is a specimen which seems to be from the same lot as the type of that species; it answers well to the description but is hardly larger than fucatus. Unless the species varies remarkably more in size than is usual in this genus, it is either an unusually closely allied smaller species from the same locality, or Lewis's measurements are grossly inaccurate; in view of other such mistakes by that author the latter alternative is a distinct possibility.

\section{Subfamily Saprininae}

\section{Genus Saprinus}

Saprinus oblongus sp. nov.

Type from Tancitaro, Michoacan, Mexico. A female in the collection of Field Museum of Natural History. Collected from under moss at 6,000 feet elevation, June 25, 1941, by Harry Hoogstraal.

Description.-Color black with a feeble aeneous luster. Form oblong-subparallel. Head with a short, oblique, obsolescent stria on each side in front of the eyes; surface finely, strongly, rather densely punctate. 
Pronotum a little less than twice as broad as long (22:13), sides nearly straight and convergent from base to apical fourth, thence arcuate to apical angles. Basal margin broadly arcuate, with two rows of strong, moderate punctures. Disk smooth, sides strongly, densely, moderately punctate basally, the punctate area becoming broader and the punctures coarser in the region of the anterior angles. Marginal stria coarse, punctate, complete.

Elytra very sparsely, strongly punctulate, excepting apical fourth, which is moderately, sparsely punctate, and the region of the oblique humeral stria, which is finely, strongly punctate. Epipleura strongly, very sparsely punctulate, punctures becoming a little coarser at middle. Marginal epipleural stria fine, impunctate, complete. Marginal elytral stria strong, punctate, extending around apical angle and halfway across apical margin, thence obsolete. Subhumeral striae absent. Oblique humeral strongly impressed, present on basal third. Dorsal striae one to four well impressed, punctate, the first and second subequal, extending a little beyond the middle; third dorsal longer, extending to near apical third; fourth dorsal not quite reaching the middle, arched toward the suture at base, the arch feebly impressed and consisting chiefly of punctures. Sutural stria very fine, abbreviated at basal third and a little before apex.

Pygidia feebly micro-alutaceous. Propygidium densely punctate, the punctures fine at base, becoming coarser apically. Pygidium moderately coarsely punctate, the punctures separated by their diameters or a little less, scarcely finer or sparser apically.

Prosternum apically distinctly deflexed and rather strongly convex, middle of apical margin with a stria; keel of moderate width, very finely, sparsely punctate and feebly convex; carinal striae punctate, their outer edges subcariniform, divergent basally, thence subparallel and becoming somewhat coarser anteriorly, abbreviated at apical fifth. Lateral striae very coarse, terminating anteriorly in deep foveae.

Marginal mesosternal stria complete, punctate, united on each side with the coarsely punctate lateral metasternal stria. Mesosternum very sparsely punctulate at middle, the punctures becoming moderately coarse laterally. Metasternum impunctate within the lateral stria, with the exception of an apical band of coarse punctures on each side near the hind coxa, the punctures becoming finer and sparser at middle; elevated metasternal sides very coarsely punctate. 
Protibiae nine-denticulate, the teeth blunt and rather small. Mesotibiae with a row each of marginal setae and very blunt short spinules; a longitudinal row of short fine spinules also present along outer face near middle. Metatibiae similar to the preceding, but the spinules of the marginal row finer, becoming progressively longer apically.

\section{Length 3.57 ; width $2.38 \mathrm{~mm}$.}

Remarks.-This species belongs to Horn's group IV, which includes pectoralis, posthumus, paeminosus and allies. It may be readily distinguished from related species by its distinctly oblong, subparallel form (as in aequipunctatus Horn). The females of certain southeastern United States species possess similar extremely variable pygidial excavations which are entirely lacking in the males; their identity cannot be determined definitely without a study of the Casey types.

At hand is a specimen which is tentatively associated with oblongus; it is a female from Orizaba, Vera Cruz, collected with ants from under a stone, July 9, 1941, by C. H. Seevers. This example differs from the type as follows:

Size a little smaller: length 3.2 , width $2.14 \mathrm{~mm}$. Dorsal striae a little longer; elytra moderately punctate on apical third. Pygidium not alutaceous, the punctures becoming noticeably finer and sparser apically; sulci narrower and confined to apical fourth. Prosternal striae a little shorter (abbreviated at apical fourth), not as coarse anteriorly. Apical band of punctures interrupted at middle of metasternum.

Inasmuch as the species of this group are among the most variable of the Saprininae, it is probable the Orizaba specimen and the type are conspecific.

\section{Saprinus carinipennis sp. nov.}

Type from Chapada, Brazil. A male in the collection of Carnegie Museum. Collected in November.

Description.-Form oval, moderately convex. Color reddishbrown, shining. Vertex sharply, deeply punctulate; epistoma with punctures of similar size but with appearance imbricate. Supraorbital stria fine, complete. Frontal stria feeble, carinulate, apparently connected on each side with the supraorbital, complete, though very feeble anteriorly at middle of epistoma where it is strongly arcuate. 
Pronotal sides rather feebly arcuate and not very strongly convergent on basal two-thirds, thence strongly arcuate and convergent to apices; apical angles not impressed, somewhat rounded. Marginal stria complete. Disk finely, sparsely punctate in a broad antescutellar area, the punctures becoming finer and sparser anteriorly, and becoming a little coarser and denser in a rather narrow longitudinal area along the sides, particularly subapically. Basal margin with two rows of fine strong punctures.

Elytra finely, evenly punctate medial to the second dorsal stria, the punctures separated by one to one and one-half times their diameters, slightly finer in the region of the scutellum, slightly larger apically; punctures not very deeply impressed but sharply defined, their bottoms flat; punctures of first interval finer; flanks strongly punctulate. Marginal epipleural stria complete, its outer edge finely, feebly subcariniform. Marginal elytral stria complete, strongly impressed, its outer edge rather strongly subcariniform, not continued across elytral apex. External subhumeral deeply impressed, distinct from, and parallel with, the marginal elytral, present on a little less than basal fourth. Internal subhumeral extending from near base to apical sixth, feeble basally and fine at apex, elsewhere strong and with a subcariniform, crenate, outer edge. Oblique humeral deeply impressed, close to, and parallel with, the first dorsal. First dorsal stria coarsely impressed, extending nearly to apical third, its outer edge strongly, obtusely, subcariniform; second, third, and fourth dorsals replaced by well-defined carinae, the second about as long as the first, the third and fourth respectively shorter, the fourth reaching a little beyond the middle; third with a finely crenulate, inwardly bent, basal hook. Sutural stria consisting of a finely crenulate line on about basal fifth, united with the fourth in an arch.

Pygidium moderately punctate basally, the punctures separated by slightly more than their diameters, becoming fine apically; extreme apex at right angles to the rest of the pygidium and more sparsely punctate, set off from it by two oblique, almost transverse, deep sulci which are narrowly separated at middle and extend laterally to the margin.

Prosternum sparsely punctulate, its structure basically as in azureus and allies but without apical foveae; keel flat and shallowly impressed on basal fourth, becoming progressively convex and then slightly compressed and obtusely carinate to within a short distance of apex; carinal striae subparallel on a little less than basal half, 
thence feebly divergent and ascending to unite with the descending lateral striae a little beyond the middle, thence continuing to ascend to about one-fifth from apex, thence descending to unite with the apical marginal stria. Mesosternal disk sparsely, strongly, finely punctate; anterior mesosternal margin feebly, broadly, outwardly arcuate (not emarginate); marginal stria complete, its outer edge finely subcariniform along anterior margin, rather strongly cariniform laterally. Metasternal disk smooth with the exception of a transverse apical band of moderate, strong punctures, these finer at middle; elevated sides coarsely, closely punctate. First abdominal sternum with a single, fine subcariniform stria on each side medial to the hind coxae, the stria feebly oblique and extending from basal to apical margin; intercoxal disk moderately coarsely, sparsely punctate on basal half, sparsely punctulate on apical half.

Protibiae expanded, outer margin arcuate and bearing seven spinules of which the apical spinule and the two basal ones are fine, the rest strong; first five spinules occupying a little more than apical half. Outer margin of mesotibiae with a submarginal row of short, rather inconspicuous spinules and a marginal row of eight to nine which become longer apically and alternate with strong setae. Metatibiae with one or two short, setiform spinules on basal half, and five or six progressively larger ones on apical half.

Length 3.1 ; width $2.33 \mathrm{~mm}$.

Remarks.-The members of the genus Platysaprinus have the first dorsal stria as in carinipennis, but the latter is the only saprinine species known to the writer which has dorsals two to four replaced by strong carinae.

\section{Genus Geomysaprinus Ross}

The interesting association of beetles of the family Histeridae and other insects with burrowing mammals and reptiles has been pointed out by various authors. In 1940 Ross erected a new genus, Geomysaprinus, to receive two new saprinine species, G. tibialis and G. goff; these were collected from burrows of the Florida pocket gopher, Geomys f. floridanus Audubon and Bachman, and seem to be allied to Chelyoxenus xerobatis Hubbard, a species which apparently is confined to the burrows of the gopher tortoise, Gopherus polyphemus Daudin. In the spring of 1940, Mr. J. L. Hill collected a single male of Saprinus rugosifrons Fall, which proved to be a third and remarkable species of Geomysaprinus; the specimen was taken 
from human feces at Berwyn, Illinois (May 14), an area in which Geomys is not represented. Though it was collected "at large," its true ecological niche may well be that of a commensal predator in rodent burrows; the thirteen-lined ground squirrel, Citellus $t$. tridecemlineatus Mitchill, is abundant in the locality. The following redescription is based upon the male type in the Fall Collection at the Museum of Comparative Zoology, the Berwyn example in the collection of Field Museum, and a female from the type locality in the collection of the United States National Museum.

\section{Geomysaprinus rugosifrons Fall (pl. 2, fig. 2, $a, b$ )}

Saprinus rugosifrons Fall, Can. Ent., 51, p. 213, 1919-Canada (Aweme, Manitoba).

Description: Male.-Form oval. Color black, shining. Head finely rugulose, the rugulosities short, distinct, evenly distributed; supraorbital stria finely cariniform; frontal stria absent; a short longitudinal stria is imperfectly connected to the supraorbital and extends anteriorly to the level of the anterior margin of the eye on each side. Mandibles acutely margined.

Pronotum slightly less than twice as broad as long, sides feebly sinuate on basal three-fourths, strongly arcuate and convergent on apical fourth. Anterior angles obtusely rounded. Marginal stria complete, extending inward along the basal margin for a short distance on each side. Disk rather sparsely, finely, deeply punctate with punctulation intermingled, the punctures becoming longitudinally rugulose in a rather broad area on each side. Basal margin with two rows of moderate, deep, closely placed punctures, which become more numerous in front of the scutellum.

Elytra together distinctly broader than the pronotum (43:36) and a little broader than long. Sides not very strongly convergent, distinctly arcuate at base and near apex, nearly straight at middle. Marginal epipleural stria finely cariniform, impunctate, complete. Marginal elytral stria complete, extending from base to apex and thence around outer apical angle and along apical margin to suture; along the side of the elytron this stria is punctate and has a subcariniform outer edge, but across the apical margin it is impunctate and has a very finely cariniform outer edge. External subhumeral stria close to, but distinct from, the marginal elytral, impunctate, present within basal fourth, not reaching to base; internal subhumeral stria punctate, extending from apical fourth to a little beyond the middle, not united with the oblique humeral, which is 
finely impressed and present on slightly more than basal third. Dorsal striae crenately punctate, the sutural more finely so than the others; first dorsal extending to apical third or fourth; second, third, and fourth dorsals progressively shorter, though the third may be longer than the first; fourth dorsal extending to the middle or a little beyond, arched at base and united with the sutural which extends nearly to apex; the basal ends of the second and third dorsals bent inwardly at right angles for a short distance. Surface finely, not densely punctate (the punctures separated by one to two times their diameters), in an area which extends laterally to the second dorsal stria and anteriorly to the middle between the third dorsal and sutural striae; between the second and third dorsals the punctures extend slightly beyond apical third; elsewhere the elytra are sparsely, distinctly punctulate, except that a rather narrow longitudinal area along the flanks is slightly more coarsely and densely punctate.

Propygidium and pygidium finely, rather closely punctate, the punctures transversely elongate, their posterior margins of ten evanescent so that an imbricate appearance is effected; pygidial punctures rugulose along the sides; pygidium margined laterally and apically, the marginal stria deeply impressed, its outer edge subcariniform.

Prosternum densely punctulate along apical margin, elsewhere sparsely punctulate. Carinal striae subparallel, sinuous, most widely separated at middle, abbreviated at basal sixth and apical fourth, not united at either end; lateral striae strongly impressed, terminating in round deep foveae which are not united across apex by a line, though a feeble indication of a line is present.

Mesosternum moderately coarsely, rather densely punctate; marginal mesosternal stria complete, well impressed, its outer edge subcariniform. Meso-metasternal stria rather strongly, crenately punctate. Marginal mesosternal stria continuous with the lateral metasternal which extends obliquely to near the hind coxa on each side. Metasternum broadly, roundly, distinctly impressed at middle, this area moderately coarsely, rather densely punctate, the punctures bearing short setae; disk sparsely, finely punctate within the lateral metasternal stria on each side; elevated sides of the metasternum, mesepimera, and metepisterna coarsely, rather densıly punctate; metepimera with longitudinally strioliform punctures. Abdominal sterna alutaceous. First sternum moderately punctate within the coxae, the punctures separated by one to two times their diameters and becoming sparser and markedly finer at middle near apex where 
a large tubercle is present; a longitudinal, cariniform stria present on each side medial to the hind coxa; elevated sides rather coarsely, somewhat densely punctate, the posterior margins of the punctures evanescent. Sterna two to five with punctures similar to those of the pygidium, though they are more elongate and more frequently confluent on sterna four and five; fifth sternum ventrally produced and bitumescent at middle (see pl. 2, fig. 2,a), the disk of the produced area impunctate.

Protibiae as shown in pl. 2 , fig. $2, b$; meso- and metatibiae triseriately spinulose, the spinules rather slender, those of the marginal row the longest. Tarsomeres one to four of prolegs each bear a strongly expanded and flattened ventral seta in addition to a short normal seta; tarsomeres one to four of middle and hind tarsi each bear a single dorsal seta and a pair of slender ventral setae, the inner of which is twice the length of the outer; claws long, slender, equal.

Female.-Rugulosities of front of head sometimes united. Punctation of pronotal disk stronger. The coarser apical punctures of the elytra extend nearly to base between the fourth and sutural striae and remain rather strong basally in the other interstrial spaces. Metasternal disk only feebly impressed in a rather narrow apical area, the discal punctures finer and bearing inconspicuous setae which can be seen only under very high magnification. First abdominal sternum feebly impressed and without a median apical tubercle, the punctures nearly uniform throughout (a trifle finer at middle). Fifth sternum strongly convex but not bitumescent at middle, a small foveole present on each side of the middle near base. Tarsomeres one to four of prolegs with both ventral setae normal.

Measurements.-Length 3.7-3.8; width $2.6-2.8 \mathrm{~mm}$.

Remarks. - The elytra of the type and the topotypic female are distinctly alutaceous apically, but in the Berwyn example they are only feebly so. The modified setae of tarsomeres one to four of the male prolegs are a remarkable secondary sexual character which exists in all the saprinines examined, though it has not heretofore been noted in the literature. In the figure of the under side of the male (pl. 2, fig. 2,a), the only punctures shown are those bearing setae.

G. rugosifrons may be separated from tibialis and goffi as follows:

1. Internal subhumeral stria short, present from apical fourth to a little beyond the middle; prosternal foveae not transversely united across apex by a line; basal margin of pronotum with two rows of moderately coarse punctures which become more numerous at middle. Male: metasternum with rather 
dense setigerous punctures, the setae conspicuous; first abdominal sternum with a large tubercle near apex; fifth abdominal sternum ventrally produced and bitumescent at middle (pl. 2, fig. 2,a) ............ rugosifrons Fall

Internal subhumeral complete or nearly so; prosternal foveae united across apex by a line; basal margin of pronotum with fine punctures. Male: metasternum sparsely punctate; first and fifth abdominal sterna without tubercles or bitumescent production . . . . . . . . . . . . . . . . 2

2. Sutural stria united with the fourth dorsal; marginal elytral stria terminating at apical angle. Male: anterior tibiae with rows of fine, crenulate striae on the inner face in place of tarsal groove; metasternum not depressed medially, finely, evenly punctate, alutaceous throughout..........tibialis Ross

Sutural stria abbreviated at basal third; marginal elytral stria extending around apical angle to suture. Male: anterior tibiae with a distinct, shallow tarsal groove, metasternum depressed medially, with a few coarse, median setigerous punctures............................ Ross

Hypocaccus iris Fall (=H. alutiger Wenzel)

Saprinus iris Fall, Can. Ent., 51, p. 214, 1919-Canada (Aweme, Manitoba).

Saprinus alutiger Wenzel, Can. Ent., 68, p. 789, 1935-Wisconsin (Lake Ripley).

Comparison of the types of iris and alutiger shows that only one species is involved; consequently alutiger must be placed as a synonym of iris. In addition to locality records of this species already published, Pentwater, Michigan, may be noted.

Reichardtia gen. nov.

Genotype Pachylopus pedator Sharp, 1876, p. 25 (pl. 2, fig. 1, $a, b$ )

Diagnosis.-Epistoma large, nearly twice as broad as long, its posterior margin distinctly elevated above the rest of the head and separated from it by a coarse, deep, inwardly arcuate groove; anterior margin of epistoma broadly, shallowly emarginate. Supraorbital stria present, frontal stria absent. Vertex without transverse impressions, erosions, or wrinkles. Labrum nearly as broad as the epistoma, its anterior margin distinctly emarginate and impressed at middle.

Pronotum without a lateral stria. Marginal stria complete and continued along entire basal margin. Surface without punctures. Elytra with four dorsal striae and a sutural in addition to the strong, oblique humeral and a complete marginal elytral stria; the latter traverses the elytral apex to unite with the sutural. Pygidium large, triangular.

Prosternal keel strongly cariniform, not differentiated anteriorly; carinal striae short, united in a sharp apex between the procoxae; anterior prosternal margin bisinuate, pointed at middle; prosternal alae notched for the reception of the antennal funicle in repose. 
Antennal cavities poorly defined. Mesosternum narrow, longer than broad (more distinctly so than in Pachylopus), its anterior margin with an acute projection which fits into a notch of the prosternum, a flange of the prosternal base covering it from below. ${ }^{1}$ Meso-metasternal suture well marked. Metasternum short, strongly transverse. Sides of meso- and metasterna, the meso- and metathoracic pleurites, the sides of the first abdominal sternum, and the posterior margins of the remaining abdominal sterna with setigerous punctures which bear moderately long, fine yellow hairs.

Anterior femora normal. Protibiae expanded apically, the outer margin arcuate and bearing from sixteen to nineteen movable, flattened, narrowly lancet-shaped spinules which articulate in open sockets on the outer face and can be deflected ventrally. Meso- and metafemora very stout and swollen, particularly the metafemora, which are nearly twice as broad and thick as the mesofemora. Meso- and metatibiae as in Pachylopus.

Remarks.-This genus is named in honor of Axel Reichardt whose studies on the Saprininae form one of the few notable contributions to histerid taxonomy. The genotype, pedator (from New Zealand), was unknown to Reichardt at the time of his brief revision (1926) of the genera allied to Pachylopus. It does not remotely resemble the members of Pachylopus, Neopachylopus, and Baeckmanniolus in the structure of the protibiae and of the head.

\section{Subfamily Dendrophilinae}

In the course of an investigation of the soil fauna of Georgia peach orchards, two examples of an undescribed, blind, subapterous histerid beetle were collected by W. F. Turner. The specimens were sent to the United States National Museum where they were determined as belonging to a new genus by Mr. Herbert S. Barber, who subsequently suggested to the writer that he describe them.

\section{Geocolus gen. nov.}

Genotype Geocolus caecus sp. nov.

Diagnosis.-Form elongate-oval, moderately convex. Epistoma large, nearly as long as broad; frontal stria not present. Labrum setose, as broad as anterior margin of epistoma. Antennae elevensegmented, inserted under the margin of the front; scape enlarged

${ }^{1}$ In Pachylopus and Neopachylopus the notch of the prosternal base and the median mesosternal projection are visible from below. 
apically; second segment stout, nearly twice as broad as the following segments; club apparently three-segmented, with scattered erect longer setae and recumbent shorter setae which form annulae. Submentum transversely concave.

Anterior margin of pronotum broadly emarginate for the reception of the head. Marginal pronotal stria present, lateral striae absent. Scutellum not visible from above. Elytra not connate, without discal striae. Propygidium short, strongly transverse; pygidium broader than long, nearly vertical.

Prosternal keel flat, of moderate width, striate; lateral and lateral marginal striae ascending and terminating in irregular, shallow foveae which are united; prosternal lobe well developed, not separated from the keel by a visible suture; prosternal alae deeply and narrowly emarginate on each side to accommodate the antennal funicle in repose. Antennal cavities well developed, entirely open beneath, situated in the anterior angles of the prothorax and extending posteriorly to the procoxae. Mesosternum emarginate anteriorly. Metasternum without a median suture; metepisterna concealed by the elytral epipleura.

Protibiae expanded, their outer margins oligodenticulate; tarsal grooves poorly defined, their inner edges margined. Outer margins of meso- and metatibiae with setae and spinules in a single row.

Remarks.-Geocolus is tentatively placed in the subfamily Dendrophilinae because of prosternal and protibial structure. It differs from all other members of this group in having the antennal cavities situated in the anterior prothoracic angles and extending posteriorly to the procoxae. Within the subfamily it would occupy a position somewhat analogous to that of Acritus and allied genera in the subfamily Abraeinae. In general appearance $G$. caecus resembles certain species of Isolomalus and Pachylomalus, but in these genera the epistomal region is very much reduced, the male genital structures are very different, and the antennal cavities are situated at the middle of the hypomera. The genus Triballodes Schmidt, erected for a single rare Grecian species, acritoides Reitter, is apparently closely related to Geocolus, but the two can be separated as follows:

1. Eyes normally developed; scutellum visible from above; prosternal keel rather broad . . ........................ Triballodes Schmidt Eyes absent; scutellum concealed; prosternal keel of moderate width.

Geocolus gen. nov.

Triballodes was placed in the tribe Tribalini by Bickhardt, but the genus cannot even be keyed out to the subfamily (Histerinae) 
using Bickhardt's key (1917), much less be regarded as an ally of the other genera within the tribe.

Perhaps the most satisfactory disposition of the two genera would be to regard them as constituting a tribe within the Dendrophilinae.

Geocolus caecus sp. nov. (pl. 3, figs. 1-6)

Type from Peach County, Georgia. A specimen of undetermined sex in the collection of the United Ștates National Museum. Collected April 27, 1939.

Paratype from Thomaston, Upton County, Georgia. A male in the collection of Field Museum. Collected through a soil funnel, July, 1936.

Description.-Form narrowly elongate-oval. Color pale reddishbrown. Surface micro-alutaceous throughout, with the exception of the sternal disks which are indistinctly or obsoletely so. Surface distinctly, sparsely, very finely punctate throughout; the elytra less strongly and more sparsely punctate than the pronotum, the punctures very sparse at apex. Frontal suture visible as an oblique dark line on each side (indicated by dotted line in pl. 3, fig. 3). Supraorbital stria represented on each side by a short curved stria above the insertion of the antennal scape and continued along the posterior margin of the vertex by a complete, feeble carinule. Eyes absent.

Pronotal length to width 5.5: 7.5; lateral margins rather strongly deflected in front, nearly straight on basal half, arcuate and more strongly convergent apically. Marginal stria complete. Anterior angles acute. Basal margin strongly, evenly arcuate with a small antescutellar impression.

Elytra together a little longer than broad (9:8.3). Marginal elytral stria fine, subcariniform, extending from base to apex; marginal epipleural stria absent; epipleural fossette not defined. Metathoracic wings reduced to small pads.

Pygidium two-fifths broader than long.

Prosternal lobe with an apical marginal stria which forks on each side as an inverted U-shaped stria. Prosternal keel of moderate width, carinal striae finely cariniform, subparallel, not united anteriorly though they may be rather feebly united along basal margin. Lateral and lateral marginal striae finely cariniform, ascending and terminating on each side in irregular, ill-defined 
anastomosed foveae. Mesosternum rather narrow and short, its anterior margin narrowly, not deeply emarginate, oblique on each side of the emargination. Marginal stria indistinct or absent along the emargination; laterally it is subcariniform and continuous with the lateral metasternal stria which extends obliquely a little more than a third the length of the metasternum and then recurves anteriorly to the mesepimeral-metasternal suture. An arcuate stria margins the posterior edges of the mesocoxal cavities. Meso-metasternal stria absent, the suture indicated by a dark line. Intercoxal disk of first abdominal sternum with a subcariniform, longitudinal stria on each side which extends posteriorly nearly to the apical margin, thence laterally to a point near the lateral margin, and thence anteriorly to the metepimeral-metasternal suture.

Tibiae as figured.

Length 1.54; width $0.87 \mathrm{~mm}$.

Remarks.-Geocolus caecus is the second blind histerid species known; the blind, subapterous condition appears to be correlated with an obligate, soil-dwelling existence and parallels the modifications found in many cavernicolous insects.

\section{Genus Bacanius Le Conte}

As pointed out by Wenzel and Dybas in 1941, the terminology of the lateral elytral striae in the genus Bacanius has been confused by various authors in the past. In studying further a considerable number of species, the writer has come to the conclusion that the stria called the "first dorsal" in such species as subcarinatus and punctiformis is in reality a subhumeral, but that it is entirely absent in other species, so that the marginal elytral stria is often thus named. Since an attempt to apply the proper terms would only confuse the worker who has an inadequate representation of species, the writer has decided to apply the term "first dorsal" to the innermost stria of the flank in all species; this application is to be understood in the following descriptions and key.

Bacanius subcarinatus Wenzel and Dybas

Bacanius subcarinatus Wenzel and Dybas, Field Mus. Nat. Hist., Zool Ser., 22, p. 436, 1941.

Costa Rica: La Palma, two specimens, collected under loose bark by F. Nevermann, January 18, 1929, at 1,400 meters (U.S.N.M.).

${ }^{1}$ Spelaeacritus anophthalmus Jeannel was described from Fersine Cave, Asia Minor. The condition of the inner wings was not noted. 
In one of these specimens the first dorsal stria is abbreviated basally on one side. The pygidia are finely, sparsely punctate; the elytral disks are a little more distinctly punctate than in the types. Color dark reddish-brown.

\section{Bacanius debilitans Casey}

Bacanius debilitans Casey, Ann. N. Y. Acad. Sci., 7, p. 560, 1893.

Cuba: Cayamas, three specimens, collected March 4, January 1, and June 6 by E. A. Schwarz (U.S.N.M.).

\section{Bacanius scalptus Lewis}

Bacanius scalptus Lewis, Biol. Centr.-Amer., Coleop., 2, pt. 1, p. 237, pl. 7, fig. 10, 1888.

Argentina: El Quemado, Jujuy, four specimens, collected May 3, 1926, by G. L. Harrington (U.S.N.M.). This species is now known from the West Indies and from Mexico to Argentina.

\section{Bacanius rugisternus sp. nov.}

Type from Colombia. A specimen of undetermined sex in the collection of Field Museum.

Paratypes.-Fifteen specimens from the west slope of Volcan Irazu, Costa Rica, at an altitude of 1,500-2,000 meters; collected from under loose bark March 22, 1928, by Ferdinand Nevermann. One specimen from Vara Blanca, Costa Rica, at an altitude of 1,700 meters; collected from under loose bark, July 7, 1928, by Ferdinand Nevermann. Paratypes are in the collections of the United States National Museum, Field Museum, and Rupert L. Wenzel.

Description.-Color reddish-brown, shining. Form oval, strongly convex. Head with a few very fine punctures. Pronotum strongly, very finely, sparsely punctate. Marginal stria complete, crenulate and rather close to the edge along the anterior margin.

Elytra sparsely punctulate, the punctures coarser along the suture, apparently less distinct apically. Marginal epipleural stria not distinct; marginal elytral stria finely cariniform, complete. First dorsal stria finely cariniform, abbreviated at basal third, continued around the apical angle to the suture. Pygidium finely, strongly, sparsely punctate.

Prosternum with a few very fine punctures; carinal striae usually convergent anteriorly, sometimes rather strongly so, nearly parallel in the type; prosternal lobe large, a little longer than the keel, 
with longitudinal, deeply impressed rugae. Meso-metasternal disk deeply punctulate, elevated sides with sparse, moderate punctures.

Protibiae expanded, outer margin with a fine tooth about onefourth from apex. Mesotibiae with a fine spinule about one-third from apex.

Length 1.22-1.33; width $0.92-0.95 \mathrm{~mm}$.

Remarks.-This species is apparently related to convergens and may be separated from it by the characters given in the key.

\section{Bacanius striatinotum sp. nov.}

Type from Cacao, Tres Aguas, Alta Vera Paz, Guatemala. A specimen of undetermined sex in the collection of the United States National Museum. Collected April 15 by H. S. Barber and E. A. Schwarz.

Paratype.-A specimen of undetermined sex, same locality and collectors as the type, in the collection of Field Museum; collected April 24.

Description.-Form roundly oval, rather strongly convex. Color dark reddish-brown, shining. Head strongly, rather closely punctate, the punctures moderately coarse.

Marginal pronotal stria well impressed, complete, closely crenulate along the anterior margin. Pronotum moderately, strongly, sparsely punctate (a trifle more finely so than the head), the punctures separated by about twice their diameters or a little more, becoming finer laterally. Antescutellar stria strongly, crenately punctate, feebly arcuate.

Elytra with a marginal epipleural stria which is broadly arcuate and present on apical two-thirds; marginal elytral stria broadly interrupted at middle, present on about basal third and on a little more than apical third, medial to the marginal epipleural stria; first dorsal stria complete, extending around apical angle, thence across apical margin to suture and recurving along suture to apical fifth or sixth. A very fine stria is present along suture from near base to basal third. Elytra finely, sparsely punctate in a common sutural area which is narrowest basally; baso-laterally the disks are coarsely, sparsely punctate, the area narrowing somewhat apically, the coarse punctures becoming a little finer apically. Pygidium sparsely, moderately coarsely. punctate, the punctures becoming finer apically.

Prosternal keel short, about as long as broad, and moderately, deeply punctate; lobe coarsely, closely, rugosely punctate. Meso- 
sternal disk short, with a double row of deep, elongate punctures (along the meso-metasternal suture) which together give the appearance of being a row of sulciform punctures such as are found in Aeletes. Metasternal disk with a few moderate punctures along anterior margin and with sparse, coarse punctures along the elevated sides, elsewhere microscopically, very sparsely punctulate.

Protibiae with a denticle near apex and a row of fine setae thence to base.

Length $0.92-0.95$; width $0.72-0.73 \mathrm{~mm}$.

Remarks.-This is the only neotropical species of Bacanius known to the writer which has an antescutellar pronotal stria.

Bacanius pusillus sp. nov.

Type from Penuela, Vera Cruz, Mexico. An example of undetermined sex in the collection of Field Museum. Collected July 17, 1941, by Henry S. Dybas.

Paratypes.-Two, same data as the type; two from Tezonapa, Vera Cruz, August 8, 1941 (H. Dybas); one from Tierra Blanca, Vera Cruz, July 28, 1941 (H. Dybas); four from Tamazunchale, San Luis Potosi, June 22, 1941, in rotten log (H. Dybas and C. H. Seevers).

Description.-Color reddish-brown, shining. Form oval, rather strongly convex. Front and epistoma with very fine, rather strong, sparse punctures. Pronotal punctation similar to that of the head but a little sparser. Marginal stria fine, complete, close to the margin and not crenulate behind the head.

Elytra impunctate, covering the propygidium. Marginal epipleural stria absent. Marginal elytral stria finely cariniform, extending from base to apex. First dorsal stria finely cariniform, complete, extending around apical angle to suture. Epipleura with a few irregular coarse impressions in the fossette between the marginal elytral and first dorsal striae. At the middle of each elytron a finely cariniform, transverse, feebly arcuate stria extends outwardly from the suture for about a third of the elytral width. Pygidium not as strongly inflexed as in most species, the punctures similar to those of the pronotum.

Prosternal keel very short, nearly twice as broad as long, impunctate; carinal striae straight, parallel, very finely cariniform. Prosternal lobe not strongly deflexed, short, as long as the keel, with an apical marginal stria which is united on each side with the lateral 
prosternal striae; apical half of lobe with a few fine, deep punctures, some of which are connected. Mesosternum margined along the oblique sides but not at middle; meso- and metasternal disks impunctate; elevated metasternal sides with a few shallow, moderate punctures.

Protibiae expanded, the outer edge bearing five or six extremely small setae, without teeth. Mesotibiae with a few fine setae along outer margin and a small spinule just beyond middle. Metatibiae with very fine marginal setae.

Length $0.67-0.70$; width $0.52-0.54 \mathrm{~mm}$.

Remarks.-This is one of the smallest species of Bacanius and may be separated from its allies by the characters given in the key.

\section{Bacanius sulcisternus sp. nov.}

Type from Hamburg Farm, Reventazon, Limon, Costa Rica. A specimen of undetermined sex in the collection of the United States National Museum. Collected on a sandbank, January 2, 1935, by Ferdinand Nevermann.

Paratypes.-Two specimens, same data as the type; one each in the collections of the United States National Museum and Field Museum.

Description.-Form oval, moderately convex. Color rather pale yellowish-brown, shining. Head very finely, very sparsely punctate. Pronotum sparsely, deeply, moderately punctate at middle, the punctures somewhat finer anteriorly and laterally. Marginal pronotal stria complete, very finely and closely crenulate along the anterior margin; basal margin with a row of fine, very closely placed punctures, which crenate the edge.

Elytra with a complete epipleural stria and a complete "first dorsal" stria, the latter continued around apex to suture. A wellimpressed sutural stria present on basal third. Surface finely, very sparsely punctate, the punctures becoming minute or disappearing laterally. Pygidium very finely, sparsely punctate.

Prosternal keel about as broad as long, distinctly convex anteriorly, the carinal striae parallel; prosternal lobe with deep, longitudinal rugae. Mesosternum with a row of sulci which extend anteriorly from the transversely impressed meso-metasternal suture for about half the length of the disk, the latter otherwise very sparsely, finely punctate. Metasternum sparsely punctulate, the punctures a little larger on the elevated sides. 


\section{Length $0.65-0.70$; width $0.50-0.52 \mathrm{~mm}$.}

Remarks. - This very small species may be distinguished from other neotropical allies by its mesosternal sulci, which resemble those found in the genus Aeletes.

\section{Bacanius crenulatus sp. nov.}

Type from Hamburg Farm, Reventazon, Limon, Costa Rica. An example of undetermined sex in the collection of Field Museum of Natural History. Collected May 1, 1929, by Ferdinand Nevermann from a nest of Gymnostinops montezuma Lesson.

Description.-Color reddish-brown, strongly shining. Form oval, rather strongly convex. Head and elytra remotely punctulate. Pronotum very finely, sparsely, strongly punctate. Marginal stria complete; rather distant from the edge and strongly, closely crenulate along the anterior margin.

Marginal epipleural stria absent. Marginal elytral stria complete, finely cariniform. First dorsal stria finely cariniform, abbreviated at about basal third, extending around apical angle to suture. Pygidium with a few very fine punctures.

Prosternum with a few very fine punctures; keel about as long as broad, carinal striae straight and rather strongly convergent apically. Prosternal lobe large, a little longer than keel, at middle (on basal half) with about three deep longitudinal rugae which encroach a little on the keel; marginal stria strongly impressed, united on each side with the lateral prosternal striae. Mesosternum with a marginal stria along the oblique sides only. Meso- and metasternal disks impunctate; elevated sides of metasternum with a few moderate punctures.

Protibiae expanded; outer margin rounded on basal half, thence straight to tooth (about one-fourth from apex), thence oblique to apex. Mesotibiae with a single fine spinule a little beyond the middle.

Length 0.88 ; width $0.63 \mathrm{~mm}$.

Remarks. - This species is allied to rugisternus but is a smaller species with more finely punctate elytra and impunctate meso- and metasternal disks.

Seventeen species of Bacanius are now known from the new world. Of these, two, ferrugineus and convergens, are unknown to the writer and the characters given for them in the following key are taken from the original descriptions. 
In debilitans, the first dorsal stria (sublateral stria of Casey) is extremely fine basally and may be confused with punctures, thus appearing to be abbreviated as it was thought to be by Casey. In order to avoid confusion the species has been included under.both alternatives of No. 8.

\section{Key to The New World Species of BaCaniUs}

1. Pronotum with an antescutellar stria............ striatinotum sp. nov. Pronotum without an antescutellar stria................ 2

2. Elytral punctures coarse, connected by short, deep grooves; first dorsal elytral stria arching across base and recurving posteriorly a short distance from the suture.

Elytral punctures sometimes coarse but never connected by deep grooves; ${ }^{1}$ first dorsal stria frequently abbreviated basally, never arching across the

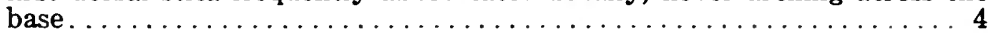

3. Pronotal punctures dense, connected by deep longitudinal grooves throughout. . . ....................... scalptus Lewis $(1888$, p. 237)

Pronotal punctures sparse, connected by fine longitudinal grooves in a narrow area along anterior margin, elsewhere isolated and distinct.

punctiformis J. L. Le Conte $(1853$, p. 288)

4. Elytra with a transverse stria near middle, this stria extending outwardly from the suture ....................... 5

Elytra without such a stria . . . . . . . . . . . . . . . 6

5. Form broadly oval; upper surface moderately coarsely, sparsely punctate; transverse elytral stria a part of a hamiform stria whose longitudinal portion extends anteriorly along the suture. .hamatus Lewis (1888, p. 238)

Form more narrowly oval; pronotum very finely punctate; elytra impunctate; transverse elytral stria simple, not part of a hamiform stria.

pusillus sp. nov.

6. Elytra with a well-impressed sutural stria on basal third; mesosternum with a row of sulci which extend anteriorly from the meso-metasternal suture. sulcisternus sp. nov.

Elytra without a sutural stria; mesosternum without sulci . . . . . . 7

7. Upper surface impunctate.............humicola Marseul (1856, p. 570)

At least with pronotum punctate, this often very finely but always rather

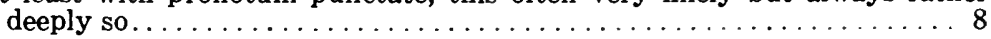

8. First dorsal stria abbreviated, usually on basal third . . . . . . . . 9

First dorsal stria complete. . . . . . . . . . . . . . . . 14

9. Meso-metasternal disk coarsely or moderately coarsely punctate. . . . . . 10

Meso-metasternal disk finely punctate, if at all . . . . . . . . . . 12

10. Metasternal disk coarsely punctate, excepting at middle where it is longitudinally impressed and more densely, very finely punctate.

tantillus J. L. Le Conte (1853, p. 291)

Metasternum without an impressed median area which is more finely and densely punctate than the rest of the disk .................

${ }^{1} B$. tantillus has some elytral punctures, particularly those at apex, connected by very fine, short aciculations. 
11. Pronotum more coarsely punctate laterally than at middle; elytra basally with a rather narrow, common, smooth space along the suture; epipleural fossette with a row of coarse punctures; pygidium coarsely, densely punctate; prosternal striae slightly divergent apically; metasternum closely, coarsely punctate.................. globulinus Casey $(1893$, p. 560)

Pronotum a little more coarsely punctate medially than laterally; elytra without a smooth, basal, sutural area; epipleural fossette smooth; pygidium finely, rather closely punctate; prosternal striae slightly convergent apically; metasternum moderately, sparsely punctate anteriorly, the punctures becoming coarser posteriorly.............. debilitans Casey

12. Marginal pronotal stria closely crenulate along the anterior margin . . . . 13 Marginal pronotal stria not crenulate along the anterior margin.

convergens Schmidt $(1896$, p. 65)

13. Metasternal disk impunctate; elytra remotely punctulate; size smaller, length $0.88 \mathrm{~mm} . \ldots \ldots \ldots \ldots \ldots \ldots \ldots \ldots \ldots \ldots \ldots \ldots \ldots$ crenulatus sp. nov. Metasternal disk sparsely, rather deeply punctulate; elytra sparsely punctulate, the punctures coarser along the suture; size larger, length 1.22-1.33 mm........................ rugisternus sp. nov.

14. Marginal elytral and first dorsal striae nearly parallel throughout their length; elytra minutely, obliquely rugose, except apically and exterolaterally..........................minatus Casey $(1893$, p. 561)

Marginal elytral and first dorsal striae divergent basally, the basal interval twice as wide as the apical .......................

15. Elytra moderately or rather coarsely punctate . . . . . . . . . . 16

Elytra punctulate.............................

16. Metasternal disk punctate throughout, the punctures moderate and sparse anteriorly, becoming coarse posteriorly............debilitans Casey

Metasternal disk with a few moderately coarse punctures medial to the mesocoxae and near apex. . . . . . . . . misellus J. L. Le Conte (1853, p. 292)

17. Elytral punctures rather uniform; meso-metasternal disk smooth.

ferrugineus Bickhardt (1918, p. 286)

Elytral punctures coarser on basal half along the suture; metasternum coarsely, shallowly, sparsely punctate...subcarinatus Wenzel and Dybas

\section{Genus Carcinops Marseul}

Carcinops cribripuga sp. nov.

Type from Key West, Florida. A male in the collection of the California Academy of Sciences.

Paratypes.-Three specimens from Florida; one each in the collections of Edward S. Ross, Field Museum, and the United States National Museum. One specimen from Jacksonville, Florida, in the collection of the United States National Museum.

Description.-Form somewhat elongate, oblong-oval, moderately convex. Color deep brownish-black, shining. Head finely, deeply, sparsely punctate, with finer punctulation intermingled. Marginal stria not extending beyond the eyes, completely absent in front. 
Pronotum three-fourths as long as broad, sides nearly straight and feebly convergent on basal two-thirds, thence strongly arcuate and convergent to apical angles. Marginal stria complete, strongly impressed. Disk strongly, somewhat densely punctulate, coarser punctures intermingled on about each lateral third but inconspicuous along the margin. Basal margin rather strongly arcuate, with a row of strong, closely placed, elongate punctures. Antescutellar puncture round, well impressed, not very coarse.

Elytra together slightly broader than long, at humeri distinctly broader than pronotum; sides behind the humeri nearly straight and moderately converging to near apex, thence slightly arcuate. Surface rather densely punctulate throughout, extreme apices longitudinally strigoso-punctate. Marginal epipleural stria finely subcariniform, complete, very close to the margin apically; epipleural fossette rather coarsely, confluently punctate, apically with a rather irregular, subcariniform stria between the marginal epipleural and marginal elytral striae. Marginal elytral stria complete, deeply impressed, its outer edge coarsely subcariniform. Outer subhumeral stria complete or abbreviated at basal fourth; inner subhumeral stria complete, deeply impressed at base, fine apically. Dorsal striae one to five and sutural complete, the fifth and sutural united in a narrow arch; all the dorsal striae rather strongly crenate, one to five much more coarsely impressed basally than apically.

Propygidium coarsely, very densely punctate; pygidium similarly but a trifle more finely punctate.

Under surface, with the exception of the elevated sternal sides, micro-alutaceous, subopaque. Prosternal keel impunctate, dull; carinal striae rather coarsely cariniform, united basally, imperfectly united apically, sinuous at middle; prosternal lobe rather coarsely, closely punctate, without a marginal stria. Mesosternum coarsely punctate, its anterior margin feebly emarginate; marginal mesosternal stria entire, rather coarsely subcariniform, continuous with the lateral metasternal stria. Meso-metasternal stria absent, the suture represented by a smooth line. Metasternal disk rather densely punctulate, coarser punctures intermingled medial to the lateral striae. Lateral metasternal striae very coarsely impressed, the inner bending outwardly and extending about two-thirds the length of the metasternum, not reaching the posterior coxal cavity; outer lateral striae almost straight, oblique, extending nearly to middle.

First abdominal sternum coarsely bistriate on each side medial to the hind coxae, both striae reaching nearly to apex; disk at middle 
with punctulation and moderate punctures intermingled, the larger punctures becoming noticeably coarse laterally near the striae.

Outer margin of protibiae bidentate, the teeth widely separated, the interval emarginate but not strongly so. Outer margin of mesotibiae with two distantly placed spinules, one a little beyond basal third, the other near apical fourth. Outer edge of metatibiae with a single spinule at about apical fourth. Outer faces of meso- and metatibiae longitudinally striolate.

Measurements.-Length 2.5-2.8; width 1.6-1.75 mm.

Remarks. - Since the middle and posterior tibiae of the type and paratypes are absent or in poor condition, it is possible that they normally have more spinules than have been indicated in the description. The species is related to quattuordecimstriata Stephens, troglodytes Paykull, and assimilis sp. nov.; it may be separated from them by the long external subhumeral stria, the strongly impressed union of the fifth and sutural striae, the character of the elytral punctation, and the cribrately punctate pygidia.

\section{Carcinops assimilis sp. nov.}

Type from Satipo tropical rain forest, Department of Junin, Peru. A male in the collection of Field Museum of Natural History. Collected in November, 1935, by Felix Woytkowski, from a débris pile of Atta sp.

Allotype.-A female, same data as the type, in the collection of Field Museum.

Paratypes.-Twenty specimens, same data as the type; two each in the collections of Edward S. Ross, the United States National Museum, and Field Museum, the remainder in the collection of Rupert L. Wenzel.

Description.-Oblong-oval, subconvex. Color brownish-black, shining. Head with a complete stria. Front microscopically, sparsely punctate.

Pronotum nearly twice as broad as long. Sides feebly, subarcuately converging anteriorly. Marginal stria complete. Disk finely punctulate, with coarser punctures intermingled, the latter sparser in a rather narrow area along sides and at middle. Antescutellar impression deep, well defined.

Elytra nearly twice as long as, and at humeri distinctly broader than, pronotum; sides feebly, subarcuately converging to apex. Surface sparsely punctulate throughout. Epipleura near base with an 
indication of two striae, the inner of which is represented apically by a row of fine punctures. Marginal stria subcariniform, extending around apex, thence obsolete. External subhumeral fine, abbreviated basally and apically; internal subhumeral complete. Five entire dorsal striae, these deeply impressed basally, becoming finer apically; striae punctate, the punctures rather coarse basally, becoming finer apically in conformity with the width of the striae; inner edges of striae evanescent so that the striae appear feebly subcariniform; fifth dorsal arching at base and recurving slightly; sutural nearly complete. Elytra, basally between suture and sutural stria, elevated so that the latter stria is apparently, not actually, complete and joined to the fifth.

Propygidium sparsely, finely punctate, punctures often poorly impressed, with sparse punctulation intermingled, general appearance rather smooth; pygidium sparsely punctulate.

Prosternum narrowed near middle, the striae fine, subcariniform, the interval between the striae flat or concave.

Anterior margin of mesosternum distinctly emarginate, the marginal stria complete, subcariniform and united with the lateral metasternal stria. Disk of mesosternum usually nearly smooth as in $C$. troglodytes, sometimes moderately sparsely punctate, with very fine punctures intermingled. Metasternum remotely punctulate.

Protibiae strongly arcuate, with several small, indistinct, closely placed teeth on basal half of outer margin; apical half with two conspicuous, rather widely separated teeth, the interval between the teeth emarginate. Middle and posterior tibiae each with two rather widely separated spines and a row of fine, hair-like spinules.

Length 2.2-5.45; width $1.35-1.65 \mathrm{~mm}$.

Remarks. - C. assimilis is closely allied to troglodytes and 14striata. From $C$. troglodytes it may be distinguished by its less strongly crenate dorsal elytral striae, the flattened or concave prosternal keel, the sparsely, more finely punctate propygidium, the simple punctation of the pygidium (punctulate only, no larger punctures intermingled), and the less distinctly punctate elytral apices.

Carcinops densepunctata sp. nov.

Type.-Collected in New York in fiber of seed cotton from Ecuador, January 10, 1935. A male in the collection of the United States National Museum. 
Paratype.-A male, same data as the type, in the collection of Field Museum.

Description.-Form oblong-oval, rather strongly convex. Color black, shining. Head very densely, finely punctate, the punctures deep and often confluent; marginal stria of head subcariniform, complete (in type) or interrupted at middle (paratype).

Pronotum twice as broad as long; sides nearly straight and moderately convergent on basal two-thirds, arcuate and strongly convergent on apical third. Marginal pronotal stria subcariniform, very fine and complete (in type) or narrowly interrupted at middle (paratype). Surface finely, irregularly alutaceous, and coarsely, rather shallowly, densely and subconfluently punctate, the punctures largest on each side in an area which extends from about lateral two-fifths to lateral fifth; along the margin the punctures are a little smaller and deeper; at middle near base in a roughly triangular area the punctures are sparser and shallower; minute punctures are scattered throughout.

Elytra together a little broader than long, at humeri distinctly broader than the pronotum; sides nearly straight and moderately convergent from humeri to near apex. Elytra moderately coarsely, deeply, densely punctate throughout, excepting the scutellar region which is punctulate; minute punctures intermingled; the punctures along the apices and near the suture about one-half the size of the discal punctures. Marginal elytral, external subhumeral, internal subhumeral, and dorsal striae one to five complete; sutural stria abbreviated at basal sixth; striae punctate, their inner margins indistinct and their outer margins feebly costiform; apices of the striae broken up into punctures; fifth dorsal stria arching over toward the suture; sutural stria sinuate near base.

Propygidium moderately coarsely, very densely punctate, with minute punctures intermingled. Pygidium similarly but more finely punctate, the punctures very fine at apex; pygidium strongly convex, the apical portion being at right angles to the basal portion.

Prosternal lobe immarginate, very finely, sparsely punctate. Prosternal keel punctulate, rather narrow, moderately convex between the striae, the striae sinuous and most widely separated apically, extending to the prosternal lobe. Mesosternum moderately coarsely punctate, the punctures separated by about their diameters, minute punctures intermingled; marginal stria coarse, complete; anterior mesosternal margin straight. Meso-metasternal suture distinct, not marked by a stria. Metasternum punctulate at middle, 
the punctures becoming gradually larger laterally, coarse near the inner lateral metasternal stria; the latter is united anteriorly with the marginal mesosternal stria and extends posteriorly to the anterior margin of the hind coxal cavity; medial and parallel to lateral metasternal stria on each side is a moderately strong longitudinal impression which extends from basal third of metasternum to near apex. Elevated metasternal sides with two additional lateral metasternal striae, the outer one very short. Intercoxal disk of first abdominal sternum finely, sparsely punctate, bistriate on each side, the inner stria complete.

Outer margin of protibiae bidentate on apical half. Mesotibiae with six to eight spinules on basal two-thirds of outer margin, the spinules becoming progressively longer apically; well separated from this group of spinules are two or three large spinules near apex. Metatibiae with two or three spinules near middle of outer margin and two near apex.

Length 2.27-2.6; width $1.6-1.8 \mathrm{~mm}$.

Remarks. - C. densepunctata is easily distinguished from all other neotropical species of the genus by the dense, strong punctation of the upper surface, the feebly costate outer edges of the elytral striae, and the long, numerous, stout spinules of the mesotibiae. The longitudinal metasternal impression present on each side medial to the inner lateral metasternal stria relates densepunctata to schwarzi sp. nov.

\section{Carcinops schwarzi sp. nov.}

Type from Paraiso, Panama Canal Zone. A male in the collection of the United States National Museum. Collected from male flowers of Attalea palm, March 20, 1911, by E. A. Schwarz.

Paratypes.-Thirty-two specimens from the type locality, collected from flowers of Attalea palm, March 20-April 2, 1911, by E. A. Schwarz; ten specimens, type locality, collected from flowers of Iralia palm, March 21, 1911, by A. H. Jennings. Paratypes in the collections of the United States National Museum, Field Museum, and Rupert L. Wenzel.

Description.-Form oval, moderately convex. Color black, often with a tinge of brown, shining. Head deeply punctulate, with a few coarser punctures intermingled on front. Supraorbital stria complete, united with the frontal stria, which is subcariniform and extends on each side to the anterior margin, but is interrupted for the width of the epistoma. 
Pronotum slightly less than twice as broad as long, sides nearly straight and convergent on basal two-thirds, more strongly arcuate and convergent on apical third. Marginal pronotal stria complete, well impressed. Surface sparsely, deeply punctulate throughout, with sparse, coarser punctures intermingled, the latter becoming coarser and denser near the sides.

Elytra together about one-fifth broader than long, sides slightly converging apically, arcuate at humeri and near apex, nearly straight at middle. Marginal epipleural and marginal elytral striae subcariniform, finely punctate, complete, the marginal elytral extending around the outer apical angle and about one-third across the elytral apex. External subhumeral stria fine, subcariniform, finely punctate, present on middle third or a little more; internal subhumeral and first and second dorsal striae deeply impressed, crenate, extending from base to apex; third, fourth, and fifth dorsal striae deeply impressed and crenate on basal half, but consisting of a row of moderately coarse punctures on apical half, the punctures fairly distinct from those of the elytral interstices; sutural stria crenate, consisting of punctures apically, crenate at middle, not joined to the fifth dorsal, abbreviated or consisting of one or two punctures on basal fourth. Dorsal interstrial spaces sparsely, not finely, deeply punctate on apical half; on basal half from the third dorsal stria to the suture the elytra are sparsely microscopically punctate; lateral to the third dorsal the punctures (though still sparse and fine) become distinctly coarser and deeper.

Propygidium rather coarsely, moderately, sparsely punctate, with very fine, deep punctures intermingled. Pygidium deeply punctulate throughout, with coarser, deep punctures intermingled on basal half; the coarser punctures about one-half the size of the coarse propygidial punctures.

Prosternal keel one-seventh to one-eighth the width of the prothorax, deeply punctulate; carinal striae subcariniform, deeply impressed, transversely united at base, feebly sinuate at middle, feebly convergent but not united anteriorly, extending on each side to the prosternal lobe, which is deeply punctulate and immarginate. Mesosternum sparsely, deeply punctulate, with a few moderately coarse punctures intermingled; anterior margin very feebly, broadly emarginate, marginal stria deep, complete, and continuous on each side with the lateral metasternal stria. Meso-metasternal stria present, complete, subcariniform, feebly arcuate, strongly crenate. Metasternum sparsely punctulate; medial to the lateral metasternal 
stria on each side is a well-developed stria which extends nearly the entire length of the metasternum; lateral to the lateral metasternal stria on the elevated sides of the metasternum, is an oblique stria which is basally united with the lateral metasternal stria and extends to the metasternal margin. Intercoxal disk of first abdominal sternum punctulate, coarser punctures present laterally.

Protibiae bidentate on apical half, the teeth rather small and widely separated. Mesotibiae with two widely separated spinules, one behind the middle, the other near apex. Metatibiae with a small spinule on outer margin near apex.

\section{Length 1.75-2.01; width 1.23-1.5 mm.}

Remarks.-C. schwarzi is apparently allied to punctinotum Lewis but differs from that species in terms of smaller size, a well-developed, though not complete, frontal stria, and different elytral punctation. Lewis's description of punctinotum is not adequate to characterize the species.

\section{Carcinops exigua sp. nov.}

Type from Hamburg Farm, Reventazon, Limon, Costa Rica. A male in the collection of Field Museum of Natural History. Collected on drying wood of Castillica costaricensis, in 1932, by Ferdinand Nevermann.

Paratypes.-Two males and one female from Pueblo Nuevo, Republic of Panama. Collected from rotten papaya stump, September 25, 1918, by James Zetek; a pair of these in the collection of the United States National Museum, a male in the collection of Rupert L. Wenzel.

Description.-Form oval, moderately convex. Color varying from pale reddish-brown to black with a tinge of brown, surface shining. Head with supraorbital stria fine, complete, continuous on each side with the frontal stria which is broadly interrupted and does not extend to the clypeal region but only to the angle near the eye; front shallowly impressed; head rather sparsely punctulate, the punctures somewhat coarse in the region of the supraorbital stria.

Pronotum twice as broad as long; sides feebly arcuate from base to near apex, thence more strongly arcuate. Marginal pronotal stria fine, complete. Surface minutely, not densely, punctulate throughout, a rather broad area on each side with additional moderately coarse punctures which become fine near the lateral margin. Basal margin with a row of moderate punctures. 
Elytra microscopically punctulate, together a little broader than long, sides evenly arcuate from base to apex. Marginal epipleural and marginal elytral striae complete. External subhumeral stria absent, the internal very slightly abbreviated apically. Dorsal striae one to five complete, strongly impressed, feebly punctate, fifth not arching over to the suture; sutural stria absent on a little more than basal third.

Propygidium moderately, sparsely punctate, with punctulation intermingled, the larger punctures about the same size as the coarser pronotal punctures. Pygidial punctation similar to that of propygidium but with the larger punctures a trifle finer.

Prosternum remotely punctulate; keel less than twice as long as broad (6:4), flat between the striae; carinal striae feebly sinuate at middle, transversely united at base, extending anteriorly to the prosternal lobe, the latter finely, sparsely punctate, with a marginal stria along the truncate apical margin, this stria absent laterally.

Mesosternum microscopically punctulate; anterior margin nearly straight, feebly, outwardly sinuate at middle; marginal stria complete, fine and subcariniform, continuous on each side with the inner lateral metasternal stria which extends posteriorly to the anterior margin of the metacoxal cavity. Metasternal disk microscopically punctate, and feebly, longitudinally impressed on each side within the inner lateral metasternal stria. Intercoxal disk of first abdominal sternum longitudinally bistriate on each side, its posterior margin rather deeply, broadly, arcuately emarginate in the male, straight in the female.

Protibiae with two teeth, the posterior one at middle of outer margin, the other one-fourth from apex. Mesotibiae with one or two fine spinules near apex, and one or two near middle; near base are a few fine setae. Outer margin of metatibiae sparsely fimbriate, with a single spinule near apex.

Length 1.36-1.7; width $0.97-1.23 \mathrm{~mm}$.

Remarks.-The character of the anterior mesosternal margin is sufficient to separate exigua from its allies. The emarginate apical margin of the first abdominal sternum in the male is not known to exist in any other described species.

\section{Carcinops plaumanni sp. nov.}

Type from Nova Teutonia, Santa Catharina, Brazil. A male in the collection of Field Museum of Natural History. Collected in November, 1940, by Fritz Plaumann. 
Paratypes.-Five specimens, same data as the type, in the collection of Rupert L. Wenzel. Three specimens, same locality as the type, collected in May, 1941, by Fritz Plaumann, in the collection of Field Museum.

Description.-Form elongate-oblong, parallel-sided, strongly depressed. Color black, shining. Marginal (frontal) and supraorbital striae of head complete, well impressed. Head strongly, sparsely punctulate, with sparse, coarser punctures intermingled on the vertex.

Pronotal sides straight and parallel on about basal two-thirds, thence arcuate and convergent to apical angles. Marginal stria complete and well impressed along the sides and around the anterior angles, continued along basal margin for a short distance on each side, absent behind the head. Disk microscopically punctulate, with coarser strong punctures intermingled in a broad lateral area.

Epipleura bistriate, the striae punctate, the interval between them with a row of strong, rather coarse punctures on apical twothirds; the inner (marginal elytral) stria with an obtusely subcariniform outer margin. Subhumeral striae punctate, the outer present on middle third, the inner abbreviated at apical fourth and coarsely impressed at base. Dorsal striae one to five complete, first and second normally impressed and punctate, third and fourth impressed but with closely placed oblong punctures which are more apparent than strial grooves; one to four widened and deepened at base; fifth similar apically to the fourth, but basally without the widening and deepening and with the punctures more distant, the strial groove being completely absent at base. Sutural stria variable, nearly complete or abbreviated on basal fourth or third, consisting of a row of punctures which become finer and more distant on basal half of elytron.

Pygidia sparsely punctulate with coarse punctures intermingled, the latter rapidly disappearing on apical half of pygidium.

Prosternal lobe large, scarcely deflexed, its apex broadly truncate, with a very fine, punctate stria close to the margin; disk of lobe deeply, sparsely, finely punctate at middle, the punctures becoming larger laterally. Prosternal keel of moderate width, punctulate, the striae deeply impressed, a little more distant apically, sometimes imperfectly united across basal margin. Anterior mesosternal margin rather broadly, arcuately emarginate at middle; marginal stria well impressed, complete, continuous on each side with the inner lateral metasternal stria, which is strongly oblique and extends posteriorly to a point anterior to the outer edge of the hind coxa; 
outer lateral metasternal stria short. Meso-metasternal suture not marked by a stria. Meso-metasternal disk remotely, microscopically punctulate, a few coarse punctures present on each side in front of the hind coxa. Intercoxal disk of first abdominal sternum bistriate on each side.

Tibiae not presenting any distinctive characters.

Length 2.04-2.47; width $0.95-1.33 \mathrm{~mm}$.

Remarks. - This species resembles misella Marseul and miserula Marseul in the possession of a broadly interrupted marginal pronotal stria but is readily distinguished from either of these by its larger size, the superficial fifth dorsal and sutural striae and the presence of a fine, punctate marginal stria along the apex of the prosternal lobe.

\section{Carcinops tuberata sp. nov.}

Type from Nova Teutonia, Santa Catharina, Brazil. A male in the collection of Rupert L. Wenzel, collected in October, 1940, by Fritz Plaumann.

Description.-Form elongate, oblong-oval, feebly convex, subdepressed. Color black, shining. Head strongly, rather sparsely punctulate, with coarser punctures intermingled posteriorly on the vertex, the latter with distinct tubercle at middle in front of the supraorbital stria. Marginal or frontal stria absent along the anterior margin of the epistoma, present laterally and continuous with the complete supraorbital.

Pronotal sides feebly arcuate and convergent from base to near anterior angles, thence more strongly arcuate. Marginal stria complete and strong laterally, broadly interrupted along the anterior margin (for less than the width of the head). Disk sparsely punctulate throughout, with coarser punctures intermingled (except at middle), these less noticeable along the lateral margins.

Elytra strongly, sparsely punctulate, the flanks a little more densely so, coarser punctures intermingled across apices. Epipleura with a very fine, basally abbreviated stria along the margin; medial to this is a second, complete, more strongly impressed stria; marginal elytral stria complete, running along the dorsal edge of the epipleura. Outer subhumeral stria represented by a short dash at middle; inner subhumeral abbreviated one-sixth from apex, coarsely impressed at base. Dorsal striae one to four complete, crenately punctate; first to third coarsely impressed basally, the fourth more shallowly so; fifth a little longer than the sutural, which extends slightly beyond the middle. 
Propygidium sparsely punctulate, with coarser, sparse punctures intermingled; pygidium more densely punctulate apically, a few coarser punctures intermingled basally.

Prosternal lobe distinctly deflexed and rather evenly, broadly rounded, with a very strongly impressed, arcuate, apical marginal stria, the interval between the stria and the margin appearing somewhat thickened; disk of lobe with a micro-strigose ground sculpture and deeply, rather sparsely, moderately punctate. Prosternal keel of moderate width, carinal striae subparallel, sinuate at middle, feebly united across base. Anterior mesosternal margin broadly, shallowly emarginate at middle; marginal stria fine, subcariniform, complete, united posteriorly on each side with the inner lateral metasternal stria which is strongly punctate, strongly oblique, and extends posteriorly to a point near the outer edge of the metacoxa; outer lateral metasternal stria punctate, parallel to the inner, extending from postcoxal stria of mesocoxae to the metasternal-metepisternal suture. Intercoxal disk of first abdominal sternum bistriate on each side, the inner stria complete and sinuate, the outer extending from hind margin of metacoxal cavity to posterior margin of sternum; surface sparsely punctulate, a few moderately coarse punctures intermingled on basal half.

Length 2.04; width $1.13 \mathrm{~mm}$.

Remarks.-The tuberculate head, the extensively punctate pronotum, and the strongly margined prosternal lobe distinguish tuberata from plaumanni, misella, and miserula. In plaumanni the interval between the stria and the margin of the prosternal lobe is very narrow.

\section{Subfamily Tribalinae}

\section{Genus Epierus Erichson}

The neotropical species of Epierus which possess an antescutellar pronotal impression form a very distinctive group and there is reason to believe that they should be regarded as constituting a separate genus; the male genital structures differ markedly from those of other New World species of Epierus. However, until more extensive studies can be made, they should be included in the old genus. Below are given records of two described species, descriptions of two new ones, and a key to the known species of the group.

Epierus arciger Marseul

Epierus arciger Marseul, Ann. Soc. Ent. Fr., (3), 1, p. 684, pl. 10, fig. 5, 1854.

British Guiana: Kamakusa, one specimen (A.M.N.H.). 


\section{Epierus coproides Marseul}

Epierus coproides Marseul, Ann. Soc. Ent. Fr., (3), 1, p. 682, pl. 10, fig. 5, 1854.

Colombia: Aracataca, Magdalena River, one specimen (M.C.Z.; collected by P. J. Darlington, Jr.).

\section{Epierus darlingtoni sp. nov.}

Type from Barro Colorado Island, Panama Canal Zone. A male in the collection of the Museum of Comparative Zoology. Collected May, 1929, by P. J. Darlington, Jr.

Allotype.-A female, same data as the type, in the collection of the Museum of Comparative Zoology.

Paratypes.-Six specimens (four males and two females), same data as the type; three in the collection of the Museum of Comparative Zoology and three (including a pair) in the collection of Field Museum.

Description.-Form oval, moderately convex. Color black with a tinge of brown, strongly shining. Labrum with four setigerous punctures. Head rather deeply, somewhat closely punctulate; vertex broadly concave, prominent above the antennal insertions, supraorbital stria complete; epistoma longitudinally impressed, more strongly so in the male, sides parallel; frontal suture not impressed; anterior margin of epistoma with a small setigerous tubercle at middle in the male, this absent in the female.

Pronotum microscopically punctulate throughout, with sparse fine punctures intermingled, the latter nearly absent at middle and most prominent laterally in a rather broad area (absent along the side margins). Marginal stria complete, strongly impressed. Antescutellar impression hastiform, its apex obsolete and distinguishable only in certain lights. Sides rather strongly arcuate and convergent from base to apex.

Elytra microscopically, sparsely punctulate. Epipleura with two punctate striae, the most dorsal of which (external subhumeral of authors) margins the upper edge of the epipleuron, the other well separated from the epipleural margin (marginal epipleural?), the interval between the two with a row of disconnected, coarse punctures apically. Oblique humeral stria barely discernible. Dorsal striae finely impressed and strongly, crenately punctate; first dorsal present on basal half or a little less, sometimes represented apically by a few disconnected punctures; second dorsal either complete or obsolete on 
basal fourth or less; third dorsal usually abbreviated on basal fourth or fifth, sometimes nearly complete; fourth dorsal usually represented by a short dash or a few punctures at apex, sometimes absent; sutural abbreviated at about basal fifth.

Pygidia minutely punctulate; propygidium with rather sparse, coarse punctures intermingled; pygidium deeply, sparsely punctate, the punctures moderate basally and becoming gradually finer apically; in the female the pygidium is more strongly punctate throughout than in the male.

Prosternum punctulate; keel moderately broad, the carinal striae divergent anteriorly and posteriorly; lobe with a strong, complete marginal stria. Anterior mesosternal margin very feebly bisinuate, nearly straight; marginal mesosternal stria narrowly interrupted at middle, subcariniform, briefly separated posteriorly on each side from the outer lateral metasternal stria which extends arcuately outward but terminates a considerable distance from the metasternalmesepimeral suture. Meso-metasternal stria strong, subcariniform, angulate and closely approaching the anterior mesosternal margin at middle, continuous posteriorly on each side with the inner lateral metasternal stria, which recurves anteriorly and extends to the metasternal-mesepimeral suture. Postcoxal stria (behind mesocoxae) poorly developed or absent. Metasternum with a band of coarse punctures across apex; elevated sides with a few coarse punctures. First abdominal sternum with a stria on each side medial to the hind coxa; the stria curves outwardly and posteriorly and then recurves anteriorly nearly to the suture between the first sternum and the metepimeron.

Protibiae with seventeen or eighteen minute spinules along outer margin. Meso- and metatibiae with two or three fine subapical spinules on outer edge.

Length 2.7-3.47; width 2-2.33 mm.

Remarks. - This species is allied to hastatus Marseul and may be separated from it by the characters given in the key.

Epierus striatipygus sp. nov. (fig. 11,a)

Type from Aripo Valley, Trinidad, British West Indies. A male in the collection of the Museum of Comparative Zoology. Collected deep in a cave, April 19, 1935, by Neal A. Weber. Altitude 2,600 feet.

Allotype.-A female, same data as the type, in the collection of the Museum of Comparative Zoology. 
Paratypes.-Sixteen specimens (eight males and eight females), same data as the type; eight each in the collections of the Museum of Comparative Zoology and of Field Museum Eight specimens from Balandra Bay, Trinidad, collected in April and May, 1922, by L. R. Reynolds, in the collection of Field Museum.

Description.-Form oval, rather strongly convex. Color deep reddish-brown to black, strongly shining. Labrum with four setigerous punctures. Epistoma microscopically punctulate, its anterior margin with a minute, setigerous tubercle at middle in the male (absent in the female); vertex more strongly, sparsely punctulate than the epistoma. Frontal suture (between vertex and front on a level with the antennae) evenly, inwardly arcuate, impressed.

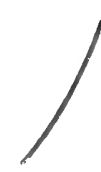

0

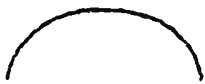

b

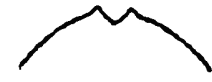

C

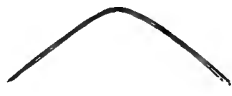

d

FIG. 11. Antescutellar pronotal impressions: a, Epierus striatipygus sp. nov.; b, E. arciger Marseul; c, E. coproides Marseul; d, E. brasiliense Tarsia in Curia.

Pronotum microscopically punctulate at middle, the punctures coarser, though still fine, in a broad lateral area; the coarser punctures are absent along the side margins. Marginal stria complete, well impressed. Antescutellar stria hastiform, well impressed, its extreme apex obsolete. Sides nearly straight and feebly convergent on basal half, arcuate and convergent on apical half.

Elytra microscopically punctulate throughout. Epipleura bistriate, the striae subcariniform and finely, sparsely punctate, the interval between the striae with a row of disconnected, fine, deep punctures; the inner or most dorsal of these striae is that referred to by Marseul as the external subhumeral. Internal subhumeral stria very fine, variable, usually present on basal fourth and again on a little more than apical half, sometimes complete. Dorsal striae finely impressed and finely, sparsely punctate; dorsals one to three complete; fourth obsolete on basal fourth or third; fifth extending to middle; sutural stria generally abbreviated at basal third, sometimes barely extending beyond the middle.

Propygidium finely, strongly, sparsely punctate, the punctures about twice the size of the largest pronotal punctures. Pygidium finely, sparsely punctate, the punctures about the same size as the 
coarsest on the pronotum, a few subapical punctures as coarse as those of the propygidium; not far removed from and parallel to the apical margin is an arcuate, punctate stria.

Prosternum punctulate; keel rather narrow, the carinal striae divergent anteriorly and posteriorly; lobe with a complete, strong, marginal stria. Anterior mesosternal margin nearly straight, marginal stria strong, not interrupted at middle. Meso-metasternal stria strong, subcariniform, feebly crenate, arcuate, not encroaching much upon the mesosternal disk, continuous on each side with the inner lateral metasternal stria which extends obliquely posteriorly to a point not far removed from the outer edge of the hind coxa. Metasternum with a postcoxal stria, which margins the posterior edge of the coxal cavity, and two lateral metasternal striae, the second or outer of which arises near the middle edge of the middle coxa and extends arcuately and transversely to a point not far removed from the mesepimeral-metasternal suture; the first or inner lateral stria is continuous with the meso-metasternal stria. In addition to these striae another extends posteriorly from the angle formed by the mesepimeron and the metepisternum nearly to the inner lateral metasternal stria. Sternal disks microscopically punctulate, elevated metasternal sides with a few moderate punctures (chiefly along the striae). First abdominal sternum with two longitudinal striae on each side medial to the hind coxae; the inner of these is straight and somewhat oblique and extends to the posterior margin of the sternum; the outer is arcuate and curves outwardly and posteriorly, without recurving anteriorly, and terminates about one-third from apex.

Protibiae rather short, distinctly expanded apically, the outer margin with eleven to thirteen spinules of which the apical four or five are strong, the basal spinules becoming minute. Outer margins of mesotibiae with spinules which become minute and setiform basally. Metatibiae with a few subapical spinules on outer edge.

Length 1.76-2.04; width 1.16-1.43 mm.

Remarks. - This species is very closely allied to schmidti and may be separated from it by the characters given in the key; both have protibiae whose shape and adornment approach the type found in Phelister, but lack tarsal grooves.

Key to the Neotropical Species of Epierus Which Possess an antescutellar Pronotal Impression

1. Antescutellar pronotal impression hastiform (fig. 11, a) . . . . . . . . . 2 Antescutellar impression arcuate or broadly triangular (fig. $11, b, c, d$ ). . . 5 
2. Pygidium with an arcuate subapical stria or sulcus $\ldots \ldots \ldots \ldots \ldots \ldots$

Pygidium without subapical stria or sulcus............... 4

3. Pygidium rather coarsely, deeply punctate with the exception of a median, swollen, smooth area; an excavated, arcuate, subapical sulcus present; internal subhumeral stria represented by a short basal portion only, if at all.....................schmidti Wenzel and Dybas (1941, p. 446)

Pygidium rather evenly, sparsely, finely punctate, with an arcuate, subapical stria; internal subhumeral stria usually interrupted and consisting of a short basal portion and a long apical portion, sometimes complete.

striatipygus sp. nov.

4. Pygidium sparsely punctate; first dorsal stria obsolete apically, the second dorsal sometimes obsolete basally, the third usually abbreviated on basal fourth or fifth, the fourth dorsal absent or represented by a short dash or a few punctures apically, fifth dorsal absent; marginal mesosternal stria interrupted at middle; length $2.66-3.47 \mathrm{~mm} . . . \ldots \ldots$ darlingtoni sp. nov.

Pygidium densely punctate; dorsal striae 1-4 complete, the fifth reaching the middle; marginal mesosternal stria complete; length $2.5 \mathrm{~mm}$.

hastatus Marseul (1854, p. 685)

5. Internal subhumeral stria complete.......... epulo Marseul (1870, p. 98)

Internal subhumeral stria absent. . . . . . . . . . . . . . . . . 6

6. Antescutellar impression broadly triangular (fig. $11, d$ ).

brasiliense Tarsia in Curia $(1935, \mathrm{p} .1)$

Antescutellar impression arcuate (fig. $11, b, c) \ldots \ldots \ldots \ldots \ldots \ldots \ldots$

7. Antescutellar stria angulately re-entrant at middle (fig. $11, c$ ); inner lateral metasternal stria extending posteriorly, then recurving anteriorly and reaching the metasternal-mesepimeral suture.

coproides Marseul (1854, p. 682)

Antescutellar stria not re-entrant at middle (fig. 11,b); inner lateral metasternal stria extending obliquely posteriorly and terminating without recurving anteriorly................. arciger Marseul $(1854$, p. 684)

\section{Epierus cylindricus sp. nov.}

Type from Pinar del Rio, Cuba. A specimen of undetermined sex in the collection of Field Museum of Natural History. Collected by C. F. Baker.

Paratypes.-Two specimens, male and female, same data as the type, in the collection of Field Museum.

Description.-Form elongate, parallel-sided, subcylindrical, a little depressed along the middle, resembling a Cylistosoma. Color black, shining. Head somewhat densely punctulate. Labrum, across the middle, with a row of four setigerous punctures bearing long setae; posterior to these are about eight others which bear shorter setae. Frontal suture very fine.

Pronotal sides nearly straight, subparallel on basal half, strongly arcuate and convergent apically. Marginal stria complete. Surface sparsely, microscopically punctulate, with fine punctures inter- 
mingled, these absent along the lateral margins and rather dense and coarser in a narrowly triangular antescutellar area.

Elytra microscopically, sparsely punctulate. Epipleura with two punctate subcariniform striae, of which the inner and more dorsal (external subhumeral of Marseul) is the coarser. Internal subhumeral stria represented by a feeble impression near the middle and (in the type) apically. Oblique humeral rather short, indistinct in one paratype. Dorsal striae one to five and sutural complete, rather closely, crenately punctate, very coarsely impressed.

Propygidium sparsely punctulate, with deep, moderately coarse, rather sparse punctures intermingled. Pygidium sparsely, microscopically punctulate, with rather fine, sparse punctures intermingled; the latter separated by about their diameters at middle along base and disappearing at apex, sparser and coarser laterally.

Prosternum deeply, sparsely punctulate; keel rather narrow, the striae strongly impressed, feebly divergent basally, more strongly divergent apically; lobe with a complete marginal stria. Anterior margin of mesosternum very feebly emarginate. Marginal mesosternal stria nearly straight, united posteriorly on each side with the lateral metasternal stria which is straight, oblique, punctate, and strongly subcariniform and extends posteriorly to the metasternalmetepisternal suture at a point immediately anterior to the metepisternal-metepimeral suture; another metasternal stria is also present, extending posteriorly from the angle formed by the junction of the metasternum, the mesepimeron, and the metepisternum and terminating at a point shortly removed from the lateral metasternal stria. Meso-metasternal suture visible, not represented by a stria. Meso-metasternal disks punctulate throughout, the punctures denser, deeper and coarser in a rather broad area on each side of the median line of the metasternum; elevated metasternal sides punctulate, with coarse, sparse punctures intermingled. First abdominal sternum on each side (medial to the metacoxae) with an oblique stria which extends from basal to apical margins; this stria is very coarsely impressed and subcariniform basally, becoming finer apically.

Outer margin of protibiae with eight or nine fine spinules. Mesotibiae with five or six spinules on outer edge, the metatibiae with two or three subapical spinules.

Length 1.9-2.4; width 1.04-1.17 mm.

Remarks.-This is the only species known to me that is parallelsided and subcylindrical. Its form would obviously seem to be an adaptation to living in burrows, perhaps of scolytoids. 


\section{Subfamily Histerinae}

\section{Tribe Hololeptini}

\section{Phylloma Erichson (=Platyeutidium Dillon)}

Phylloma Erichson, Jahrb. Ins., 1, p. 96, 1834.

Phylloma Marseul, Ann. Soc. Ent. Fr., (3), 1, p. 191, 1853.

Phylloma Bickhardt, Gen. Ins., 166a, p. 24, 1916.

Platyeutidium Dillon, Ann. Ent. Soc. Amer., 28, p. 463, 1935.

Dillon proposed the genus Platyeutidium for two species described by him as new. Of these williamsi may be identical with corticale Fabricius, while unistriatum is probably a valid species. The genus was distinguished from Phylloma on the basis of differences of prosternal and tibial characters which do not actually exist but which were inaccurately figured by Marseul.

Phylloma multispinosum sp. nov. (pl. 2, fig. 3, a, c)

Type from Hamburg Farm, Reventazon, Limon, Costa Rica. A specimen of undetermined sex in the collection of Field Museum of Natural History. Collected from under loose bark of freshly cut wood, May 26, 1930, by Ferdinand Nevermann.

Paratypes.-A specimen of undetermined sex from the type locality, in the collection of Field Museum; collected May 2, 1930, by Ferdinand Nevermann. Two specimens, sex undetermined, from British Honduras, in the collection of the Museum of Comparative Zoology; collected April 18, 1906.

Description.-Size and form of $P$. corticale and apparently distinguishable from that species only in the structure of the tibiae.

Outer face of protibiae with one complete row and two incomplete rows of closely set, blunt spinules which are inserted at right angles to the face. Mesotibiae with three subapical rows of obliquely placed subconical spinules and several additional spinules along apical margin. Metatibiae similar to the mesotibiae but with a half row of spinules along apical margin and with only two subapical rows of closely placed spinules.

Length 5.80-6.75; width $3.23-3.80 \mathrm{~mm}$.

Remarks. - In corticale the meso- and metatibiae have but a single subapical row of spinules and the protibiae have only a single row of spinules on the outer face (pl. 2, fig. 3, $b, d$ ). A series of forty specimens of corticale from Nova Teutonia, Santa Catharina, Brazil, exhibits no variation in the direction of the tibial structure found in 
multispinosum. In one example of the latter the protibial spinules are so closely placed as to be nearly indistinguishable from one another.

\section{Hololepta (Hololepta) striaticeps sp. nov.}

Type from Hamburg Farm, Reventazon, Limon, Costa Rica. A female in the collection of Field Museum of Natural History. Collected from under loose bark of freshly cut wood, July 20,1931, by Ferdinand Nevermann.

Paratype from Toledo District, British Honduras. A male in the collection of the Museum of Comparative Zoology; collected October 15, 1906 (Peck).

Description.-Form and size of $H$. curta Marseul. Front distinctly, but rather broadly, shallowly impressed in the region of the transverse strioles, the latter curved, well marked. A longitudinal interocular stria is present on each side medial to the eyes and extends anteriorly to the preocular spine; its outer edge is strongly, obtusely carinate.

Lateral pronotal margins distinctly but not strongly angulate a little before the middle. Marginal stria complete laterally, continued on each side along the basal margin for about a sixth of the width, absent along anterior margin. Sides rather broadly, moderately, shallowly punctate from base to apex.

Epipleura smooth. Subhumeral stria coarse, not crenate, abbreviated at basal sixth and shortly before apex. First dorsal stria well impressed, present on about basal third. Basal portion of second dorsal very short, about a third as long as the first dorsal; appendix present on a little less than apical third.

Propygidium bifoveolate apically, strongly in the type, feebly in the paratype; coarsely, broadly, sparsely punctate laterally, the punctures finer along the apical margin. Pygidium smooth on about apical fourth, elsewhere coarsely, strongly punctate, the punctures separated by their diameters or a little less.

Prosternum broad, lobe truncate.

Protibiae four-dentate, the two basal teeth very small. Mesoand metatibiae tridentate.

Length 6.5-6.65; width 3.6-3.7 mm.

Remarks.-This species and curta differ from all species of the subgenus Hololepta known to the writer in possessing long interocular striae, and in the extent and relative coarseness of the pro- 
notal punctation. In striaticeps the pygidium is even and punctate throughout, with the exception of a very narrow apical smooth area. In curta the pygidium is impunctate and convex on basal third, elsewhere coarsely punctate. In a series of curta from Costa Rica, British Guiana, Trinidad, and Peru there is no tendency toward the type of punctation found in striaticeps, and the second dorsal stria (with one exception) is complete or very narrowly interrupted in one or two places; in one example the second dorsal is broadly interrupted, the apical appendix being limited to apical third.

Hololepta (Leionota) insularis sp. nov.

Type from Barro Colorado Island, Panama Canal Zone. In the collection of Field Museum of Natural History. A male collected April, 1924, by J. C. Bradley.

Paratypes.-Three males from the type locality; one in the collection of Field Museum, collected July 18, 1924, by Nathan Banks; one in the collection of the Museum of Comparative Zoology, collected June 26, 1924, by Nathan Banks; one in the collection of the American Museum of Natural History, collected November 12, 1923.

Description.- Size and form of Leionota cerdo Marseul. Mandibles long, basally rather broad and impressed above; tips abruptly, inwardly bent. Head broad, preocular spines well developed. Front without transverse strioles; interocular stria short, poorly defined.

Pronotum about three-fifths as long as broad; sides impunctate, obtusely angulate a little before middle and rather strongly sinuate near apex; apical angles broad, transverse, subtruncate. Marginal stria absent behind the head, complete laterally and extending inwardly along basal margin on each side for about a sixth of the width; it is deeply excavated in the shape of an inverted $U$ around the anterior angles.

Epipleura smooth. Subhumeral stria coarse, not crenate, a little abbreviated basally and apically. First dorsal stria well impressed, present on basal fourth. Second dorsal stria strong, complete or very narrowly interrupted in one or two places near the middle.

Propygidium coarsely, densely punctate along the sides, the punctures becoming fine anteriorly and at middle of apical margin. Pygidium not margined (except indistinctly at lateral angles), cribrately, moderately coarsely punctate, the punctures about half the size of the coarsest propygidial punctures. 
Mentum finely carinate in the form of a large inverted W. Anterior half of prosternal keel very narrow; prosternal lobe rather narrowly rounded.

Protibiae three- or four-dentate. Meso- and metatibiae with the upper ridge strongly, the lower ridge feebly and bluntly, threedentate.

Length 8.2-9.2; width $4.4-4.9 \mathrm{~mm}$.

Remarks.-Although females of insularis are not known, they will probably be found to have shorter, non-impressed mandibles and to lack the excavations around the anterior pronotal angles, as do females of the allied species intersectum Lewis and cerdo. The following characters may be used to distinguish between insularis and cerdo:

cerdo

Marginal pronotal stria interrupted at lateral angulations.

Pronotal sides straight, though convergent, before apex.

Propygidium cribrately punctate at sides, punctures very coarse. insularis

Marginal pronotal stria complete and well impressed along sides.

Pronotal sides sinuate before apex.

Propygidium not cribrately punctate at sides, punctures coarse.

\section{Tribe Histerini}

\section{Genus Margarinotus Marseul}

This genus has previously been limited to two species, namely, the palaearctic scaber Fabricius and the nearctic guttifer Horn. A study of the male aedeagus shows, ${ }^{1}$ however, that the generic limits must be considerably extended to include the species placed in Paralister, Grammostethus, Stenister, and the cadaverinus-foedatus groups of the genus Hister. The last-named genus contains widely divergent groups which must be given generic status at some future date. A revision of the species of Margarinotus is in preparation, but inasmuch as it will not be completed for some time, descriptions of some of the new species are given here in order to fix the types which have already been designated. The species are predominantly holarctic in distribution, a few being known from the Oriental and Indo-Australian regions.

1 The aedeagus of scaber has not been examined by the writer, but Dr. Edward S. Ross has kindly informed the writer that it is of the same type found in guttifer (pl. 6, fig. 1). Credit is due Dr. Ross for first noting that the aedeagus of these two species relates them to others which the writer assigns to Margarinotus in the following pages. 


\section{Margarinotus Marseul}

Margarinotus Marseul, Ann. Soc. Ent. Fr., (3), 1, p. 549, 1853.

Grammostethus Lewis, Ann. Mag. Nat. Hist., (7), 18, p. 400, 1906.

Paralister Bickhardt, Gen. Ins., 166a, p. 188, 1916.

Stenister Reichardt, Rev. Russe Ent., 20, p. 270, 1926.

Genotype Margarinotus scaber Fabricius.

Diagnosis.-Frontal and supraorbital striae present, the frontal sometimes obsolescent. Anterior pronotal margin emarginate for the reception of the head. One or two lateral pronotal striae present, the outer frequently abbreviated when present. External subhumeral stria nearly always complete, occasionally abbreviated or obliterated; internal subhumeral stria absent, though a few punctures may occasionally be present apically. Dorsal striae well impressed, excepting in scaber and guttifer. Prosternal keel seldom striate, the striae when present usually rudimentary. Anterior margin of mesosternum usually emarginate, occasionally truncate (davisi) or nearly so. Protibiae with four to sixteen denticles or teeth.

Aedeagus with a ring-shaped articulating basal piece; the rest of the tegmen variable, either bifid apically on dorsal surface (pl. 4, figs. $1, b, 2, b$ ) or tetrafid (pl. 5, figs. 1, b, 2, b). Median lobe sclerotized, subcylindrical (pl. 8, figs. 2,$3 ;$ pl. 9), or spoon-shaped (text fig. $12, b ;$ pl. 6 ; pl. 7 ; pl. 8, fig. 1), with paired posterior apodemes (text fig. 12, $b$; pl. 7, fig. 4; pl. 8, fig. 2, b); gonopore distal. Median armature connected to the base of the median lobe by a sclerotized hinge or by a heavy membrane; median armature, when viewed from above, nearly always forked apically (pl. 7, fig. 4 ; pl. 9, fig. $1, b)$, the forks sometimes fused.

Remarks. - The median lobe and armature are connected to the tegmen by a common, loose, diaphragmatic membrane which arises from the inflexed anterior and dorsal margins of the tegmen. The median lobe is extruded by the contraction of paired muscles, whose origin is in a somewhat fan-shaped band on the inner antero-lateral face of the tegmen on each side, and which narrow to their insertion on the posterior apodemes of the median lobe. As the lobe is extruded, the median armature rotates upwardly (text fig. 12,c) and probably functions as a mechanism for holding the aedeagus in the copulatory bursa of the female. In some species which have a tetrafid tegmen, a cylindrical median lobe, and a more or less reduced median armature, the last-named structure serves to spread the finger-like dorsal tegminal lobes upwardly and outwardly for the same function. 


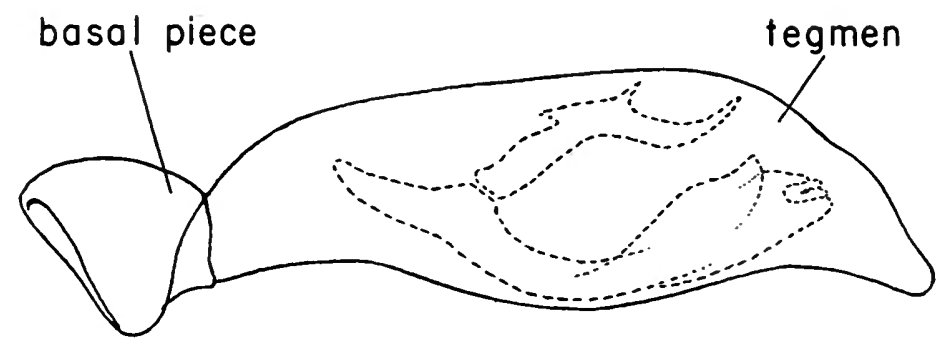

0

b
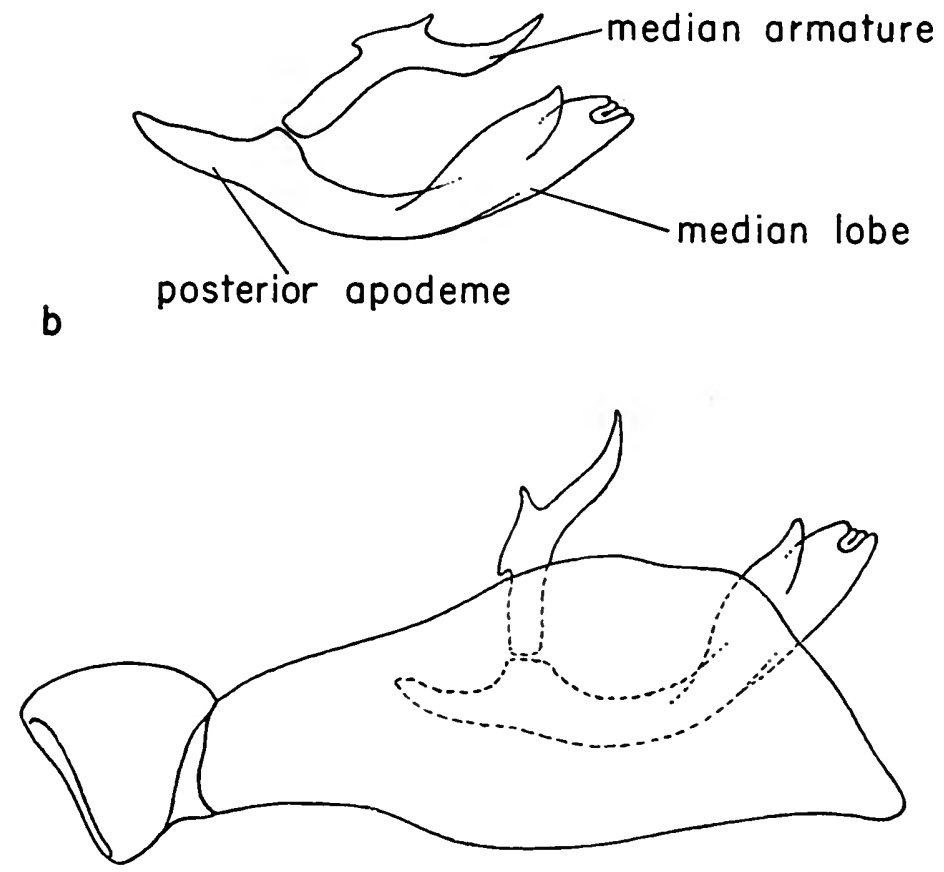

C

FIG. 12. Aedeagus of Margarinotus cadaverinus Hoffmann. a, Lateral view; sclerotized internal structures indicated by dotted lines. $b$, Lateral view of sclerotized internal structures (median lobe and median armature). $c$, Lateral view with median lobe extruded and median armature rotated upwardly. 
The females of many closely allied species cannot be identified except by association with the males or in conjunction with extensive reference collections.

The following species are placed in Margarinotus as defined above; there may be a few other described forms which, unknown to the writer, must be included. Names preceded by a question mark are only tentatively included because they have not been examined by the writer and their status is doubtful. The genus or subgenus to which each species had last been assigned is indicated in parentheses.

adonis Blatchley (Atholus)

aenigmaticus Wenzel (Hister)

arrosor Bickhardt (Hister)

balloui sp. nov.

bickhardti Reitter (Stenister) bipustulatus Schrank (Paralister) boleti Lewis (Hister)

bueckingi Bickhardt (Paralister) cadavericola Bickhardt (Hister)

cadaverinus Hoffmann (Hister)

(?)californicus Marseul (Paralister)

carbonarius Illiger (Paralister)

cognatus Le Conte (Paralister)

confusus sp. nov.

curvicollis Bickhardt (Grammostethus)

davisi Schaeffer (Atholus)

distinctus Erichson (Hister)

ednae Carnochan (Hister)

egregius Casey (Hister)

(?)faldermanni Marseul (Hister)

felipae Lewis (Hister)

fidelis Casey (Hister)

fractifrons Lewis (Hister)

fractistrius Lewis (Grammostethus)

fragosus Lewis (Grammostethus)

gentilis Lewis (Hister)

graecus Brullé (Paralister)

guttifer Horn (Margarinotus)

hailar sp. nov.

hamatilis Lewis (Grammostethus)

ignobilis Marseul (Paralister)

immunis Erichson (Hister)

impiger Lewis (Grammostethus)

incognitus Marseul (Hister)

indicus Lewis (Grammostethus)

indiicola Desbordes (Hister)

integer Brisout (Hister)

interruptus Beauvois (Hister)

koenigi Schmidt (Paralister)

kolzei Schmidt (Hister)

kurdistanus Marseul (Hister)

laevifossa Marseul (Paralister)

lecontei sp. nov. (?)litus Marseul (Paralister) longus Bickhardt (Paralister) marginatus Erichson (Grammostethus) marginicollis Le Conte (Paralister) marginipunctatus Lewis (Grammostethus) merdarius Hoffmann (Hister) mormon Casey (Hister) multidens Schmidt (Hister) navus Marseul (Grammostethus) neglectus Germar (Paralister) niponicus Lewis (Grammostethus) oblitus Casey (Hister) oblongulus Schmidt (Hister) occidentalis Lewis (Grammostethus) planiceps Lewis (Grammostethus) planifrons Lewis (Hister) pluto Casey (Hister)

(?)punctiventer Marseul (Paralister) purpurascens Marseul (Paralister) rectus Casey (Hister) remotus Le Conte (Paralister) ruficornis Grimmer (Grammostethus) scaber Fabricius (Margarinotus) sinensis Lewis (Grammostethus) sinuaticollis Lewis (Grammostethus) sinuosus Lewis (Paralister) socius Lewis (Grammostethus) sodalis Lewis (Grammostethus) stenocephalus Lewis (Grammostethus) stercorarius Hoffmann (Paralister) stercoriger Marseul (Grammostethus) striola Sahlberg (Hister) striolides sp. nov. stygicus Le Conte (Hister) terricola Germar (Hister) tristriatus sp. nov. umbilicatus Casey (Hister) umbratilis Casey (Hister) umbrosus Casey (Hister) uncostriatus Marseul (Paralister) ussuriensis Reichardt (Hister) ventralis Marseul (Paralister) weymarni sp. nov. 
Margarinotus hailar sp. nov.

Type from Hailar, Barga Upland, Heilunkiang Province, North Manchuria. A male in the collection of Field Museum of Natural History. Collected in August, 1939, by A. Loukashkin.

Description.-Form oblong-oval. Frontal stria of head complete, straight at middle. Marginal pronotal stria abbreviated at basal third and broadly interrupted behind the head. Outer lateral pronotal stria close to the margin, complete laterally; inner lateral pronotal stria complete laterally and behind the head, sinuate at middle on the sides.

Epipleural fossette with a row of punctures along each margin. Transverse subapical elytral impression feeble. External subhumeral and dorsal striae one to four complete; fifth dorsal without basal rudiment, almost reaching the middle; sutural stria more strongly crenate than the others, abbreviated at basal third.

Pygidia with feebly alutaceous ground sculpture. Propygidium coarsely, rather sparsely punctate, the punctures fine along apical margin; minute punctures scattered throughout. Pygidium moderately coarsely, sparsely punctate, the punctures becoming finer apically, minute at apex.

Prosternal lobe rounded at apex, marginal stria interrupted. Anterior margin of mesosternum rather shallowly emarginate, marginal stria complete. Lateral metasternal stria subcariniform, feebly crenate, extending obliquely posteriorly for about half the length of the metasternum. The oblique stria which usually extends medially from the metasternal-metepisternal suture is lacking. No coarse punctures are present medial to the lateral metasternal stria.

Protibiae with four evenly separated denticles on outer margin; apical margin with one minute denticle.

Length 4.5; width $3.2 \mathrm{~mm}$.

Remarks.-This species is allied to kolzei Schmidt but the latter has more densely and more coarsely punctate pygidia, three complete dorsal striae, five denticles on the outer margin of the protibiae, and on the elevated metasternal sides an oblique stria which extends medially from the middle of the metasternal-metepisternal suture.

Margarinotus weymarni sp. nov. (pl. 4, fig. 2; pl. 6, fig. 3)

Type from Erhtaohotze, Kirin Province, North Manchuria. A male in the collection of Field Museum of Natural History. Collected by A. Loukashkin, September 2-8, 1939. 
Paratypes. - North Manchuria: thirty-five specimens, same data as the type. Thirty-three from Hsiolin Station, sixty miles west of Harbin, Kirin Province; collected July 10-25, 1938 (Michael Weymarn). Eighteen from Hsiaoling, Kirin Province; collected August, 1938 (A. Loukashkin). Seventeen from Weishaho, Kirin Province; collected August, 1938 (A. Loukashkin). One from Hailar, Barga Upland, Heilunkiang Province; collected August, 1938 (A. Loukashkin). Fifty-two from Chalantun (Djalantun), Greater Khingan Mountains, Heilunkiang Province; collected May, 1934, and June, 1938 (M. Weymarn). Thirty-five from Cheng-Chin, Lesser Khingan Mountains, Heilunkiang Province; collected June 16-22, 1938 (A. Loukashkin).

Japan: six specimens from Mashike. One from Nikko, collected July 17, 1931 (L. Gressitt).

The Japanese specimens are in the collection of Field Museum. Of the other paratypes, seventy-five representing all localities are in the collection of Field Museum; the remainder are in the collection of Rupert L. Wenzel.

Description.-Almost identical with cadaverinus Hoffmann in external characters but differing in the following respects:

A shallow impression is present basally in the region of the third and fourth dorsal elytral striae. Pygidia very densely punctate and more coarsely so than in cadaverinus. Lateral metasternal stria extending obliquely posteriorly for about two-thirds the length of the metasternum, not united with the strong stria which extends obliquely and medially from a point near the middle of the metasternal-metepisternal suture; metasternum with a narrow band of coarse punctures medial and approximate to the lateral metasternal stria.

Length 5.52-7.5; width 4.1-5.7 $\mathrm{mm}$.

Remarks. - This is probably the species on which Manchurian, Chinese, and Japanese records of cadaverinus have been based. The prosternal lobe is typically truncate at apex with the marginal stria interrupted, but occasionally the margin is rounded and sometimes the marginal stria is complete. In a few examples the outer lateral pronotal stria is narrowly interrupted at middle. The conformation of the median armature varies somewhat, but not sufficiently to make identification questionable.

In cadaverinus there is no band of coarse punctures along the inner margin of the lateral metasternal stria and the latter is continuous with the oblique stria mentioned in the description. 
Margarinotus balloui sp. nov. (pl. 6, fig. 2)

Type from Nikko, Japan. A male in the collection of Field Museum of Natural History. Collected July 19, 1931, by L. Gressitt.

Description.-Form oblong-oval. Frontal stria of head narrowly interrupted at middle. Marginal pronotal stria complete; outer lateral stria complete along the sides, feebly hooked apically; inner lateral stria complete laterally and behind the head, terminating basally in an irregular striole on the one side and in a series of elongate punctures on the other.

Subapical impression of elytra very feeble, basal impressions in the region of the third and fourth dorsal striae not present. Epipleural fossette sparsely punctate at middle. External subhumeral stria complete. Dorsal striae one to four complete; fifth and sutural striae represented by a series of connected punctures, the fifth a little shorter than the sutural and represented at base by a short arc; sutural present on apical half. Pygidial punctation as in cadaverinus.

Prosternal lobe truncate at apex, the marginal stria interrupted. Anterior margin of mesosternum feebly emarginate, marginal stria complete; lateral metasternal stria extending obliquely posteriorly and continuous with the transverse oblique stria which extends medially from the metasternal-metepisternal suture; inner edge of lateral metasternal stria with a row of coarse punctures.

Outer margin of protibiae arcuate, bearing seven or eight small denticles, of which the basal two or three are minute; teeth of apical margin not discernible in the type though they probably normally exist.

\section{Length 5.6; width $4.1 \mathrm{~mm}$.}

Remarks.-The writer is unable to separate balloui from cadaverinus on the basis of external characters; however, the median armature of the male aedeagus is very distinct and somewhat approaches that of stygicus Le Conte from eastern North America.

\section{Margarinotus striolides sp. nov. (pl. 7, fig. 1)}

Type from Tunkun, Sajan Mountains, Siberia. A male in the collection of Field Museum of Natural History.

Paratypes.-A male from Weishaho, Kirin Province, North Manchuria, collected in August, 1938 (A. Loukashkin). A male from Cheng-Chin, Lesser Khingan Mountains, Heilunkiang Province, North Manchuria, collected June 16-22, 1938 (A. Loukashkin). Both in the collection of Rupert L. Wenzel. 
Description.-Form oblong-oval. Frontal stria complete and feebly, inwardly angulate at middle. Marginal pronotal stria interrupted behind the head. Outer lateral pronotal stria abbreviated on basal fourth or less, hooked at apex. Inner lateral stria complete laterally and behind the head.

Elytra with a transverse subapical impression and an impression at the base of the third dorsal stria. Epipleural fossette densely punctate. External subhumeral stria complete. Dorsal striae one to four complete; fifth and sutural striae subequal and present on apical half or a little less, the fifth without a basal rudiment.

Pygidial punctation dense, a trifle finer than that of the propygidium excepting laterally; apex more finely and sparsely punctate, without alutaceous ground sculpture.

Prosternal lobe rounded, marginal stria complete. Anterior margin of mesosternum distinctly (not feebly) emarginate; marginal mesosternal stria complete. Lateral metasternal stria extending obliquely posteriorly, not united with the oblique stria, which extends medially from the middle of the metasternal-metepisternal suture. Metasternal disk with a narrow band of moderate or fine punctures medial to the lateral stria.

Protibiae with two fine denticles on apical margin and five or six denticles on outer margin, the basal one very fine.

Length 5.5-5.78; width 3.8-4 mm.

Remarks.-This species is probably the one on which the far eastern records of striola have been based; in the latter species the pygidium is more finely and densely punctate. The median lobe and armature of the aedeagus of both species are shown in pl. 7, figs. 1, 2. In the Cheng-chin specimen, the propygidium is more sparsely punctate than in the other two.

Margarinotus tristriatus sp. nov. (pl. 3, fig. 1; pl. 7, figs. 3, 4)

Type from Yalu Station, Greater Khingan Mountains, Heilunkiang Province, North Manchuria. A male in the collection of Field Museum of Natural History. Collected September 20-October 5, 1939 , by A. Loukashkin.

Description.-Form oblong-oval, humeri somewhat inflated. Frontal stria of head narrowly re-entrant at middle.

Marginal pronotal stria interrupted behind the head, complete laterally. Outer lateral pronotal stria broadly interrupted at middle along the sides (absent on middle third), hooked at apex; inner lateral 
pronotal stria complete, feebly punctate, irregular along the sides, and more widely separated from the lateral margin anteriorly than posteriorly, its posterior end nearly in contact with the basal portion of the outer lateral stria. Sparse, moderately coarse punctures are present near the posterior end of the inner lateral stria and within the hook of the outer lateral stria.

Elytra with a strong, transverse subapical impression and an impression at the base of the third dorsal stria. Epipleural fossette densely punctate. External subhumeral stria and dorsals one to three complete; fourth and fifth dorsals represented by apical rudiments, sutural present on apical half; basal rudiment of the fifth represented by two rather widely separated, coarse punctiform impressions.

Propygidium coarsely and rather sparsely punctate along the sides and base, becoming finer apically, particularly at middle; a few minute punctures are intermingled in the area of coarse punctation. Pygidial disk rather evenly, finely, sparsely punctate, the punctures coarser laterally, minute at apex.

Prosternal lobe rather narrowly rounded at apex, marginal stria complete. Anterior margin of mesosternum distinctly (not feebly) emarginate. Marginal mesosternal stria complete; meso-metasternal suture not marked by a stria; the lateral metasternal stria extends posteriorly to, but is not continuous with, the oblique stria which extends medially from the middle of the metasternal-metepisternal suture.

Protibiae with eight teeth along outer margin (the two basal teeth minute); two minute teeth present along apical margin.

Length 7 ; width $4.8 \mathrm{~mm}$.

Remarks.- The interrupted outer lateral pronotal stria may be an aberration. Bickhardt's arrosor seems to be related but may be separated by the characters given in the key.

The following key will aid in separating the preceding new species from their far eastern allies, i.e. the species with two lateral pronotal striae.

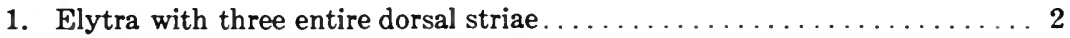

Elytra with four entire dorsal striae.......................6 6

2. Inner lateral pronotal stria strongly bent behind the eyes; dorsal elytral striae strongly crenate. Length $7 \mathrm{~mm} . . . \ldots \ldots \ldots$..... boleti Lewis $(1884$, p. 135)

Inner lateral stria without a strong angulation behind the eyes; dorsal elytral

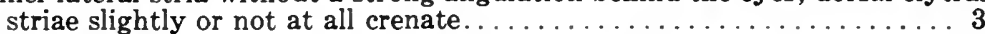

3. Marginal pronotal stria complete along the sides and attaining the base. 4 Marginal pronotal stria abbreviated on basal half or third ......... 5 
4. Outer lateral pronotal stria abbreviated anteriorly and posteriorly; propygidium densely, pygidium very densely punctate; body form elongate, subparallel, somewhat depressed...........oblongulus Schmidt (1892, p. 24)

Outer lateral pronotal stria complete; propygidium and pygidium moderately, coarsely, densely punctate, the pygidial punctures separated by about half their diameters; form oblong-oval. Median lobe as in pl. 8, fig. $2, a, b \ldots \ldots \ldots \ldots \ldots \ldots \ldots \ldots \ldots \ldots \ldots$ kolzei Schmidt $(1889$, p. 369)

5. Fourth and fifth dorsal striae without basal rudiments; ${ }^{1}$ pronotum with moderate punctures around the base of the inner lateral stria and within the apical hook of the outer lateral stria, the last-named stria interrupted on middle third (aberration?); anterior margin of mesosternum rather deeply emarginate at middle; median lobe as in pl. 7, fig. 3, $a, b$.

tristriatus sp. nov.

Fourth and fifth dorsal striae with basal rudiments; pronotum impunctate; outer lateral stria complete; anterior margin of mesosternum feebly emarginate.......................... arrosor Bickhardt (1920a, p. 99)

6. Protibiae with $12-16$ denticles.......... multidens Schmidt (1889, p. 94)

Protibiae with $4-7$ denticles.................... 7

7. Fifth dorsal stria with a basal rudiment................... 10

Fifth dorsal stria not represented basally by a rudiment. . . . . . . 8

8. Marginal pronotal stria abbreviated on basal half or third; outer lateral pronotal stria close to the margin.................... 9

Marginal pronotal stria complete along the sides and attaining base; outer lateral stria more distant from the margin; epipleural fossette coarsely and moderately densely punctate .................. striolides $\mathrm{sp}$. nov.

9. Epipleural fossette impunctate; pygidia very densely punctate; outer lateral pronotal stria abbreviated anteriorly and posteriorly (sometimes reduced to a dash near middle or absent) . . . . . . koenigi Schmidt (1888, p. 189)

Epipleural fossette with a row of punctures along inner and outer edges; pygidia rather sparsely punctate; outer lateral pronotal stria complete.

hailar sp. nov.

10. Dorsal elytral striae strongly crenate; interval between the lateral pronotal striae usually with numerous moderate punctures, these rarely absent, sometimes extending from apex to base, nearly always present near the apical angles, and frequently present on the disk medial to the inner stria; median lobe and armature of aedeagus as shown in pl. 8, fig. 1.

ussuriensis Reichardt (1929, p. 285)

Dorsal elytral striae moderately or feebly crenate; interval between the lateral pronotal striae at most with strong punctation or fine punctures.....11

11. Posterior margin of propygidium smooth.

cadavericola Bickhardt (1920a, p. 102)

Propygidial punctures extending to the hind margin . . . . . . . . 12

12. Lateral metasternal striae extending to, but not united with, the oblique stria which extends medially from the middle of the metasternal-metepisternal suture; median lobe and armature as shown in pl. 6, fig. 3 .

weymarni sp. nov.

Lateral metasternal stria continuous with the oblique stria; median lobe and armature as shown in pl. 6 , fig. $2 \ldots \ldots \ldots \ldots \ldots \ldots \ldots$ balloui sp. nov.

1 The fifth is represented at base by two strongly punctiform impressions but not by a striole; similar variants are known in other species which normally have no basal rudiments. 
Margarinotus confusus sp. nov. (pl. 9, fig. 3)

Hister (Paralister) marginicollis Wenzel, Can. Ent., 68, p. 270, 1936.

Type from Joliet, Illinois. A male in the collection of Field Museum of Natural History. Collected in fungus, March 23, 1935, by Frank Schuett.

Paratypes.-Illinois: A pair, same data as the type. One from Evanston, collected in fungus, March 28, 1933 (J. Robinson). One from Kankakee, collected April 25, 1936 (Janet Wilder).--Indiana: One from Turkey Run, collected April 2, 1925. One from Marion County, collected March 13, 1910 (W. S. Blatchley).-Pennsylvania: One from Jeannette, collected in July (H. G. Klages).-New York: One from Central Park, Long Island, collected April 11, 1935.Massachusetts: Six from Natick, collected in a fox hole, May 4-11, 1941 (C. A. Frost). One from Framingham, collected April 18, 1915 (C. A. Frost).

Description.-Form oblong. Frontal stria of head deep, straight or feebly and narrowly bowed inward at middle. Marginal pronotal stria complete laterally, broadly interrupted behind the head. Outer lateral stria absent; inner lateral stria complete, crenate behind the head, strong and usually sinuate along the sides, the interval between it and the margin somewhat convex. Disk with a few moderate to moderately coarse punctures medial to the lateral stria.

Epipleura finely margined. Marginal elytral stria complete, well impressed, its outer edge strongly subcariniform. On apical half, between the marginal elytral and the marginal epipleural striae, is a poorly impressed coarse stria; epipleural fossette moderately to moderately coarsely, deeply, and sparsely punctate. External subhumeral stria complete, well impressed. Dorsal striae one to three complete; fourth dorsal variable, usually abbreviated at basal fifth, occasionally at basal fourth or third; fifth dorsal variable, usually present on apical third, sometimes extending to middle. Sutural stria usually extending slightly beyond the middle, occasionally to basal third. Dorsal striae usually not noticeably punctate.

Pygidia micro-alutaceous, the pygidium usually more feebly so; propygidium sparsely, moderately coarsely punctate, a few minute punctures intermingled; pygidium similarly but a little more finely punctate, the punctures minute apically.

Prosternum micro-alutaceous; keel sparsely punctulate, often with fine rudimentary carinal striae between the coxae; lobe sparsely punctulate at middle, coarsely punctate laterally, its marginal stria 
deep, sometimes interrupted at middle. Anterior margin of mesosternum feebly emarginate; marginal stria complete, strongly punctate. Meso-metasternal stria usually complete, sometimes almost entirely absent, continuous on each side with the lateral metasternal stria which extends obliquely posteriorly nearly to the oblique stria which extends inwardly and posteriorly from the metasternalmetepisternal suture.

Protibiae with five or six denticles externally, the basal two minute; truncate apical margin with two minute denticles.

Length 3.5-3.9; width 2.5-2.8 mm.

Remarks.-Upon examining a fairly large series of specimens which had been determined as marginicollis Le Conte, the writer found that two very closely allied species were represented. Since the only definite character by which they can be separated is the structure of the median lobe and armature of the aedeagus, the question naturally arises as to which is the Le Conte species. The type of the latter is not extant, and inasmuch as the distribution of the two species seems to be nearly the same, the indefinite type locality of marginicollis gives no aid in the interpretation. Thus the writer has arbitrarily assigned the more common of the two to marginicollis; it can be distinguished by its larger size $(4.1-4.8 \mathrm{~mm}$.) and the structure of the median lobe and armature (pl. 9, fig. 1, $a-c$ ) of the aedeagus, the sinuate forks of the median armature being particularly characteristic; in confusus the forks are straight. Margarinotus felipae Lewis, known from Kansas and Iowa, is a larger and more elongate-oblong species than either of the above mentioned; in the structure of the median lobe and armature (pl. 9, fig. 2) it closely approaches marginicollis, but has straight armature forks.

Margarinotus lecontei sp. nov. (pl. 8, fig. 3)

Hister cognatus auct. (not Le Conte, Bost. Journ. Nat. Hist., p. 58, 1845).

Type from Delavan, Wisconsin. A male in the collection of Field Museum of Natural History. Collected July 13, 1940, by Henry S. Dybas.

Paratypes.-Wisconsin: Eight specimens, same locality as the type, collected June 18-July 13 (H. S. Dybas). Seven from Madison, on decaying bracket fungus, collected August 11, 1935 (H. R. Dodge). Two from Clintonville, on decaying mushrooms, collected October 23, 1935 (H. R. Dodge).--Minnesota: Five from Ramsey County, on rotting banana, collected June 26, 1936 (H. R. Dodge). One from St. Paul, on rotten banana, collected August 19, 1935 
(H. R. Dodge). One from Washington County, collected September 7, 1936 (H. R. Dodge).-Michigan: One from Camp Steuben, Schoolcraft County, collected May 31, 1935 (J. R. Gross).-Illinois: Two from River Forest, in bracket fungus, collected September 28, 1941 (J. L. Hill). Three from Urbana, collected April 29, 1920. One from Algonquin (W. A. Nason).--Indiana: Five from Beverly Shores, collected May, 1933 (H. S. Dybas).-Maine: One from Monmouth (C. A. Frost).-Massachusetts: One from Framingham, collected April 19, 1910 (C. A. Frost). Two from Amherst, collected May 2, 1930 (Field). One from Natick, collected May 22, 1938 (C. A. Frost).-New York: Five from South Fallsberg, collected May 7-September 22, 1941 (W. Spector). One from Cooks Falls, collected April 23, 1929. One from Olcott, collected July 18, 1926 (H. Dietrich).-Pennsylvania: One from Bear Lake. One from Jeannette, collected May 24 (H. G. Klages). One from Alleghen.Maryland: One from Edgewood, collected October 18, 1918 (H. Dietrich).-North Carolina: Two labeled "N.C." One from Sunburst, collected October 25, 1935 (O. L. Cartwright).- South Carolina: One from Mountain Rest, collected August 11, 1931 (O. L. Cartwright). One from Rocky Bottom, collected May 3, 1931 (O. L. Cartwright).-Georgia: One from Clayton, collected July, 1910 (W. T. Davis).-Tennessee: One from Gatlinburg, Great Smoky Mountains National Park, on fungus, collected June 16, 1942 (C. H. Seevers).-Canada: One from Montreal, Quebec. Six from Hemmingford, Quebec, June 7-21, 1917 (J. I. Beaulne). One from Fort Coulonge, collected June 13, 1918 (J. I. Beaulne). Five from Ottawa, Ontario, collected September 23, 1912 (J. I. Beaulne). Four labeled "Ontario."

Paratypes are in the collections of Field Museum, the University of Illinois, Edward S. Ross, H. R. Dodge, William Spector and Rupert L. Wenzel. At a later date others will be deposited in the larger collections of the country.

Description.-Form rather broadly oblong-oval. Head minutely, sparsely punctate. Frontal stria deeply impressed, straight at middle or feebly, outwardly arcuate.

Marginal pronotal stria very fine along the sides, obsolescent basally, absent on basal half or third, well impressed along anterior margin but narrowly interrupted at middle for about half the width of the head. Outer lateral pronotal stria absent, the inner complete and well impressed, crenate, usually sinuate along the sides; interval between the lateral stria and the margin distinctly convex. 
Disk sparsely punctulate at middle; deep and rather close punctures present in a longitudinal area on each side within the lateral stria, the punctures coarser basally.

Marginal epipleural stria absent, marginal elytral stria complete, very coarse apically, rather closely and shallowly punctate basally. Epipleural fossette smooth or very sparsely punctate. External subhumeral and dorsal striae one to four complete, well impressed; fifth dorsal and sutural striae a little finer than the preceding, both variable in length, the fifth usually present on apical two-fifths or half, sutural a little longer, frequently extending a little beyond the middle. All the dorsal striae distinctly crenate.

Propygidium and pygidium coarsely, densely punctate (punctures sometimes feebly umbilicate) with a few microscopic punctures intermingled; pygidial punctures minute at apex.

Prosternal keel sparsely punctulate, usually with rudimentary striae between the coxae; lobe rather strongly deflexed, sparsely and moderately punctate, the marginal stria often narrowly interrupted at middle and somewhat abbreviated laterally.

Anterior margin of mesosternum feebly emarginate, marginal stria entire, crenate. Meso-metasternal stria obtusely angulate at middle, united on each side with the oblique, coarsely punctate, lateral metasternal stria which extends posteriorly nearly to, but not united with, the oblique stria which extends inwardly from the middle of the metasternal-metepisternal suture.

Protibiae six-denticulate.

Length $3.67-4.9$; width $2.7-3.52 \mathrm{~mm}$.

Remarks. - This rather common species has been referred to as cognatus by all workers since the elder Le Conte; however, reference to the original description and figure of that species clearly indicates that the name cognatus applies to the species described by Casey as unicus and since referred to by that name. Perhaps the error has resulted chiefly from reference to Le Conte's figure, poor impressions of which do not show the characteristic basal arc of the fourth dorsal stria. I previously considered (1936) that the two were one species since the only apparent differences were in the extent of pronotal punctation and in the presence of the basal arc; however, the median lobe and armature of the aedeagus are entirely different.

Margarinotus cadaverinus Hoffmann (= Hister obtusatus auct., H. virginiae Casey).

Hister cadaverinus Hoffmann, Ent. Hefte, 1, p. 34, pl. 1, fig. 2, 1803. 
(?) Hister obtusatus Harris, Trans. Hartf. Nat. Hist. Soc., 1, p. 76, 1837.

Hister obtusatus auct.

Hister virginiae Casey, Ann. N. Y. Acad. Sci., 7, p. 541, 1893.

The species which has been identified by North American workers as Hister obtusatus Harris is the palaearctic cadaverinus, probably introduced into this country and now very common throughout the eastern and middle-western states. Since the type of obtusatus apparently is no longer in existence, it is not possible to determine finally whether or not obtusatus auct. equals obtusatus Harris. The genital structures of the male type of virginiae have been dissected and examined by the writer.

Margarinotus stercorarius Hoffmann (=Hister semisculptus Le Conte)

Hister stercorarius Hoffmann, Ent. Hefte, 1, p. 57, pl. 1, fig. 5, 1803.

Hister semisculptus Le Conte, Smiths. Misc. Coll., 6, p. 60, 1863.

The writer has studied the type of semisculptus and found it to be identical with the palaearctic stercorarius. In North America the species has been taken in "Illinois" (type locality of semisculptus), at Framingham, Massachusetts (C. A. Frost), and at Forest Grove, Cornelius, and Blooming, Oregon (Schuh and Gray). Through the courtesy of Dr. E. S. Ross, the writer has seen a fairly extensive series from the Oregon localities.

Further synonymy of cadaverinus and stercorarius may be found in the Genera insectorum (Bickhardt, 1917).

\section{Genus Atholus Thomson}

Atholus bolteri sp. nov.

Type from "Fla." Sex undetermined. No. 25572 in the Le Conte collection, Museum of Comparative Zoology. Collected by Bolter.

Description.-Form elongate-oval, rather strongly convex. Color black, shining. Head strongly, very finely, rather sparsely punctate. Frontal stria straight at middle, feebly crenate, complete. Supraorbital stria absent. Labrum somewhat compressed anteroposteriorly.

Pronotum nearly twice as broad as long (12:7). Sides straight and rather strongly convergent nearly to apex, thence abruptly angulate to the apical angles. Surface sparsely punctulate throughout. Marginal pronotal stria complete laterally, extending around apical angles and interrupted along anterior margin for less than the 
width of the head. Outer lateral pronotal stria rather close to the margin, finely subcariniform, extending from the region of the apical angle to basal fifth; inner lateral pronotal stria complete, strongly sinuous and finely crenate laterally, very distinct and subcariniform around the anterior angle and along the anterior margin; within the anterior angle of the inner lateral stria is a small, alutaceous, subopaque area which has coarser, rather closely placed punctures.

Elytra together distinctly broader at humeri than pronotum, sides rather evenly, distinctly arcuate from base to apex. Epipleura alutaceous; marginal epipleural stria very fine and close to the margin, nearly indistinguishable. Marginal elytral stria complete, well impressed; lateral and approximate to it on apical half is a short stria. Oblique humeral very finely impressed. Subhumeral striae absent. Dorsal striae feebly crenate, first to fifth and sutural complete, the fifth and sutural united in an arch. Elytra sparsely punctulate.

Pygidia alutaceous. Propygidium rather coarsely, rather evenly, moderately sparsely punctate, the punctures separated by their diameters for the most part, a few minute punctures intermingled. Pygidium basally rather evenly, a little more finely punctate than the propygidium, the punctures moderately sparse, becoming abruptly finer on apical half, minute at apex.

Ventral surface alutaceous throughout. Prosternum punctulate, without striae; prosternal lobe with a deep, inverted U-shaped marginal stria, sparsely, deeply, finely punctate. Anterior margin of mesosternum feebly, outwardly arcuate, the marginal stria subcariniform, well impressed, complete, narrowly separated from a short arcuate stria which extends around the posterior margin of the middle coxal cavity. Between the marginal stria and the anterolateral angles on each side is a short stria. Meso-metasternal stria subcariniform, finely crenate, united on each side with the lateral metasternal stria which extends obliquely posteriorly to a point not far removed from the metacoxa. Sternal disks with a few microscopic punctures which are most evident on the mesosternum. First abdominal sternum with a single oblique stria on each side medial to the hind coxa, the stria subcariniform, extending from base to apex, its apical half rather coarsely crenate.

Anterior tibiae tridentate, the basal tooth small, the apical tooth strongly produced and "bifid" (bearing two blunt denticles). Middle and posterior tibiae biseriately spinulose; spinules of marginal row fairly stout and moderately long, those of the submarginal row short, stubby; a row of setae is present in addition to the spinules. 
Measurements.-Length 4.85 ; width $3.25 \mathrm{~mm}$.

Remarks. - The pronotal striae of bolteri recall those of Atholus tornatus Le Conte, ${ }^{1}$ but these two species are otherwise easily separated by their form and the entirely different character of their elytral striae; bolteri may be separated from all the other North American species of Atholus by its larger size, the presence of an alutaceous, punctate area on each side within the anterior angle of the inner pronotal stria, and its alutaceous ventral surface.

\section{Genus Phelisteroides Wenzel and Dybas}

The genus Phelisteroides was erected by Wenzel and Dybas in 1941 to include two previously known histerids and three which were described as new. Descriptions of four additional species are given below.

\section{Phelisteroides punctipennis sp. nov.}

Type from Chapada, Brazil. A specimen of undetermined sex in the collection of Carnegie Museum. Collected in November.

Description.-Form oblong, not very strongly convex, broadly and feebly depressed along the suture. Pronotum and elytra sparsely, minutely punctulate. Color deep reddish-brown, nearly black. Head strongly, not densely punctulate. Epistoma distinctly impressed basally; vertex shallowly impressed, almost flat. Frontal stria complete at middle, narrowly interrupted on each side, not united with the supraorbital.

Anterior pronotal margin feebly, outwardly arcuate at middle behind the head. Marginal stria complete laterally, interrupted at middle of anterior margin for a little less than the width of the head. Lateral stria well impressed, very feebly crenate laterally, more distinctly so anteriorly, narrowly interrupted on each side behind the eyes, the median detached portion with recurved ends. Numerous coarse punctures present on each side medial to the lateral stria.

Epipleura bistriate, both striae strongly punctate, the outer (marginal epipleural) present on a little more than apical half, the inner (marginal elytral) very wide and rather shallow, especially near base. External subhumeral stria punctate, deeply impressed on apical half, with a disconnected basal appendix which extends

${ }^{1}$ Since redescribing this aberrant species (1939, p. 389), I have examined the genitalia of a male example and established its identity as a member of the genus Atholus. 
halfway to base; internal subhumeral complete, strongly impressed. Dorsal striae crenate, first to fourth complete, the fifth extending to middle; sutural abbreviated at basal fourth. Elytral apices with sparse moderate punctures intermingled with the punctulation.

Propygidium coarsely, densely, umbilicately punctate, the narrow intervals with scattered minute punctures. Pygidium very densely, rather deeply, minutely punctate, with numerous coarser (though rather fine) punctures intermingled, these separated by one to two times their diameters; appearance subopaque. Pygidial sulcus very fine and shallow, scarcely distinguishable, its bottom with closely placed fine punctures.

Prosternum with a very fine, transverse, strigose microsculpture, this less distinct on the lobe, which is deeply, finely punctate; lobe with a deep, apical marginal stria which is strongly abbreviated on each side. Carinal striae not very strongly convergent, nearly straight, feebly sinuate near base, united anteriorly in a rounded arch and across base by a fine transverse stria. Anterior margin of mesosternum broadly, distinctly emarginate. Disk of mesosternum with the same type of ground sculpture as the prosternum; marginal mesosternal stria subcariniform, finely crenate, rather narrowly interrupted at middle. Meso-metasternal stria cariniform, crenate, rather strongly and evenly arcuate, encroaching upon the mesosternal disk, its median portion reaching the anterior margin, united on each side (about one-sixth from lateral margin) with the lateral metasternal stria. Metasternal disk rather closely, deeply punctulate anteriorly, the punctures becoming a little larger and sparser posteriorly and abruptly coarse along the hind margin near the hind coxae. First abdominal sternum bistriate on each side medial to the hind coxa, the inner stria coarse and oblique, reaching the hind margin; the outer stria extends a little beyond the middle. Intercoxal disk coarsely punctate, punctulation intermingled, the coarse punctures disappearing on apical two-fifths, a narrow apical margin transversely micro-strigose.

Protibiae not very strongly expanded, seven-denticulate, the apical tooth and the two basal ones fine. Meso- and metatibiae with about five rather short spinules on outer edge, the basal spinules fine.

Length 2.57; width $1.95 \mathrm{~mm}$.

Remarks. - The extensively punctate metasternal disk and the complete inner subhumeral stria are distinctive characters of this species. The pygidial sulcus is so fine that it is easily overlooked. 


\section{Phelisteroides ruptistrius sp. nov.}

Type from Santarem, Brazil. A specimen of undetermined sex in the collection of Carnegie Museum. Collected in December.

Paratype.-A specimen of undetermined sex, same data as the type, in the collection of Field Museum.

Description.-Form rather broadly oblong-oval, moderately convex, a little depressed along the suture. Color deep reddish-brown, shining. Head, pronotum, pygidium and under side densely punctulate. Epistoma and vertex feebly convex; frontal stria absent, supraorbital present.

Pronotal sides convergent, very feebly arcuate on basal half, thence more strongly arcuate and convergent to apical angles; anterior margin very feebly, outwardly arcuate at middle. Marginal stria complete laterally and behind the head. Lateral stria complete laterally, rather close to the margin, deely impressed, finely crenated, narrowly interrupted on each side behind the eyes, the median detached portion more strongly crenate and with recurved ends. Punctulation more feeble than that of head, noticeably so in a rather broad, feebly depressed, antescutellar area; sparse, larger punctures intermingled in a broad longitudinal area on each side medial to the lateral stria and in a narrow band behind the anterior margin, the innermost punctures being the strongest.

Elytra microscopically, sparsely punctulate, apices with a submarginal row of moderately fine punctures. Epipleura bistriate, the outer or marginal epipleural stria rather smoothly impressed, the inner or marginal elytral stria coarse and strongly, crenately punctate. External subhumeral stria present on apical half, strongly impressed, crenately punctate; internal subhumeral absent; oblique humeral finely impressed. Dorsal striae one to three complete, well impressed, but not coarsely so, rather finely and crenately punctate; fourth dorsal broadly interrupted on apical sixth or seventh and on basal third or a little less, its base arched inwardly; fifth dorsal subequal to the apical rudiment of the fourth. Sutural abbreviated at about basal third, wider and more strongly crenate than any of the preceding striae.

Propygidium feebly punctulate, very sparsely so basally; coarse punctures umbilicate, separated by less than their diameters basally, becoming sparser and finer apically. Pygidium densely punctulate, but not deeply so, somewhat larger punctures sparsely intermingled; marginal sulcus fine, striiform, finely crenate. 
Prosternal punctulation deep, effect subrugose, with somewhat coarser sparse punctures intermingled; lobe rather broad at apex with a coarse marginal stria; keel broad at base; carinal striae straight and convergent (not strongly so), extending nearly to lobe and united anteriorly in a relatively broad arch, transversely united across base. Anterior mesosternal margin broadly, feebly emarginate; marginal stria entire, finely crenate. Meso-metasternal stria arcuate and crenate, not reaching the middle of the mesosternal disk, united with the lateral metasternal stria at about lateral fourth on each side, the two striae combined forming an almost regular are of 180 degrees; meso-metasternal suture crenately punctured on each lateral fourth. Suture between the metasternum and the first abdominal sternum coarsely impressed and subsulciform between the coxae. First abdominal sternum bistriate on each side medial to the coxa, the inner stria fine, crenate, and arcuate, extending from basal to apical margin; the outer stria extends to middle. Punctulation obsolete near apex of intercoxal disk.

Protibiae rather narrow (abruptly so on basal third), with about seven spiniform denticles, the two apical and the basal denticles very small. Mesotibiae with five spinules on outer margin. Metatibiae with four spinules on apical half of outer margin.

Length 2.2-2.3; width 1.76-1.85 mm.

Remarks.-This species may be distinguished by its densely punctulate head, pronotum and under surface, its broad prosternal keel, the absence of a frontal stria and the broadly interrupted fourth dorsal stria. Only one other known species, punctipennis, has a fine, striiform pygidial sulcus.

\section{Phelisteroides angustisternus sp. nov.}

- Type from Para, Brazil. A male in the collection of Field Museum of Natural History. Collected in June.

Description.-Form rather broadly oblong, moderately convex, a little depressed along the suture. Color reddish-brown, shining. Head, pronotum, elytra, and sternal disks sparsely punctulate. Frontal stria straight at middle, well impressed, united on each side with the complete supraorbital. Epistoma and vertex lightly impressed.

Pronotal sides straight and a little convergent on somewhat more than basal half, thence abruptly oblique, straight and convergent to apical angles; lateral margins deflexed on a little less than basal half; apical margin feebly, outwardly arcuate behind the head. 
Marginal stria complete laterally and behind the head. Lateral stria crenate, rather distant from the sides, narrowly interrupted on each side behind the eyes, the detached median portion with feebly recurved ends. A few moderate punctures present on each side medial to the lateral stria.

Epipleura with two strongly bent striae, the outer fine, the inner strong and crenately punctate, its outer edge strongly subcariniform. External subhumeral well impressed, extending from middle nearly to apex; internal subhumeral absent; oblique humeral very finely impressed. Dorsal striae one to three complete, crenately punctate, more strongly so apically; fourth dorsal slightly longer than the third, the latter reaching the middle. Sutural stria abbreviated at basal fourth, strongly crenate, much wider basally.

Propygidium with coarse, close, umbilicate punctures in a basal, marginal row and in a broad, median, abruptly limited, trapezoidal area, elsewhere minutely, very densely punctate. Pygidium very densely, minutely punctate, with a few somewhat coarser punctures intermingled; basal margin with a row of coarser, though rather fine, punctures; marginal sulcus strong and deep, its edge crenate.

Prosternal lobe with a strong marginal stria; carinal striae nearly straight, strongly divergent posteriorly and united across basal margin by a very fine, feeble line, the striae rather close anteriorly and united in a narrow, rounded arch about one-third from lobe; keel moderately broad basally, strongly narrowed apically, the portion anterior to the striae being narrow, obtusely cariniform. Anterior mesosternal margin broadly, feebly emarginate; marginal stria complete. Meso-metasternal stria rather feebly crenate, arcuate on middle three-fourths of its width and arching halfway up the mesosternal disk, continuous on each side with the lateral metasternal stria. First abdominal sternum with three striae on each side medial to the hind coxa; the inner stria is feebly oblique, crenate, extending nearly to the apical margin, and continued inwardly along basal margin for about a third of the width; the middle stria is parallel to the inner and extends nearly to apex; the third is close to the second and reaches a little beyond the middle.

Protibiae rather narrow, with three, low, blunt, denticle-bearing teeth in addition to a very fine apical tooth situated near the insertion of the tarsus, the basal tooth situated a little behind the middle of the outer edge. Mesotibiae with five, metatibiae with four spinules on outer edge.

Length 2.22; width $1.5 \mathrm{~mm}$. 
Remarks.-This species is characterized by the narrow prosternal keel with relatively short carinal striae, the small number of protibial teeth, the presence of three striae on each side of the first abdominal sternum, the continuation of the inner of these striae along the basal margin of that segment, and the limitation of the coarse propygidial punctures to a basal row and a broad, median trapezoidal area.

\section{Phelisteroides fossipygus sp. nov.}

Type from Santarem, Brazil. A specimen of undetermined sex in the collection of Carnegie Museum.

Description.-Form broadly oblong-oval, moderately convex, a little depressed along the suture. Head, pronotum, elytra and under side minutely, sparsely punctulate. Epistoma and vertex distinctly impressed; frontal stria complete, well impressed, united on each side with the complete supraorbital.

Anterior margin of pronotum distinctly, outwardly angulate at middle behind the head. Marginal pronotal stria complete laterally, interrupted along apical margin for the width of the head. Lateral stria crenated, complete, rather distant from the side margins, continued along the anterior margin, straight behind the head, not following the angular conformation of the margin. A few moderate punctures present on each side within the lateral stria.

Epipleura bistriate. External subhumeral complete, bent near middle, curved inwardly at apex, the basal portion very fine, the apical strong and with a crenate, subcariniform outer margin; internal subhumeral extending from basal sixth to a little in front of middle. Dorsal striae one to three complete, crenate, well impressed, the third deeply so at base; fourth and fifth dorsals subequal, present on a little more than apical half, distinctly more crenate than the preceding. Sutural stria abbreviated at basal fourth, strongly crenate, very broad basally.

Propygidium coarsely, densely punctate in a median triangular area and in a basal row, elsewhere minutely and very densely punctate. Pygidium minutely, very densely punctate, with a few almost indistinguishably coarser punctures intermingled; pygidial sulcus strong, deep, terminating basally on each side in an expanded, deep, tear-shaped fovea.

Prosternal lobe with a coarse marginal stria; carinal striae nearly straight, strongly divergent posteriorly, not united across basal margin, extending nearly to the lobe and united anteriorly in a narrow, rounded arch. Anterior margin of mesosternum feebly 
emarginate for its entire width; marginal mesosternal stria complete, well impressed, continuous posteriorly on each side with the postcoxal stria. Meso-metasternal stria moderately crenate, feebly angulate at middle, scarcely entering upon the mesosternal disk, continuous on each side with the lateral metasternal stria, which is straight and extends obliquely posteriorly to a point near the middle of the hind coxa. First abdominal sternum with two striae on each side medial to the hind coxa; the inner of these is strong, feebly arcuate, and extends from basal margin to apical fourth; the outer extends nearly to middle.

Protibiae not much expanded, with six to seven teeth, the apical tooth and the two basal ones very small, spinule-like. Meso- and metatibiae with about four spinules on their outer margins.

Length 2.4 ; width $1.9 \mathrm{~mm}$.

Remarks.-This species is allied to fungicolus but may be separated from it by a number of characters, which are given in the key.

\section{Key to the Known Species of Phelisteroides}

1. Dorsal striae 1-4 complete.

Dorsal striae 1-3 complete; fourth dorsal either extending a little beyond the middle or broadly interrupted at middle and represented on basal third and by an apical rudiment.

2. Internal subhumeral stria complete, coarsely impressed. .punctipennis sp. nov. Internal subhumeral stria absent or represented by an apical rudiment only . . 3

3. Marginal mesosternal stria present at sides only; frontal stria of head complete and united on each side with the supraorbital.

propygidialis Hinton $(1935$, p. 12)

Marginal mesosternal stria not interrupted at middle, complete; frontal stria narrowly interrupted on each side, not united with the supraorbital.... 4

4. Lateral pronotal stria narrowly interrupted on each side behind the eyes, so that the median portion is detached; pygidial sulcus rather wide and deep, narrowest at apex; coarser pygidial punctures a little denser basally, elsewhere very sparse. ......... panamensis Wenzel and Dybas $(1941$, p. 450)

Lateral pronotal stria complete; pygidial sulcus regular and narrow; coarser pygidial punctures rather dense, separated by 1-2 times their diameters.

miladae Wenzel and Dybas (1941, p. 448)

5. Frontal stria of head absent; fourth dorsal stria broadly interrupted, represented on about apical sixth and on a little more than basal third, arched toward the scutellum at base . . .............. ruptistrius sp. nov.

Head with a frontal stria; fourth dorsal stria present on apical half or slightly more.

6. External subhumeral stria complete; internal subhumeral represented on apical half or a little more; coarse propygidial punctures scattered throughout or limited to a median triangular area ....................... 7

External subhumeral present on apical half; internal subhumeral absent; coarse propygidial punctures abruptly limited to a basal row and a broad, median, trapeziform area.................. 
7. Pygidial sulcus terminating basally on each side in a large, deep, expanded, tear-shaped fovea; marginal pronotal stria absent behind the head..... 8

Pygidial sulcus not thus excavated and expanded, though it is wider basally; marginal pronotal stria complete. ........ pygidialis Lewis (1908, p. 157)

8. Coarse propygidial punctures limited to a well-defined, median triangular area and a row along basal margin; meso-metasternal stria feebly angulate at middle, scarcely entering upon the mesosternal disk; anterior pronotal margin angulately projecting at middle............ fossipygus sp. nov.

Coarse propygidial punctures scattered throughout; meso-metasternal stria strongly, broadly arcuate, its median portion approaching the anterior mesosternal margin and the marginal mesosternal stria; anterior pronotal margin straight at middle... fungicolus Wenzel and Dybas (1941, p. 452)

\section{Subfamily Hetaeriinae}

\section{Tribe Hetaeriomorphini}

Yarmister emersoni sp. nov.

Type from Chapada, Brazil. A specimen of undetermined sex in the collection of Carnegie Museum. Collected in August.

Description.-Form parallel-sided, cylindrical. Color black, shining. Eyes rather large. Surface minutely, sparsely punctulate, with the exception of the pygidia, which are finely punctate. Epistoma short, with two striae, of which the first is marginal; the second (a little posterior to the first) is arcuate at middle and extends posteriorly along the inner margins of the eyes to unite with the fine, complete supraorbital.

Marginal pronotal stria present only around the anterior angles, absent behind the head and along the sides. Lateral stria well impressed, rather close to the margin, complete behind the head and extending for a short distance along basal margin.

Epipleura with two fine, subcariniform, complete, closely placed striae, the marginal epipleural and marginal elytral, the latter continued across apical margin and united with the sutural stria. External subhumeral complete, its outer edge subcariniform; internal subhumeral finely impressed, rather distant from the external, except apically, and parallel to the first dorsal (the interval between them equal to that between the first and second dorsals); oblique humeral finely impressed. First and second dorsal striae complete (the second obsolete on basal sixth on one side in the type); third dorsal obsolete on basal third or fourth; fourth and fifth dorsals absent. Sutural stria complete, arching outward at base. In the interval between the third dorsal and the sutural is a coarsē, longitudinal, striiform impression, possibly representing the fourth dorsal. 
All the dorsal striae are finely impressed, and are apically hooked and united with the marginal elytral stria.

Fifth abdominal tergum with a triangular area exposed between the elytral apices, the area margined by a single chevron-shaped stria. Propygidium with a fine, continuous marginal stria along basal, lateral, and apical margins.

Prosternum nearly as in barberi, but with the carinal striae more narrowly separated between the coxae and united along basal margin, and with the intermediate striae more strongly divergent apically. Marginal mesosternal stria narrowly interrupted at middle behind the deep emargination. Meso-metasternal stria single, obsolete on each side. A single, well-impressed lateral metasternal stria is present on each side and extends posteriorly from the outer end of the meso-metasternal suture to the hind coxa. Elevated metasternal sides with transverse, parallel strioles which extend from a point near the lateral metasternal stria laterally to the metasternal-metepisternal suture.

Tibiae nearly as in barberi, differing in minor details of sculpture; inner margin of mesotibiae less arcuate than in that species.

Length 3.3 ; width $1.71 \mathrm{~mm}$.

Remarks.-The genus Yarmister was erected by the writer in 1938 for a single new species barberi, from Florida; emersoni may be the undescribed species referred to at that time.

The two species may be separated as follows:

1. Elytra with a coarse, striiform impression on basal third near the sutural stria; marginal elytral stria present along apical margin, all the other striae hooked apically and united with it at their respective intervals. Marginal mesosternal stria narrowly interrupted behind the median emargination; mesosternum without discal striae; meso-metasternal stria obsolete on each side; a single lateral metasternal stria present on each side; elevated metasternal sides with transverse, concentrically arranged strioles which extend laterally from a point near the lateral stria to the metasternal-metepisternal suture, the anterior strioles strongly arcuate.........emersoni sp. nov.

2. Elytra without a basal impression near the sutural stria; marginal elytral stria not present along apical margin, the dorsal striae hooked inwardly at apex. Marginal mesosternal and meso-metasternal striae complete; mesosternum with two posteriorly divergent, oblique striae which divide the disk into three parts; two lateral metasternal striae present on each side, both coarse and sulciform, the outer one deeply, coarsely punctate; elevated metasternal sides with more or less irregular, parallel strioles of varying length . . . . . . . . . . . . . . . . . . . . barberi Wenzel $(1939$, p. 392)

The following is a list of the new genera and species described in the preceding pages. 


\section{Subfamily Abraeinae}

Acritomorphus praecursor gen. et sp. nov. Halacritus alutiger sp. nov.

Halacritus blackwelderi sp. nov.

Halacritus glabrus sp. nov.

Halacritus lewisi sp. nov.

Aeletes aciculatus sp. nov.

Aeletes assimilis sp. nov.

Aeletes dybasi sp. nov.

Aeletes laevis sp. nov.

Aeletes lissosternus sp. nov.
Aeletes nevermanni sp. nov. Aeletes rectistrius sp. nov. Aeletes rugiceps sp. nov. Aeletes rugipygus sp. nov. Aeletes schwarzi sp. nov. Aeletes subniger sp. nov. Aeletes sulcipennis sp. nov. Aeletes termitophilus sp. nov. Aeletes troglodytes sp. nov.

\section{Subfamily Trypanaeinae}

Trypanaeus fucatus sp. nov.

\section{Subfamily Saprininae}

Reichardtia gen. nov.

Saprinus oblongus sp. nov.

Saprinus carinipennis sp. nov.

\section{Subfamily Dendrophilinae}

Bacanius crenulatus sp. nov.

Bacanius pusillus sp. nov.

Bacanius rugisternus sp. nov.

Bacanius striatinotum sp. nov.

Bacanius sulcisternus sp. nov.

Carcinops assimilis sp. nov.

Carcinops cribripuga sp. nov.
Carcinops densepunctata sp. nov.

Carcinops exigua sp. nov.

Carcinops plaumanni sp. nov.

Carcinops schwarzi sp. nov.

Carcinops tuberata sp. nov.

Geocolus caecus gen. et sp. nov.

\section{Subfamily Tribalinae \\ Epierus cylindricus sp. nov. Epierus darlingtoni sp. nov. Epierus striatipygus sp. nov.}

\section{Subfamily Histerinae}

Phylloma multispinosum sp. nov.

Hololepta (Hololepta) striaticeps sp. nov.

Hololepta (Leionota) insularis sp. nov.

Margarinotus balloui sp. nov.

Margarinotus confusus sp. nov.

Margarinotus hailar sp. nov.

Margarinotus lecontei sp. nov.

Margarinotus striolides sp. nov.
Margarinotus tristriatus sp. nov. Margarinotus weymarni sp. nov. Atholus bolteri sp. nov.

Phelisteroides angustisternus sp. nov. Phelisteroides fossipygus sp. nov. Phelisteroides punctipennis sp. nov. Phelisteroides ruptistrius sp. nov. Yarmister emersoni sp. nov. 


\section{REFERENCES}

\section{Aubé, Charles}

1842. Notes sur quelque Coléoptères nouveaux. Ann. Soc. Ent. Fr., 11, pp. 225-237.

\section{BICKHARDT, HEINRICH}

1914. Neue Histeriden und Bemerkungen zu bekannten Arten. Ent. Blätter, 10, pp. 309-316, 1 fig.

1916. Histeridae. Wytsman, Genera insectorum, 166a, pp. 1-112, 15 pls.

1917. Idem, 166b, pp. 113-302.

1918. Neue Histeriden aus dem ungarischen National-Museum und Bemerkungen zu bekannten Arten. Ann. Mus. Hungar. Budapest, 16, pp. 283-297. 1920. Neue Histeriden aus den Nestern eines argentinischen Nagers. Ent. Blätter, 16, pp. 236-239.

1920a. Uebersicht der mit Hister terricola Germ. und cadaverinus Hoffm. verwandten paläarktischen Arten. Ibid., 16, pp. 29-32, 97-102.

Blatchley, Willis S.

1922. Some New and Rare Coleoptera from Southwestern Florida. Can. Ent., 54, pp. 9-14, 27-33.

\section{BRETHES, JEAN}

1923. I.-Description de deux nouveaux Coléoptères du Chili. II.-Rehabilitation d'une espece latreillienne. Rev. Chil. Hist. Nat., 27, pp. 39-43, 1 fig.

\section{Casey, Thomas L.}

1893. Coleopterological Notices V. Ann. N. Y. Acad. Sci., 7, pp. 553-578. 1916. Some Random Studies among the Clavicornia. Mem. Coleop., 7, pp. 35-292.

\section{Darlington, Phillip J.}

1936. Variation and Atrophy of Flying Wings of Some Carabid Beetles. Ann. Ent. Soc. Amer., 29, pp. 136-179, 3 pls.

\section{Erichson, Wilhelm F.}

1834. Uebersicht der Histeroides der Sammlung. Jahrb. der Insektenkunde, 1, pp. 83-208.

1839. Die Käfer der Mark Brandenburg. 1, pt. 2, pp. 385-740. Berlin.

FABRicius, JoHanN C.

1792. Entomologia systematica emendata et aucta, secundum classes, ordines, genera, species, adjectis synonymis, locis, observationibus, descriptionibus. $1,868+20$ pp. Hafniae.

Fall, Henry C.

1901. List of the Coleoptera of Southern California with notes on habits and distribution and descriptions of new species. Occ. Papers Calif. Acad. Sci., 8, pp. 1-282.

1919. New Coleoptera VIII. Can. Ent., 51, pp. 212-216.

HaRris, ThadDEUS W.

1837. Characteristics of Some Previously Described North American Insects, and descriptions of others which appear to be new in the collection of Mr. A. Halsey. Trans. Hartf. Nat. Hist. Soc., 1, pp. 65-99, 1 pl. 
Hinton, Howard E.

1935. A Short Review of the North American Species of Pseudister. Can. Ent., 67, pp. 11-15, 4 figs.

HoFFMANN, J. J., and others

1803. Entomologische Hefte, enthaltend Beiträge zur weiteren Kenntniss und Aufklärung der Insectengeschichte, eine Vorarbeit zu einer künstigen Faune des Departments vom Donnersberge und den angrenzenden Gegenden des Departments von der Saar, von Rhein und Mosel. Frankfort am Main. 2 vols., $249+16$ pp., 1 pl.

LACORDAIRE, JEAN T.

1854. Histoire naturelle des insectes. Genera des Coléoptères, ou exposé méthodique et critique du dous les genres proposes jusqu'ici dans cet ordre d'insectes. Paris. 1, $486+20 \mathrm{pp}$.

Lea, Arthur M.

1925. On Australian Histeridae. Trans. Ent. Soc. Lond., 1924, pp. 239-263, $1 \mathrm{pl}$.

Le Conte, John E.

1845. A Monograph of the North American Histeroides. Bost. Journ. Nat. Hist., 5, pp. 32-87, 5 pls.

1860. Description of New Species of the Coleopterous Family Histeridae. Proc. Acad. Nat. Sci. Phila., 1859, pp. 310-317.

LE ConTe, John L.

1851. Descriptions of New Species of Coleoptera from California. Ann. Lyc. Nat. Hist. N. Y., 5, pp. 125-216, 1 pl.

1853. Synopsis of the Species of the Histeroid Genus Abraeus Leach, Inhabiting the United States, with descriptions of two nearly allied genera. Ibid., 6, pp. 287-292.

1863. New Species of North American Coleoptera. Part I. Smiths. Misc. Coll., 6, No. 167, pp. 1-78.

1878. Additional Descriptions of New Species. In E. A. Schwarz, The Coleoptera of Florida. Proc. Amer. Phil. Soc., 17, pp. 353-474.

\section{LEWIS, GEORGE}

1884. On Some Histeridae New to the Japanese Fauna, and notes of others. Ann. Mag. Nat. Hist., (5), 13, pp. 131-140.

1888. Histeridae. Biol. Centr.-Amer., Ins.-Coleop., 2, pt. 1, pp. 182-244, 4 pls.

1901. On New Species of Histeridae. Ann. Mag. Nat. Hist., (7), 8, pp. 366-383.

1908. On New Species of Histeridae and Notices of Others. Ibid., (8), 2, pp. $137-162$.

\section{Marseul, S. A. DE}

1853. Essai monographique sur la famille des Histérides. Ann. Soc. Ent. Fr., (3), 1, pp. 131-294, 447-553, 7 pls.

1854. Idem, 2, pp. 161-311, 525-592, 670-707, 5 pls.

1855. Idem, 3, pp. 83-165, 327-506, 677-758, 7 pls.

1856. Idem, 4, pp. 97-144, 259-283, 549-628, 4 pls.

1857. Idem, 5, pp. 109-167, 397-516, 2 pls.

1861. Supplemént a la monographie des Histérides. Ann. Soc. Ent. Fr., (4), 1, pp. 141-184, 509-566, 6 pls. 
1862. Idem, 2, pp. 1-48, 437-516, 669-720, 5 pls.

1870. Descriptions d'espèces nouvelles d'Histérides. Ann. Soc. Ent. Belg., 13, pp. 54-138.

\section{REICHARDT, AXEL}

1926. Ueber die mit Pachylopus Er. verwandten Gattungen. Ent. Blätter, 22, pp. 12-18.

1926a. Notizen über paläarktischen Histeriden. Rev. Russe Ent., 20, pp. 269-274.

1929. De Histeridis novis faunae palaearcticae. Ann. Mus. Zool. Leningrad, 30, pp. 285-304, 18 figs.

Ross, EDWARD S.

1940. New Histeridae from the Burrows of the Florida Pocket Gopher. Ann.

Ent. Soc. Amer., 33, pp. 1-9, 5 figs.

\section{SCHAEFFER, Charles}

1904. New Genera and Species of Coleoptera. Journ. N. Y. Ent. Soc., 12, pp. 197-236.

\section{SCHMIDT, JOHANN}

1888. Neue Histeriden. Hor. Ent. Ross., 22, pp. 189-191.

1889. Neue Histeriden. Ent. Nachr., 15, pp. 85-96, 329-341, 361-373.

1892. Idem, 18, pp. 17-29.

1893. Histeridae des lles Séchelles. Bull. Soc. Ent. Fr., 1893, pp. xcix-ciii.

1894. Neue Arten der Gattung Hister. Ent. Nachr., 15, pp. 85-96.

1896. Aufzählung der von Herrn Professor F. Sahlberg in Brasilien gesammelten Histeriden. Ent. Zeitschr., 41, pp. 55-66.

\section{SHARP, DAVID}

1876. Descriptions of Some New Genera and Species of New Zealand Coleoptera. Ent. Monthly Mag., 13, pp. 20-28, 70-77, 97-102, 190-196, 265-275.

\section{TARSIA IN CURIA, I.}

1935. Plagiogramma brasiliense n. gen. n. sp. Nuovo Coleottero isteride del Brasile. Ann. Mus. Zool. Univ. Napoli, n.s., 6, No. 15, 4 pp., 4 figs.

\section{WENZEL, RUPERT L.}

1935. Notes on the Sexual Characters of Saprinus with the description of a new species. Can. Ent., 67, pp. 189-190.

1936. Short Studies in the Histeridae-No. 1. Can. Ent., 68, pp. 266-272.

1939. A New Genus and Several New Species of North American Histeridae. Ann. Ent. Soc. Amer., 32, pp. 384-394, 5 figs.

and DYBAS, HeNRY S.

1941. New and Little Known Neotropical Histeridae. Field Mus. Nat. Hist., Zool. Ser., 22, pp. 433-472, 4 pls. 

P LATES 


\section{PLATE 1}

Figs. 1-3. Aeletes dybasi sp. nov., A. troglodytes sp. nov., and A. politus Le Conte, respectively. Prosternal keel and mesosternal disk.

FIG. 4. Aeletes sp. Dorsal view of head (semidiagrammatic) showing complete marginal epistomal stria.

FIG. 5. Halacritus sp. Partial semidiagrammatic representation of meso- and metasternum showing complete lateral metasternal stria as it exists in $H$. maritimus Le Conte and $H$. parallelus Casey; $a$, its point of termination in $H$. glabrus sp. nov., $b$, the approximate point of termination in other species.

Fig. 6. Acritomorphus praecursor gen. et sp. nov. Aedeagus. a, Dorsal, $b$, ventral, $c$, lateral views. $d$, Tip of median lobe, much enlarged, dorsal view. 


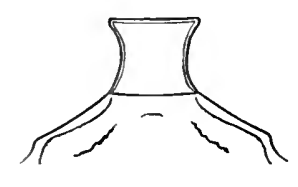

1
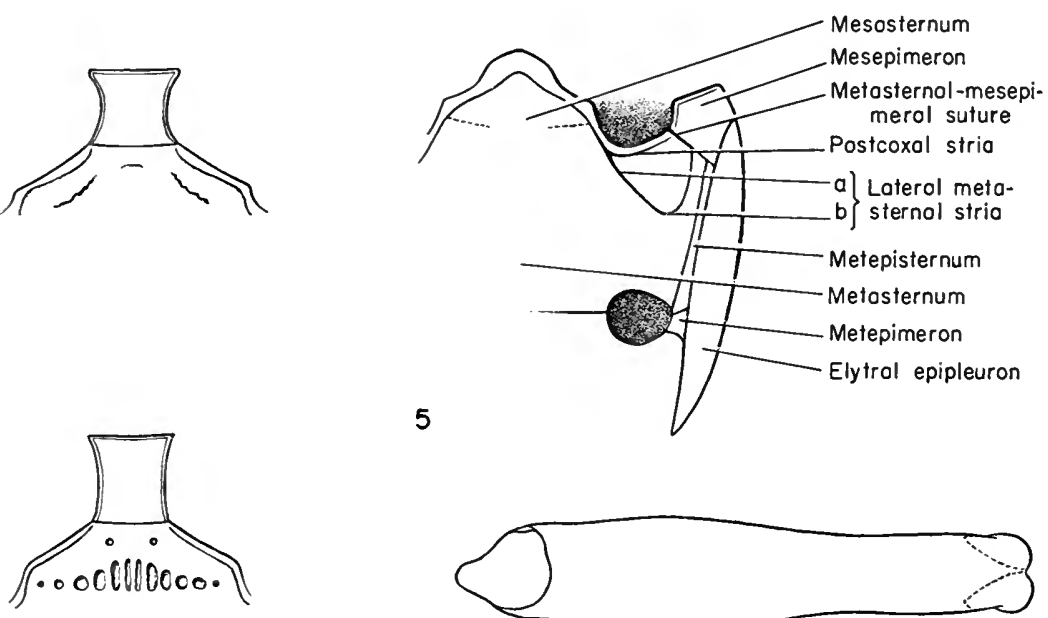

2
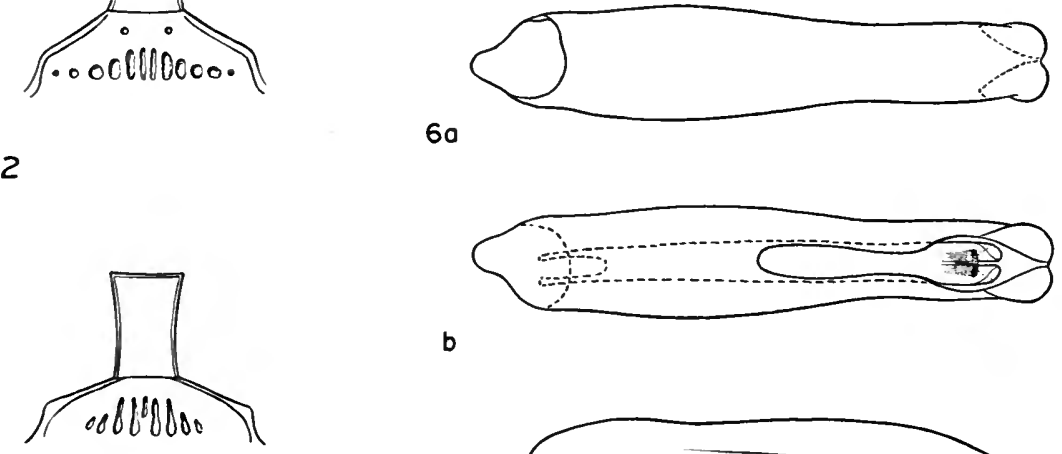

3

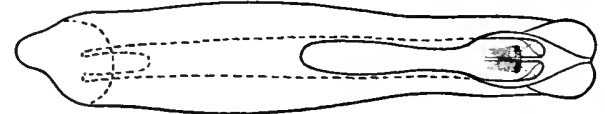

b
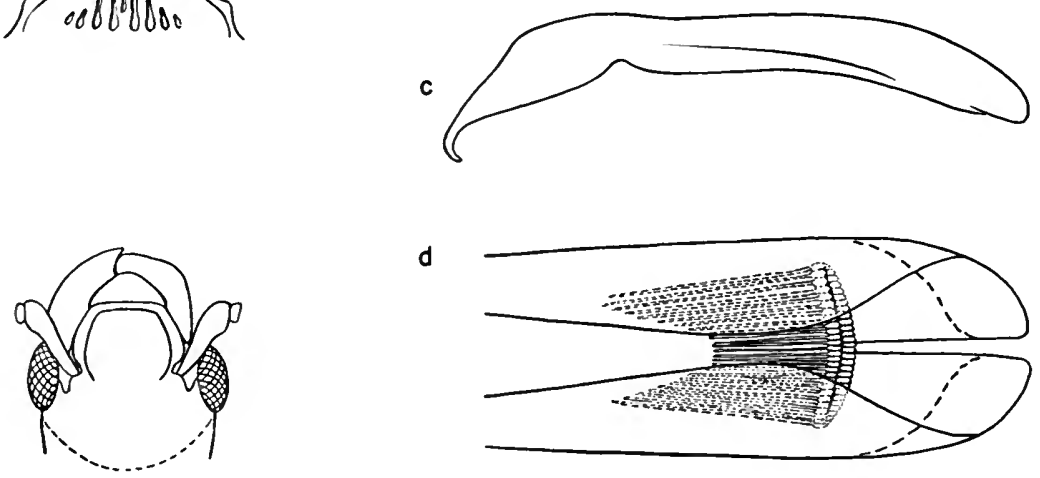

d

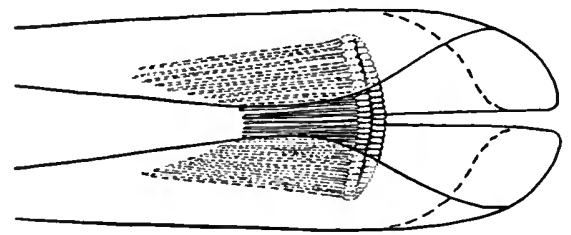




\section{PLATE 2}

Fig. 1. Reichardtia pedator Sharp. $a$, Dorsal view of head. $b$, Inner face of protibia (sculpture partially indicated).

FIG. 2. Geomysaprinus rugosifrons Fall. $a$, Ventral view of metasternum and abdomen (non-setigerous punctures omitted). $b$, Inner face of protibia.

FIG. 3. a, c, Phylloma multispinosum sp. nov. Inner faces of pro- and mesotibiae. b, d, $P$. corticale Fabricius, same structures. 


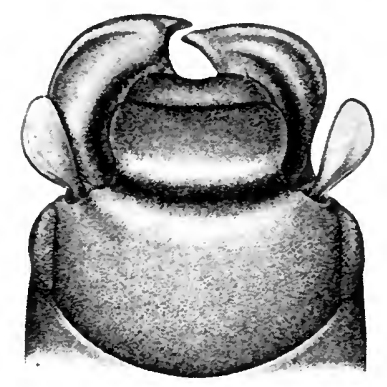

1a
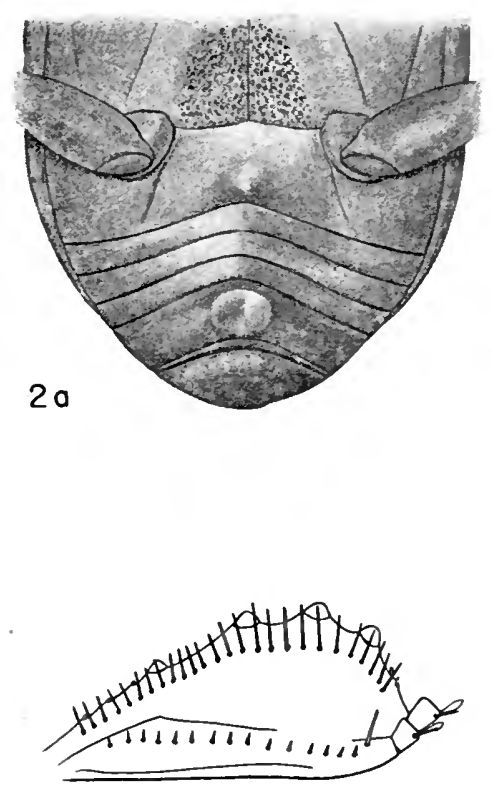

b

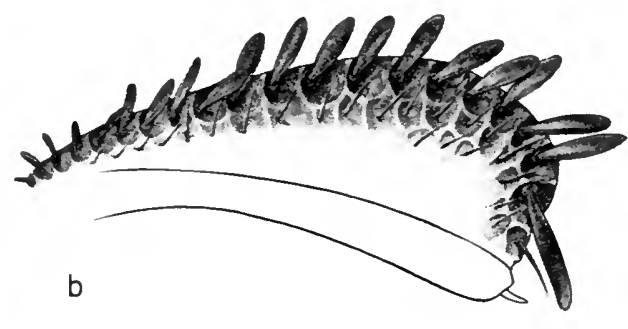

30

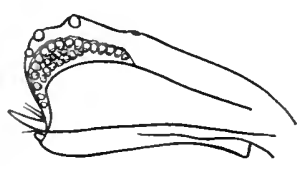

b
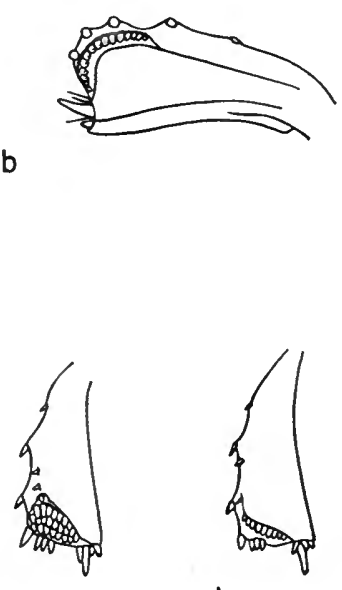

C

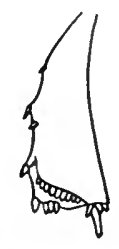

d 


\section{PLATE 3}

Geocolus caecus gen. et sp. nov.

FIG. 1. Dorsal aspect of beetle, appendages omitted.

FIG. 2. Prothorax, ventral view, coxae removed.

Fig. 3. Head, dorsal view.

FIG. 4. Head and anterior region of prothorax, lateral view.

FIG. 5. Aedeagus. $a$, Dorsal, $b$, lateral views.

FIG. 6. $a, b, c$, Inner face of protibia, outer faces of meso- and metatibiae. 

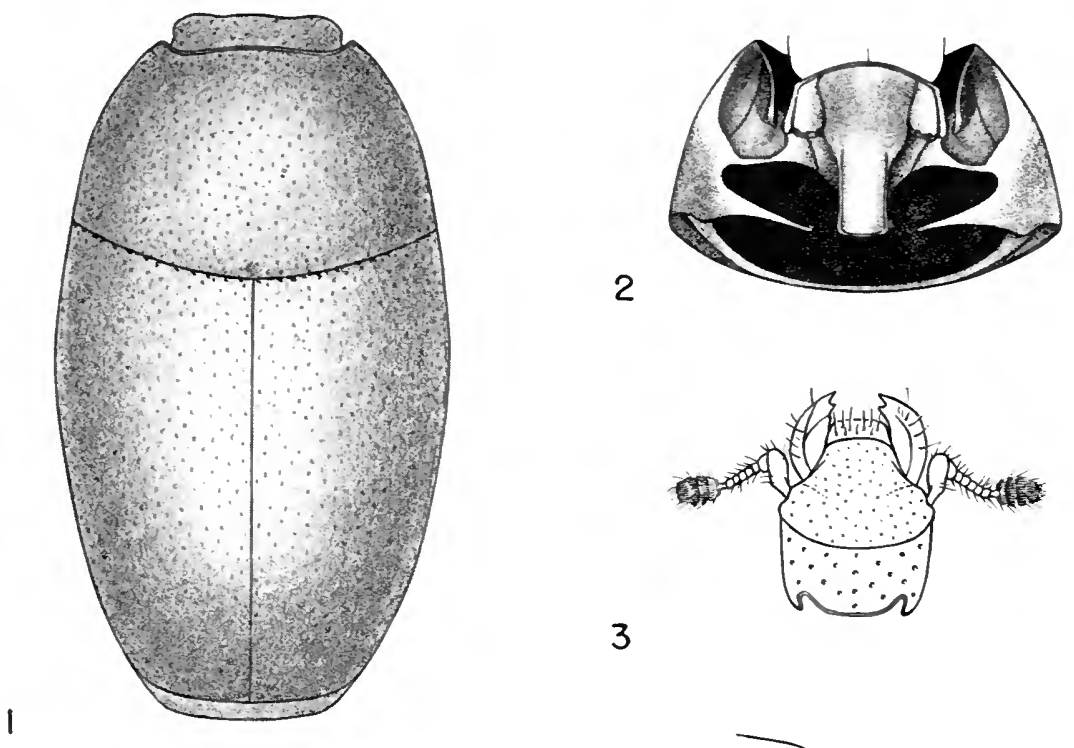

3

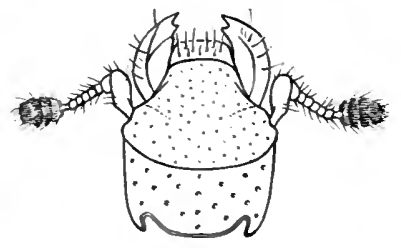

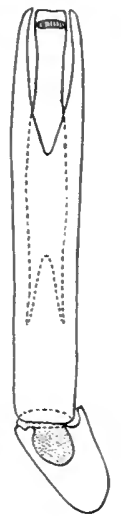

5

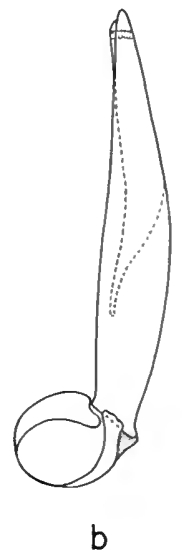

4

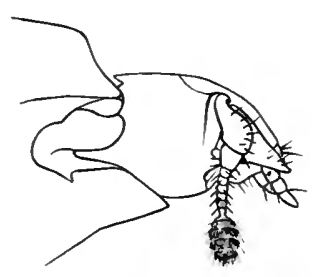

6

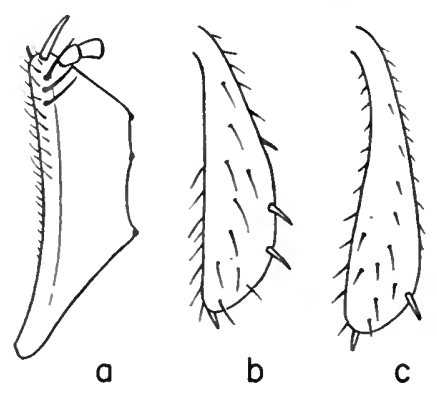




\section{PLATE 4}

Fig. 1. Margarinotus tristriatus sp. nov. Aedeagus. $a$, Lateral, $b$, dorsal views (basal piece omitted in $b$ ).

FIG. 2. Margarinotus weymarni sp. nov. Structures as in fig. 1. 


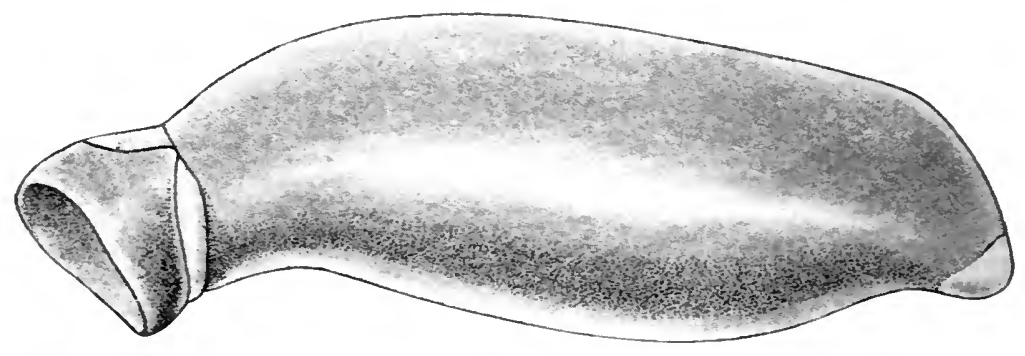

la
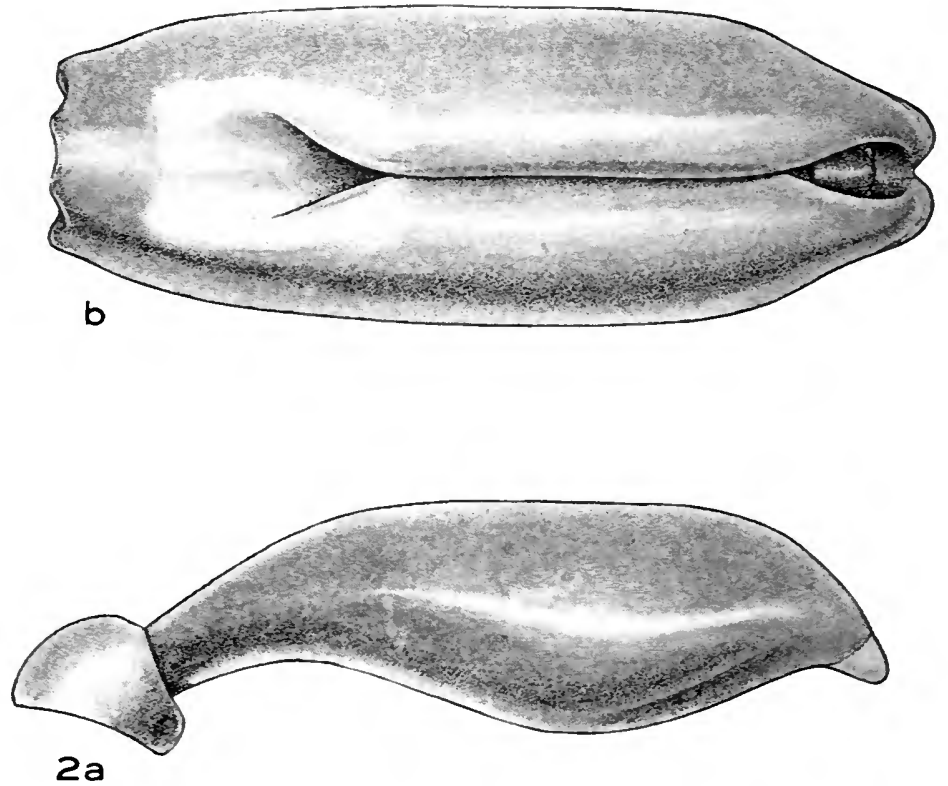

$2 a$

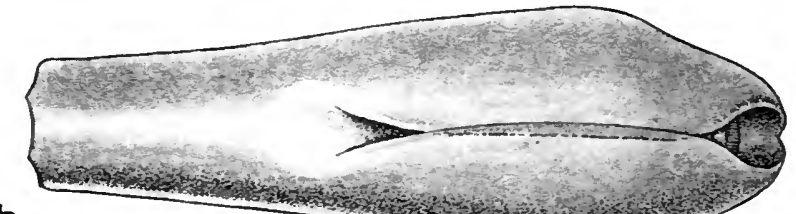

b 


\section{PLATE 5}

FIG. 1. Margarinotus koenigi Schmidt. Aedeagus. $a$, Lateral, $b$, dorsal views (basal piece omitted in $b$ ).

FIG. 2. Margarinotus marginicollis Le Conte. Structures as in fig. 1. 

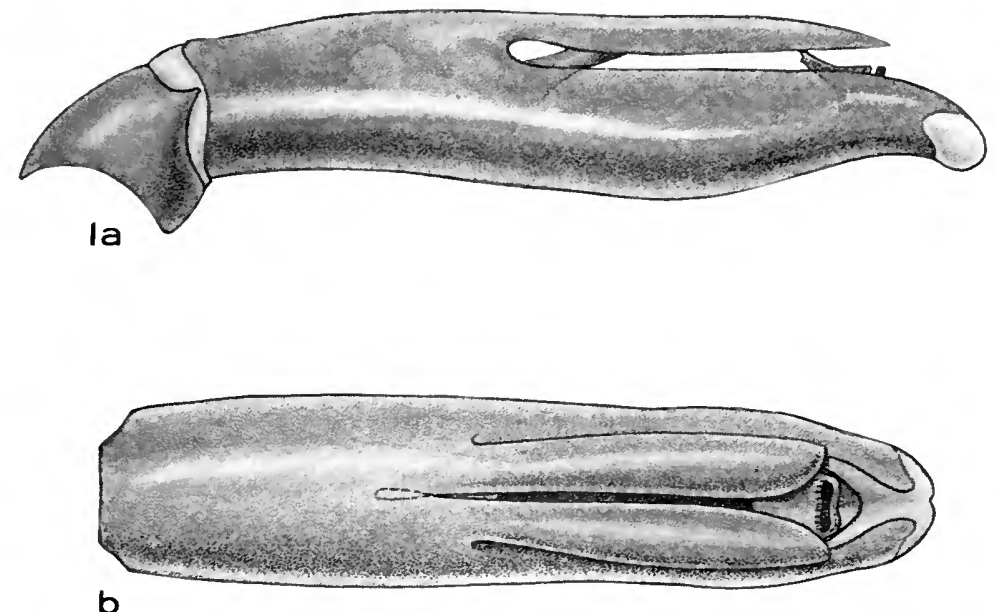

b

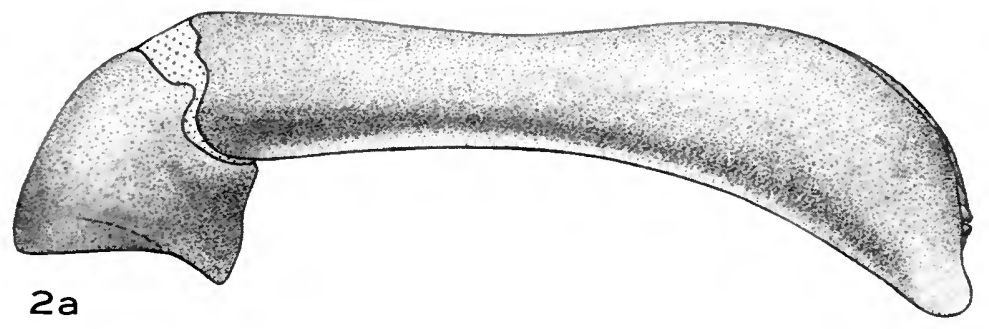

b 


\section{PLATE 6}

FIG. 1. Margarinotus guttifer Horn. Median lobe and armature of aedeagus, lateral view.

FIG. 2. Margarinotus balloui sp. nov. Structures as in fig. 1.

FIG. 3. Margarinotus weymarni sp. nov. Structures as in fig. 1.

FIG. 4. Margarinotus cadaverinus Hoffmann. Structures as in fig. 1. 

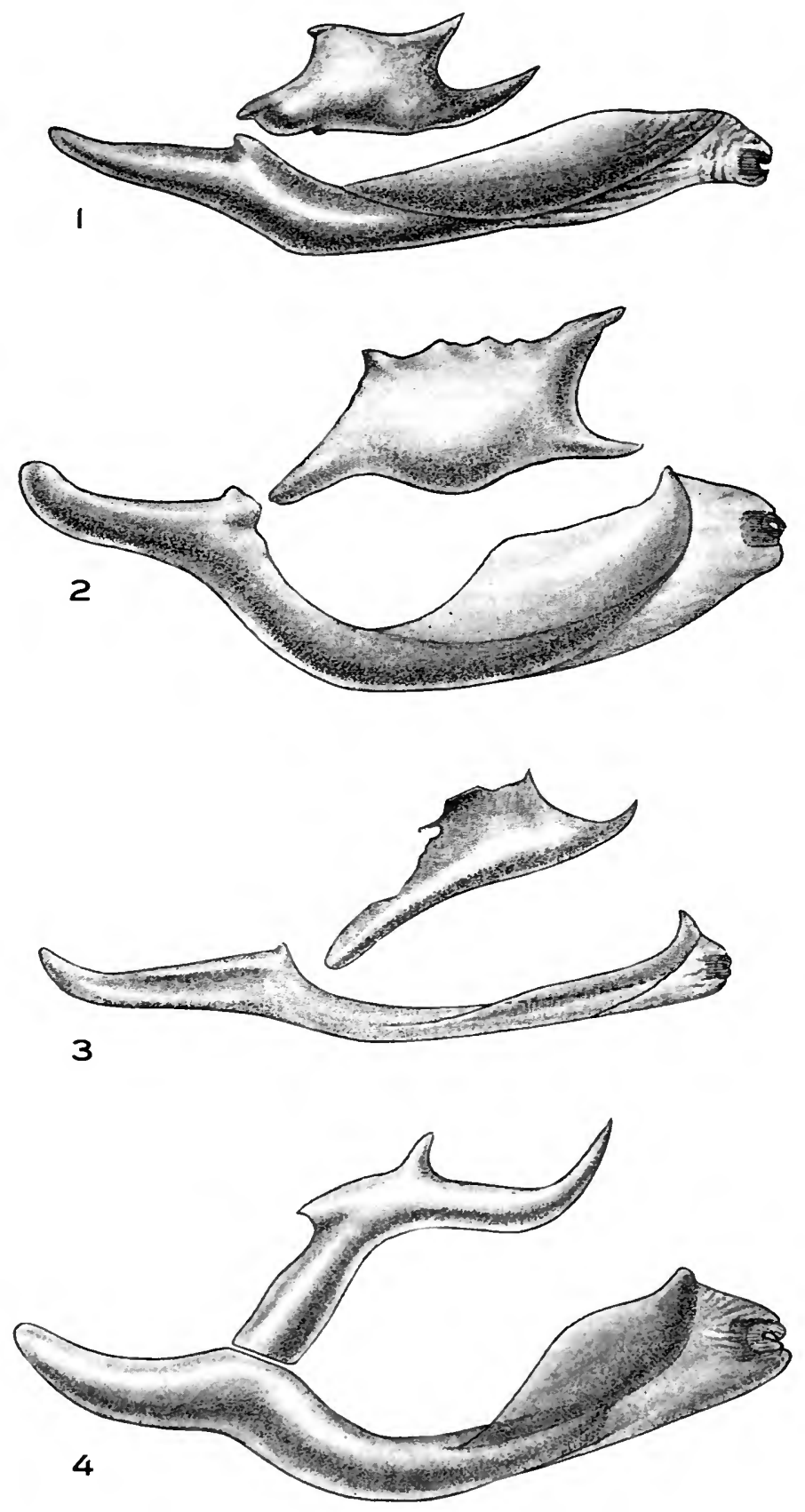


\section{PLATE 7}

FIG. 1. Margarinotus striolides sp. nov. Median lobe and armature of aedeagus, lateral view.

FIG. 2. Margarinotus striola Sahlberg. Structures as in fig. 1.

FIg. 3. Margarinotus tristriatus sp. nov. Lateral view of median lobe and armature.

FIG. 4. Margarinotus tristriatus sp. nov. Dorsal view of median lobe and armature. 

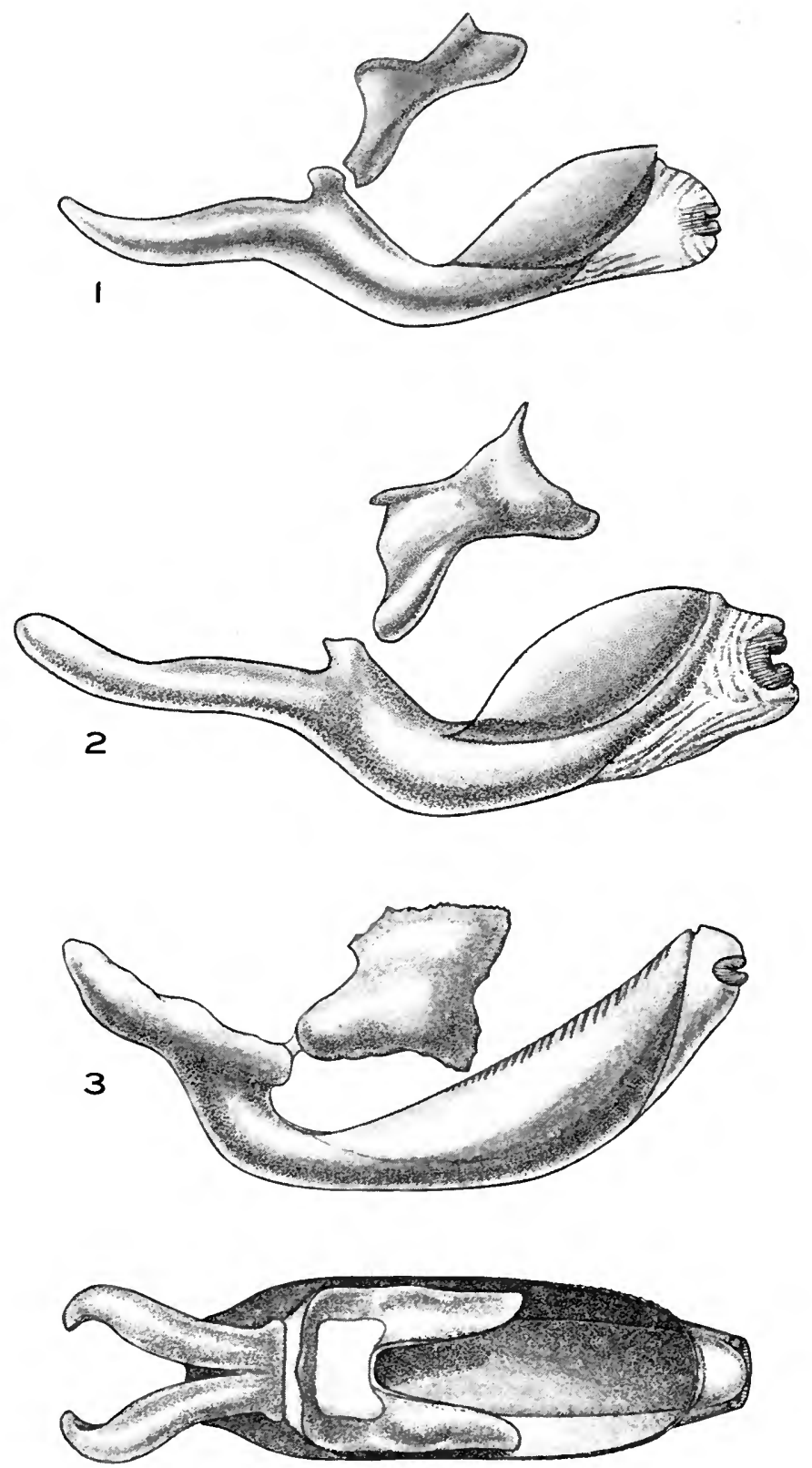

4 


\section{PLATE 8}

FIG. 1. Margarinotus ussuriensis Reichardt. Median lobe and armature of aedeagus, lateral view.

FIG. 2. Margarinotus koenigi Schmidt. $a$, Lateral, $b$, dorsal views of median lobe and armature.

FIG. 3. Margarinotus lecontei sp. nov. Median lobe and armature, lateral view. 

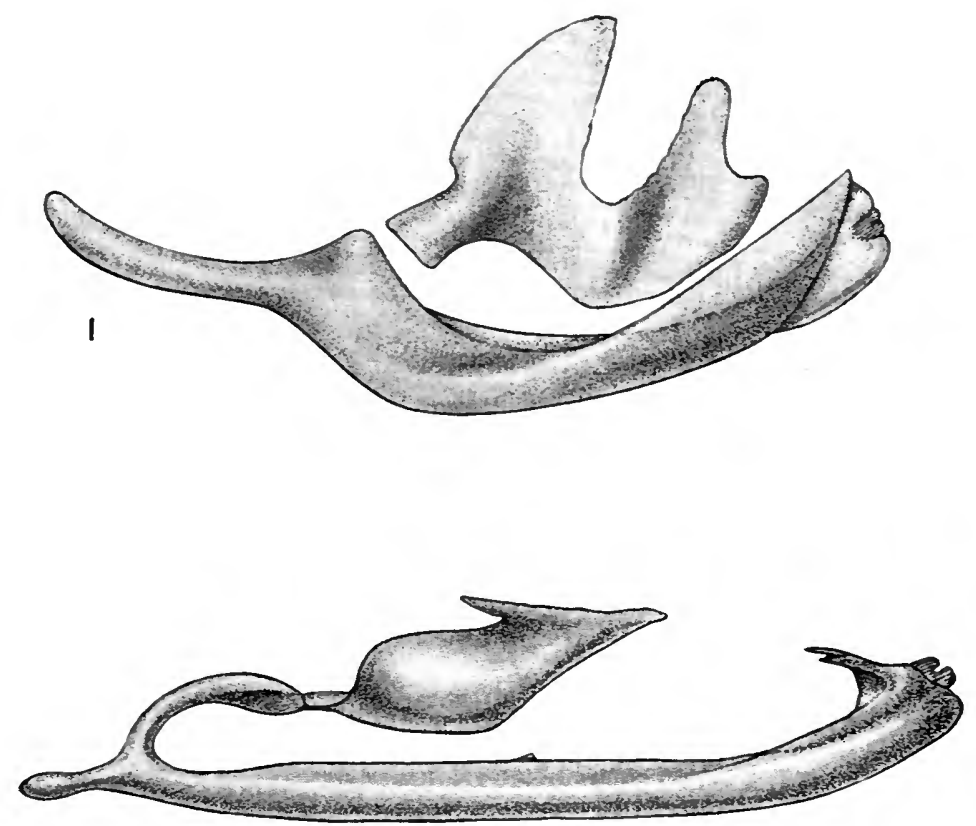

$2 a$

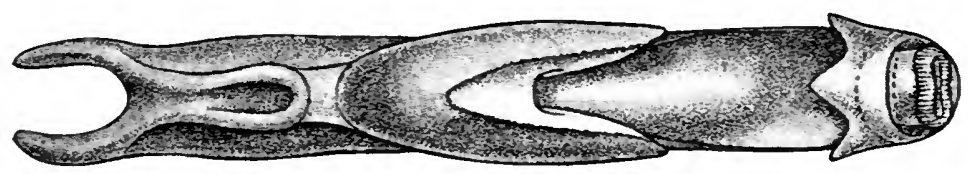

b

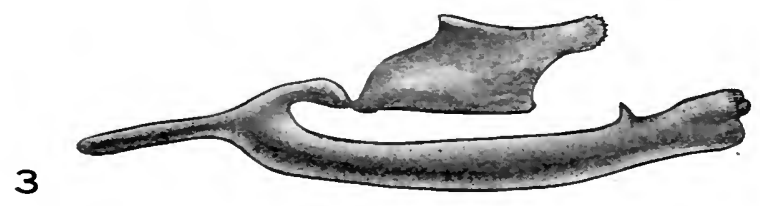




\section{PLATE 9}

Fig. 1. Margarinotus marginicollis Le Conte. a, Median lobe and armature of aedeagus, lateral view. $b$, Median armature, dorsal view. $c$, Median lobe, dorsal view.

FIG. 2. Margarinotus felipae Lewis. Median lobe and armature, lateral view.

FIG. 3. Margarinotus confusus sp. nov. Structures as in fig. 2. 


$$
\frac{\infty}{\infty}
$$







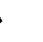









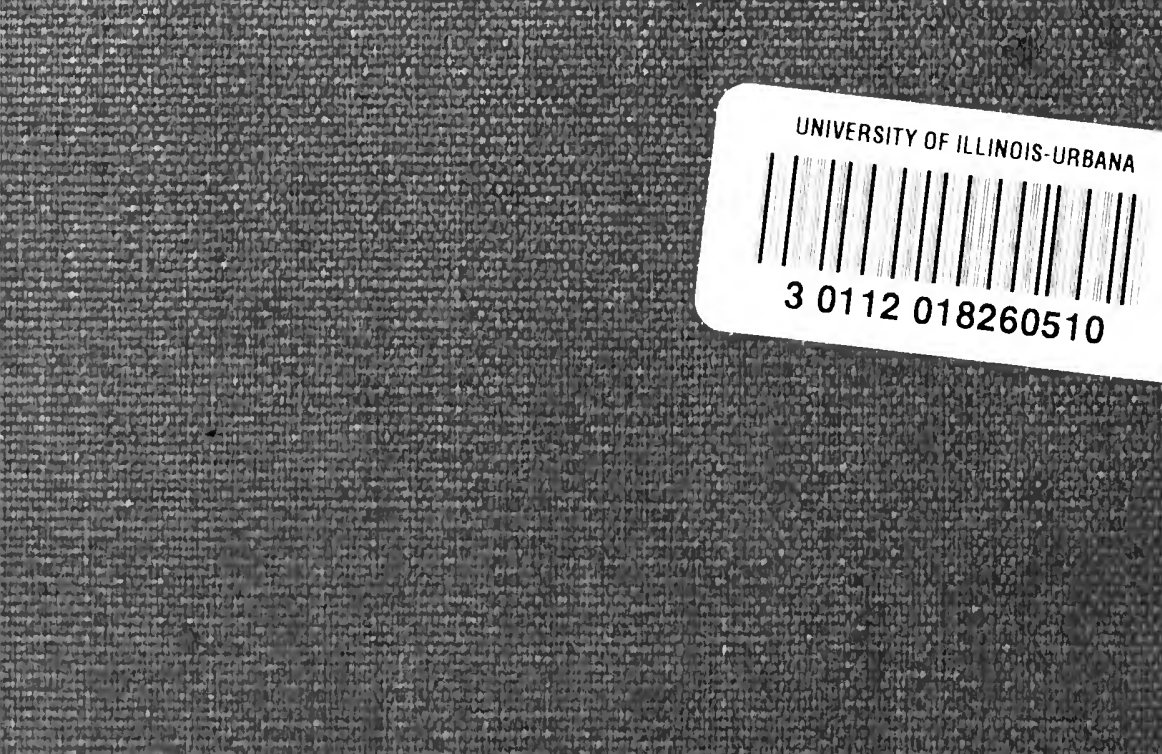